Manuscript Number: JELECHEM-D-17-00809R3

Title: A novel polyoxomolybdate/ionic liquid based sensor for ultra-high sensitive monitoring of Al(III): Optimization by Taguchi statistical design

Article Type: Research paper

Keywords: Ionic liquid/polyoxomolybdate supramolecular gel, Taguchi statistical method, potentiometric sensor, Al(III) ion

Corresponding Author: Mr. soleyman ramezani, MSc

Corresponding Author's Institution: Kharazmi University

First Author: soleyman ramezani, MSc

Order of Authors: soleyman ramezani, MSc; Rana Jahani, MSc; Mohammad Hossein Mashhadizadeh, Professor; Saeed Shahbazi, PhD; Sajad Jalilian, MSC

Manuscript Region of Origin: IRAN (ISLAMIC REPUBLIC OF)

Abstract: A novel ionic liquid electrostatically supported Nano-Cspolyoxomolybdate modified carbon paste electrode (Nano-PMo12/IL-CPE) has been developed by using 1-n-butyl-3-methylimidazolium tetrafluoroborate (Bmim.BF4) as a hydrophobic binder. The supramolecular gel (PMo12/IL) exhibits an ordered structure, various physicochemical properties, and specifically as a result of its substantial reversible self-assembly, it can be used as an intelligent ion-exchange smart platform in the carbon paste bulk of the electrode. As expected, a significant linear correspondence was found between the sensor output signal (emf/mV) and logarithm of Al(III) ion activity with a Nernstian slope of $19.9( \pm 0.2)$ mVdecade-1 over a wide concentration range of $1.0 \times 10-9$ to $2.2 \times 10-1$ molL-1 $(R 2=0.9999)$. The sensor considered, exploits an astounding lower limit of detection and short response time of $7.94 \times 10-10$ molL-1 and $8.0 \mathrm{sec}$. respectively within the working $\mathrm{pH}$ range of 2.0 to 5.0. A statistical design of experimental (Taguchi method with Qualitek-4 software and L16 orthogonal array robust design) was implemented in this work to optimize the process to achieve the least number of experimental runs as much as possible. Ultimately, practical capability of the sensor was investigated successfully by assessment of $A l$ (III) ion quantity in some aqueous samples namely mineral water, Al-Mg syrup, black tea extract, and ore samples (Basalt and Andesite), in perfect agreement with flame atomic absorption spectroscopy (FAAS). 
Dear Editor,

Enclosed is a manuscript to be considered for publication in the Journal of Electroanalytical Chemistry, entitled with: "A novel polyoxomolybdate/ionic liquid based sensor for ultra-high sensitive monitoring of $\mathrm{Al}(\mathrm{III})$ : Optimization by Taguchi statistical design ".

The research, has been funded by the Faculty of Chemistry, Kharazmi University, Tehran, Iran, and Mohaghegh Ardabili University of Ardabil, Iran.

The main reason of choosing this Journal is full matching content of the paper with the Aims and Scope of the J. Electroanal. Chem.

It should be pointed out that, about 4 months has been taken for accomplishment of the project .

By the way, all the authors coincide eagerly with together to submit the work to the JEAC, the work has not been published or being submitted to another journals and a brief description of the novelty and significant contribution of the submitted work.

Our group eventually hopes that the research deserves in terms of quality and novelty to be published through the Journal.

Best Regards

S. Ramezani (Corresponding Author), On behalf of the other authors respectively comprising: Rana Jahani, Mohammad Hossein Mashhadizadeh, Saeed Shahbazi, Sajad Jalilian 


\section{RESEARCH HILIGHTs:}

- A novel ionic liquid electrostatically supported Nano-Cs-polyoxomolybdate (Nano$\mathrm{PMo}_{12} / \mathrm{IL}$ ) was successfully synthesized and used for the first time to evaluate its selectivity and sensitivity over some alkaline, alkaline earth, and transition metal ions.

- $\mathrm{PMo}_{12} / \mathrm{IL}$ Nanocomposite gel was used as an intelligent ion-exchange smart platform in the carbon paste bulk of the electrode for ultra-high sensitive monitoring of $\underline{\mathrm{Al}}(\mathrm{III})$.

- The proposed sensor illustrates a substantial sensitivity to Al(III) ion with sub-Nanomolar quantity $\left(\underline{7.94} \times 10^{-10} \mathrm{molL}^{-1}\right)$.

- Taguchi statistical method was suitably applied for experimental design of process to save cost, time and create an efficient optimal conditions.

- The sensor was well stablished as an indicator electrode for potentiometric analysis of $\mathrm{Al}(\mathrm{III})$ content in the different matrices being pharmaceutical and ore samples, black tea leaf extraction, and mineral water. 


\section{(Author's Response to Reviews)}

Title: A novel polyoxomolybdate/ionic liquid based sensor for ultra-high sensitive monitoring of Al(III): Optimization by Taguchi statistical design

Dear Dr. Opallo,

Prior to anything, thank you for the opportunity to revise our manuscript number JELECHEM-

D-17-00809R1, entitled “A novel polyoxomolybdate/ionic liquid based sensor for ultra-high sensitive monitoring of $\mathrm{Al}(\mathrm{III})$ : Optimization by Taguchi statistical design". We also sincerely appreciate the careful review and constructive suggestions of the reviewers for their positive feedback, investing time and brainpower in providing comprehensive comments, as well as their constructive criticisms to the manuscript. We honestly believe that the manuscript is substantially improved after making the suggested editions. Please find our enclosed revised manuscript JELECHEM-D-17-00809R1 which we ask you to consider for publication in Journal of Electroanalytical Chemistry (JEAC). We have addressed all the reviewers' concerns point-by-point, and have included a Marked revision with the changes all indicated by underlining in different colour. An Unmarked version was also enclosed. Following are the numbered list of reviewer's comments with all coauthor's consensual responses in different colour.

Thank you again for consideration of our revised manuscript.

Best regards,

Soleyman Ramezani (corresponding author)

On behalf of all the authors

\section{Authors:}


Soleyman Ramezani* (MSc.) (soleyman.ramezani@ yahoo.com)

Rana Jahani (MSc.) (rana.jahani@yahoo.com)

Mohammad Hossein Mashhadizadeh (Prof.) (mashhadizadeh@khu.ac.ir)

Saeed Shahbazi (PhD.) (saeed.shahbazi@yahoo.com)

Sajad Jalilian (MSc.) (sajad.jalilian1983@yahoo.com)

Date: 03 September 2017

\section{Reviewer's comments:}

\section{Reviewer \#1:}

The paper deals with the development of an ion selective electrode for $\mathrm{Al}(\mathrm{III})$ based on polyoxomolybdate and ionic liquid. The paper may be considered for publication after a major revision considering the following points:

1- The description/ explanation/ discussion given in many sections are found to be verbose and repetitive. For example, to cite a few:

Introduction section should be revised by making it short. Section 2.3.2; Electrode preparation: method should be written in strait forward (straightforward) manner. The functioning of different components should be included under result and discussion which is already given in section $3 ; \ldots . .$.

\section{Reply:}

To summarize, about 218 words were wiped off the introduction section. (it was well abridged from 976 to 758 words).

The section 2.3.2 was rewritten for simple digestion.

The section of "3.3. Composition and characteristics of the electrodes" was initially as a subset of Section 3. Results.

2- Section 3.1, page 11, Proposal response mechanism of the electrode: The electron transfer reaction involving $\mathrm{Al}(\mathrm{III})$ at the indicator (modified paste) electrode is missing without which mechanism is incomplete.

\section{Reply:}

As is well-known, in potentiometry we measure the potential of an electrochemical cell under static conditions. Because no current or only a negligible current flows through the 
electrochemical cell. So, it is undeniable that, there is no electron transfer in the response mechanism of the electrode.

With this approach, the most likely response mechanisms of the Nano-PMO $\mathrm{PM}_{12} / \mathrm{IL}-\mathrm{CPE}$ toward $\mathrm{Al}(\mathrm{III})$ ion is translocation in the octahedral hole of the nanocluster network without net-charge transfer. Based on this mechanism, there is no coordinative interaction between $\mathrm{Al}(\mathrm{III})$ ion and Nano-POM involving electron transfer process. $\mathrm{Al}^{3+}(\mathrm{aq}) \rightarrow \mathrm{Al}^{3+}$ (surface)

This mechanism is based entirely on the physical transfer of target ion from solution to electrode surface with no change in the oxidation state of the target species.

This mechanism was graphically depicted through scheme 2 in more details.

3- Section 3.3, page 15, line 10-14: "Such electrode ........ $4.5 \times 10^{-10} \mathrm{molL}^{-1}$ (Fig. 6)". The concentration range of $\left(5.7 \times 10^{-10}\right.$ to $\left.2.2 \times 10^{-1}\right) \mathrm{molL}^{-1}$ and limit of detection of $4.5 \times 10^{-10}$ molL ${ }^{-1}$ do not match with the plot given in Fig. 6. Both range and detection limits are found to be higher in the figure. The authors should check and calculate these reported values.

\section{Reply:}

By carefully scrutinizing the calibration curve, it was found that the linear range and limit of detection are $1.0 \times 10^{-9}$ to $2.2 \times 10^{-1}$ and $7.94 \times 10^{-10} \mathrm{molL}^{-1}$ respectively.

The necessary changes were done.

4- No experimental potentiometric measurement data are given in the manuscript which should be included in tabular form.

\section{Reply:}

All the potentiometric evaluations of 16 manufactured electrodes were illustrated through Figs. 4 to 8 . Furthermore, potentiometric characteristics of the various electrodes were summarized in the Table 2. All in all, to avoid prolonging of the manuscript, the table comprising Liner range, Limit of detection, Response time, and $\mathrm{pH}$ range of all the 16 electrodes was ignored. Nevertheless, all of the above-mentioned potentiometric characteristics were hinted over and over throughout the manuscript for optimized electrode.

5- Abstract: 2nd line from bottom 'quantity in some aqueous, oral, ...' is not clear

\section{Reply:}

All the real samples of Mineral water, Al-Mg syrup, Black tea extract, and Ore samples (Basalt and Andesite) were noted clearly at the end of the section of Abstract. 
6- Highlights, Point 2: AL(III) should be as Al(III); Point 3: LOD should be confirmed, Point 4 should be deleted; Point 5: Statement is not true. How for the statement "Taguchi statistical method will save cost, time and create efficient optimal conditions" will be applicable in routine application of the electrode?; Last point 'black tea leave' should be 'black tea leaf'.

\section{Reply:}

All the suggested corrections were applied.

But about Point 5. It should be noticed that, Taguchi Statistical Method (TSM) was particularly applied to design and construction of a specific sensor under the optimal experimental conditions mere for the first time. To produce the next similar electrodes (routine constructions and applications), the experimental conditions will be certainly same as the first time and there is no need to rerun the TSM program. Hence, application of this method entirely meets the efficient optimal conditions. Likewise, particularly by Taguchi's development of designs it is prevented from repeating many experiments especially in the complex projects necessitating to study the effect of multiple factors. Hereby, it is avoided wasting time and expense.

7- Page 3, Line 4: 'To complete planning ... software'. In page 12 line 10 states 'four -four level process parameters were evaluated'. It contradicts line 4 since after experimental performance then optimization is done statistically.

\section{Reply:}

As can be evidently seen from Table 1, a $\mathrm{L}_{16}$ orthogonal array type of Taguchi method (Qualiteck-4 software) possessing four factors of control (Graphite powder (mg), $\mathrm{PMo}_{12}$ (mg), Type of binder, and Preconcentration time (min)) at four levels was employed at the present study. It should be emphasized that, the main effect of factors, ANOVA, and Optimization process, are separate analysis of the obtained data performed by software. Three stages of data analysis are completely independent of four factors in four levels. With a humbly apologize of the dear reviewer, this question has come strongly from a misunderstanding of the matter.

8- Page 3, Introduction, Line 2: 'diseases of dialysis'-not clear

\section{Reply:}

Aluminum is absorbed from the gastrointestinal tract and is normally excreted by the kidneys in the urine. In patients with chronic renal failure, aluminum appears to be of proven 
toxicological importance. In these patients the accumulation of aluminum in tissues causes an encephalopathy (dialysis encephalopathy or dialysis dementia), a specific form of metabolic bone disease (osteomalacic dialysis osteodystrophy), and an anemia and also plays an etiological role in some of the other complications associated with end-stage chronic renal disease .

[Ref] M.R. Wills, J. Savory, Water Content of Aluminum, Dialysis Dementia, and Osteomalacia, Environmental Health Perspectives, 63 (1985) 141-147.

9- Page 3, Line 7: 'comprising sorts of'- should have been 'comprising of'.

\section{Reply:}

The "sorts" (= types, kinds) refers to the "spectrophotometry". As is well-known, Spectrophotometry technique deals with Visible light, Near-ultraviolet, and Near-infrared, that leads to appear UV-Vis Spectrophotometry, FTIR Spectrophotometry.

10-Page 3, Line 16 to 23, Line 16 to 19 discusses about CPEs and the references from 7-14 discusses about chemically modified electrodes and same reference is repeated in line 23 as 7-9 for chemically modified electrodes

\section{Reply:}

To resolve the detected contradiction by Reviewer \#1, p. 3, paragraph 2, line 11-17 was removed.

11- Page 5, Line 8 from bottom: 'provided in laboratory....through reverse micelles containing nanoreactor' sentence not clear.

\section{Reply:}

The critique was entirely rational. So, the mentioned sentence has been clarified as good as possible.

12- Page 6, Line 2 from bottom: 'At last' - sentence formation error

\section{Reply:}

The correction has been made.

13- Page 8, Line 3 'glossy graph paper' is it a graph paper to smoothen the paste?

\section{Reply:}

As can be seen in the majority of the similar works has been reported till now, applying a piece of a glossy graph paper (smoothed shiny paper) (like ATM receipts) as a mostly suited method to smoothen the expose-end surface of both modified and unmodified electrodes to 
appear shiny. (Any paper that is able to create an electrode surface shiny and smooth, can be used. But based on experience, and due to its smooth, shiny and cellulose-free surface, the most appropriate paper is graph paper).

14- Page 11, line 8-11: The sentence mentions 4 electrodes while Fig 4 (page 34) has 5 electrodes. The abbreviations for electrodes do not match in the sentence and Fig.

\section{Reply:}

The comparison was fulfilled only between four POM modified electrodes that is; POPOM/PO-CPE, POM/DOP-CPE, POM/DBP-CPE, and POM/IL-CPEs.

The suggested correction has been made.

15- Page 13, table 4, Footnote: What is "RTIL"?

\section{Reply:}

As explained at Page 4, the "RTIL" is was used as an abbreviation of "Room Temperature Ionic Liquid".

16- Page 13, table 5: 'Results of ANOVA .....' are not clear as notations have not been defined anywhere.

\section{Reply:}

At the present study, the main emphasis is on the electrode modification process, and an optimization method was used to confirm the results obtained. This is not a mere statistical work. Just like the similar work published previously, in this work the taguchi method comprising ANOVA, Optimization process, and Main effects of factors were adequately bolded as an side subsidiary tool.

17- Section 4.1.3, Page 17, para 2: 'A graph of ... detection'. The graph is not shown

\section{Reply:}

The correction was done.

18- Page 37, Fig 10: Unit of $\Delta \mathrm{E} / \Delta \mathrm{V}$ should be given.

\section{Reply:}

The correction was done as bellow;

$\Delta \mathrm{E} / \Delta \mathrm{V}\left(\mathrm{mV} / \mu \mathrm{L}^{2}\right)$

19- The abbreviations of electrodes are not consistent throughout the paper.

\section{Reply:}

All of the abbreviations were fully integrated. 
20- The article needs to be corrected for language and grammatical mistakes.

\section{Reply:}

Throughout the manuscript was fully checked and all of the grammatical errors and misspells were satisfactorily rectified.

\section{Reviewer \#2:}

The present manuscript describes the preparation, performance characteristics and applications of a composite electrode for the quantification of $\mathrm{Al}(\mathrm{III})$ ions. The topic is interesting, a lot of aspects describing an ion selective electrode are considered, and the utilization of a systematic design of experiment are important aspects, so all in all the manuscript should be considered for publication. However, a major drawback is that the manuscript does not follow a logical way, and some parts should be rearranged, some parts are double. Some results are questionable; some interpretations should be reconsidered or discussed more in detail.

\section{Some points in detail:}

1. Introduction: Rearrange the last part of the introduction.

\section{Reply:}

The correction has been made as suggested.

2. Apparatus: I would not speak about a "chemically modified Al(III) carbon paste indicator electrode...". It could be understood in a wrong way: the electrode is modified with Al(III). It is better to use the term "chemically modified carbon paste indicator electrode...".

\section{Reply:}

The correction has been made as suggested.

3. Page 7, first line: "blue shit...".. I guess it should be "blue shift...".

\section{Reply:}

It was a typographical error. The correction has been made as suggested.

4. Electrode preparation: Why different holders (Teflon and pipette tip) were used? I guess that is not an important point, but the description of electrode preparation is a little bit confusing and not consistent with description in Table 4. Authors should give numbers or abbreviations for each electrode and use these numbers or names consequently in the complete manuscript. Why are the ranges of graphite powder and nanoparticles so narrow? 


\section{Reply:}

Electrode preparation process was well integrated and all contradictions resolved.

It should be pointed out that, the electrodes provided in the preliminary examinations were much more than what is given in the Table 2. To avoid prolonging of the discussion, the electrodes around the modified specimen have only been summarized in the Table 2. As can be seen from this table, the 16 manners proposed by TSM, QT-4 with various weigh ratio of the components and type of binder were tested in three replicate experiments $(\mathrm{N}=3)$.

5. Results and Discussions: I would start with the description of the electrode response, first. The first paragraph in the chapter results reads like a part of conclusion. Fig. 4: What is meant with preliminary evaluations? It is rather difficult to distinguish between the curves, and I doubt that the response of the proposed electrode is linear over the complete range. It seems to be that the deviation from linearity starts at around $10^{-8} \mathrm{~mol} / \mathrm{L}$, and also at high concentrations a deviation from linearity is obvious. In Fig. 5, too much information is given. In addition, a discussion of the selectivity is given in part 4.1.4, and both Fig. 5 and Table 6 should be discussed together.

\section{Reply:}

About the calibration curve of $\mathrm{Al}(\mathrm{III})$ ion as a primary ion, it should be noticed that, the curve illustrated in the Fig. 5 is exactly the same as what was shown in the Fig. 6. Then, it can be simply opined about that. Secondly, about the interfering ions, there is no need to evaluate some trivial details. The difference between the potentiometric response of the electrode over the primary ion and interfering species in terms of linear range, detection limit, and Nernstian slop is sufficiently visible.

As regards to Fig. 5 and Table 6, it could be opined that, the philosophy of the preliminary study is to identify a species as a primary ion among all of the tested species. After that the modified sensor should undergo a lot of side experiments over both primary ion and interfering species. Determination of selectivity coefficients over target ion and interfering species is one of these side experiments. So, determining selectivity coefficients of the species and preliminary study steps are quite separate items. Nevertheless, they can be discussed with together in some parts like it was hinted at the section 4.1.4. 
6. Taguchi design of optimization: The results of the optimization could be shortened. I wonder why preconcentration time of $40 \mathrm{~min}$ is proposed as to be optimal, although in DOE the highest level was $30 \mathrm{~min}$, and level 3 was suggested as being optimal?

\section{Reply:}

Yes you right, it was just a typographical error. As shown in the Table 4. the optimal preconcentration time is $20 \mathrm{~min}$. The correction has been made as suggested.

7. Fig. 6: Parameters of the linear regression line should be given with meaningful significant number of digits. How dynamic range was evaluated? Again, there is a deviation from linearity in the upper and in the lower part of the curve. A plot of residuals is more meaningful than $\mathrm{R}^{2}$. How the detection limit was determined?

\section{Reply:}

The correlation coefficient $\left(\mathrm{R}^{2}=0.9999\right)$ obtained by MS word corresponds exactly to the linear range from $1.0 \times 10^{-9}$ to $2.2 \times 10^{-1} \mathrm{molL}^{-1}$.

The linear (i.e., Nernstian) response curve of the electrode as a function of the primary ion activity is extrapolated until, at the lower detection limit (DL), it intersects with the observed potential for the background alone (interfering ion activity).

The LOD value was calculated from the two extrapolated linear segments of the calibration curve, each relating the analytical response of the ISE to one respective ion only.

According to the IUPAC recommendation of 1976, the detection limit (DL) is defined by the cross-section of the two extrapolated linear calibration curves (see the figure below) as is evidently depicted in Fig. 6. 


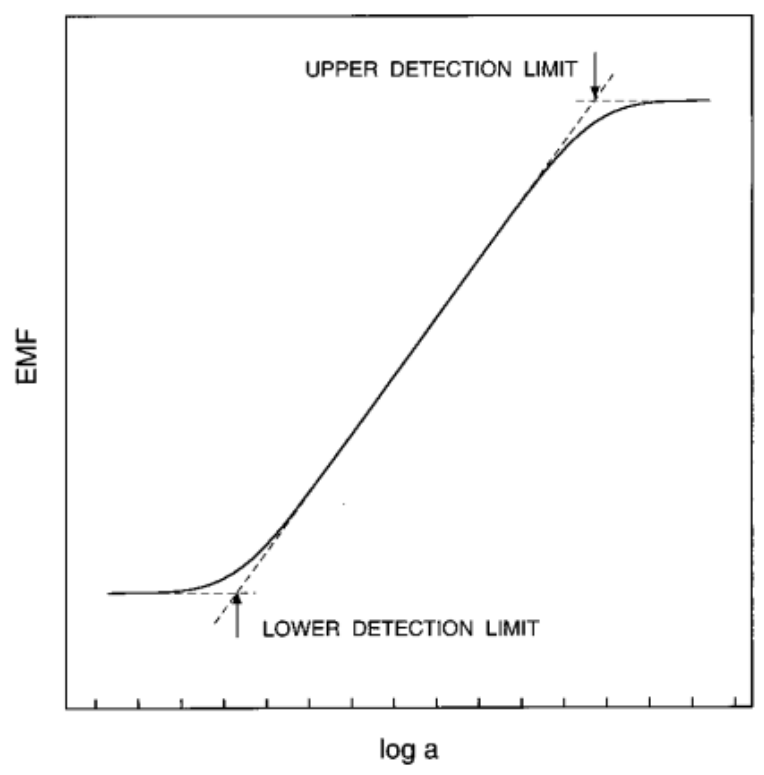

8. Optimal pH range: Some sentences are double in this part of the manuscript. Authors should be aware that not only $\mathrm{Al}(\mathrm{OH})_{3}$ precipitation can be formed. It is well known, that aluminium ions form various complexes (cf. Scholz F, ChemTexts (2015) 1:7); the calculations with the solubility product are only rough estimations.

\section{Reply:}

Yes, exactly, but it should be kept in mind that the main Hydroxide sediment of aluminum is $\mathrm{Al}(\mathrm{OH})_{3}$ with the $\mathrm{Ksp}=1.9 \times 10^{-33}$, the other forms of $\mathrm{Al}(\mathrm{III})$ sediment are so soluble (High $K s p$ ) that cannot affect the working $\mathrm{pH}$ range of the electrode. As can be seen from all of the similar researches reported previously, the most common form of $\mathrm{Al}^{3+}$ hydroxide sediment is $\mathrm{Al}(\mathrm{OH})_{3}$.

9. Response times: How solutions have been changed? In Fig. 8, the point of changing solution should be marked.

\section{Reply:}

As can be seen obviously, in the Fig 8, from low to high concentrations trend at each concentration the potential was recorded for 4 times (almost once per 5 second). It is quite clear that after fourth record the concentration was changed by 10 -fold. It should be noticed that, the concentration changes was performed by serial dilution without replacing the indicator electrode (modified electrode). 
10. Stability: What is meant with "the potentiometric signal decreased just faintly...". It should be quantified.

\section{Reply:}

That meant, after the mentioned period of time, any significant divergence was not observed in the potentiometric signal, implying on the rational stability of the modified sensor.

Nevertheless, to be more digestive the statement was corrected.

11. Reproducibility: Reduce number of significant digits.

\section{Reply:}

The correction was admittedly done!

12. Fig. 9: There is obviously a constant decrease of the signal even after 300 seconds? But before, authors claimed that the potentiometric signal is stable?

\section{Reply:}

As is evident from Fig 9. over 50 seconds, the potentiometric response of the electrode is satisfactorily stable and this period of time is long enough to trust to the electrode response. Nonetheless, you suppose for each concentration increasing you take a $300 \mathrm{~s}$ interval, then, to draw a calibration curve with ten times concentration change, it should take more than 3,000 seconds. This is completely in contradiction with the fastness of the CPE based electrochemical methods.

After all, the stability of the electrode response is defined for a constant concentration of target species over a specific period of time, not in the conditions of permanent and intermittent changes of target ion concentration. 
A novel polyoxomolybdate/ionic liquid based sensor for ultra-high sensitive monitoring of Al(III): Optimization by Taguchi statistical design

Soleyman Ramezani ${ }^{\mathrm{a},}$, , Rana Jahani ${ }^{\mathrm{b}}$, Mohammad Hossein Mashhadizadeh ${ }^{\text {a }}$, Saeed Shahbazi $^{\text {a }}$, Sajad Jalilian ${ }^{\mathrm{c}}$

${ }^{\text {a }}$ Faculty of Chemistry, Kharazmi University, Tehran, Iran

${ }^{\mathrm{b}}$ Department of Applied Chemistry, Faculty of Science, University of Mohaghegh Ardabili, Ardabil, Iran

${ }^{\mathrm{c}}$ Material Physic Center (CFM), University of Basque Country (EHU-UPV), San Sebastian 20018, Spain

Email: Soleyman.ramezani@yahoo.com 


\begin{abstract}
A novel ionic liquid electrostatically supported Nano-Cs-polyoxomolybdate modified carbon paste electrode (Nano-PMo ${ }_{12} / \mathrm{IL}-\mathrm{CPE}$ ) has been developed by using 1-n-butyl-3methylimidazolium tetrafluoroborate $\left(\mathrm{Bmim}_{\mathrm{B}} \mathrm{BF}_{4}\right)$ as a hydrophobic binder. The supramolecular gel $\left(\mathrm{PMo}_{12} / \mathrm{IL}\right)$ exhibits an ordered structure, various physicochemical properties, and specifically as a result of its substantial reversible self-assembly, it can be used as an intelligent ion-exchange smart platform in the carbon paste bulk of the electrode. As expected, a significant linear correspondence was found between the sensor output signal $(\mathrm{emf} / \mathrm{mV})$ and logarithm of $\mathrm{Al}(\mathrm{III})$ ion activity with a Nernstian slope of $19.9( \pm 0.2)$

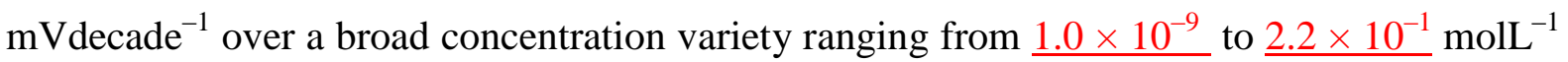
$\left(\mathrm{R}^{2}=\underline{0.9999}\right)$. The sensor considered, exploits an astounding lower limit of detection and

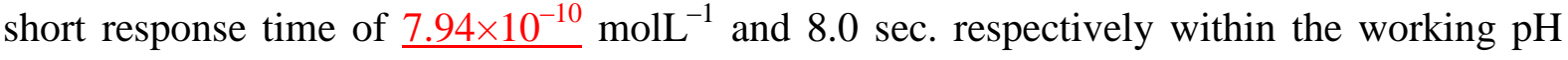
range of 2.0 to 5.0. A statistical design of experimental (Taguchi method with $\mathrm{L}_{16}$ orthogonal array robust design and Qualitek-4 software) was implemented in this work to optimize the process to achieve the least number of experimental runs as much as possible. Ultimately, practical capability of the sensor was investigated successfully by assessment of $\mathrm{Al}$ (III) $\underline{\text { ion }}$ quantity in some aqueous samples namely mineral water, Al-Mg syrup, black tea extract, and ore samples (Basalt and Andesite) in perfect agreement with flame atomic absorption spectroscopy (FAAS).
\end{abstract}

Keywords: Ionic liquid/polyoxomolybdate supramolecular gel, Taguchi statistical method, potentiometric sensor, $\mathrm{Al}(\mathrm{III})$ ion 


\section{Introduction}

Due to the important roles of Aluminum in the pathology of Parkinson's disease (PD), Alzheimer's disease and diseases of dialysis (dialysis encephalopathy or dialysis dementia), also it's toxicological effects on living system, especially on human beings and because of its utility as an aggregating agent in potable water treatment units [1-4], there is an increasing necessity for aluminum monitoring in real samples. So, a sensitive, fast, and specific methods for the determination of this element in different biological and physiological matrices and in environmental and food samples are needed. Up to date, various methods comprising different sorts of spectrophotometry, spectrofluorimetry, and chromatography have been successfully applied for determination of aluminum ion quantity in trace levels [5]. In spite of their intrinsic assets, this method has some inherent shortcomings such as time-consuming, involving tedious pre-treatment procedures, or too expensive $[3,5]$.

As an appropriate and reliable alternative, electrochemical methods utilizing chemically modified carbon paste electrodes (CMCPEs) are the most reliable methods for the determination of some biologically important molecules, medicines and toxic metal ions [36]. CPEs characterized of many properties such as low background current, easy renewal surface, rich surface chemistry, facile fabrication and modification with desired properties via incorporating different substances during the paste preparation, and above all, suitability for various sensing and detection applications [7-14].

Polyoxometalates (POMs) as mediators shuttling the redox equivalents between the substrate and the electrode for indirect electrochemical processes have attracted much attention in recent years [15-18]. Owing to the strong Brønsted acidity and special structural properties, Keggin-type POMs, as a non-coordinating templates have attracted much attention. They especially have some very useful and interesting properties including high stability, tunable ability of their redox potentials, and the possibility of their reversible multielectron transfer [18].

The unique properties of ionic liquids, including high thermal stability, tunability of their acidities, and excellent retention of polar or charged catalysts, make them appealing media for a broad range of catalytic applications [19]. Supported ionic liquid catalysis is a concept that combines the advantages of ionic liquids with those of heterogeneous support materials. The catalytically active polyoxometalate anion $\left[\mathrm{PMo}_{12} \mathrm{O}_{40}\right]^{3-}$ was immobilized onto the IL support by stoichiometric anion exchange via a very simple preparation procedure under 
relatively benign and easy-to-handle conditions (Fig. 1) [20-22]. Contrary to its bulk form, Nano-sized POMs possess some intrinsic preferences of high electrical conductivity, high specific surface area, low solubility in aqueous media (metal salt form), and in consequence high stability $[23,24]$. In this context, the combination of room temperature ionic liquid (RTIL) with Cs-Nano-PMo 12 [PMo 12 [ILs], can be concluded to be a novel kind of supramolecular gel. The results indicate that it's properties (i.e., transformation points and conductivities) can be tuned by the design of the organic part. The features of unique Nanosized space and functional surface of metal-organic frameworks, enable them to efficiently serve as host materials for various species (target species) [15, 25-30].

Design of Experiments (DOE) using Taguchi approach can economically satisfy the needs of problem solving and product/process design optimization complex projects to study the effect of multiple factors (i.e. variables, parameters, ingredients, etc.) simultaneously [3133]. To complete planning of experiments and evaluation criteria before conducting experiments, steps for analysis are standardized (main effect, ANOVA and Optimum), using taguchi statistical method (TSM) executed by Qualitek-4 (QT-4) software. A $\mathrm{L}_{16}$ orthogonal array type of QT-4 possessing four factors of control at four levels has been employed at the present study. The analysis of variance (ANOVA) of the mean electrode response and signalto-noise ratio showed the great influence of $\mathrm{PMo}_{12} / \mathrm{GP}$ weigh percentage ratio on the electrode potentiometric response. On the contrary, the other factors revealed low or no significant effect.

$\mathrm{PMo}_{12}$ is a Keggin type of anionic complex that has several applications in fuel cells, catalysis, molecular materials, electrochromism, super capacitors, medicine and some antibacterial activity against Escherichia coli and Bacillus subtilis [34]. As a unique class of metal oxide clusters, Keggin-type $\left[\mathrm{PMo}_{12} \mathrm{O}_{40}\right]^{3-}\left(\mathrm{PMo}_{12}\right)$ would represents as an IL supported building block to play key role of an ion-exchange or size-matching selective agent on the CPE assemblies. Due to its synergetic physicochemical properties, IL impregnated Nano$\mathrm{PMo}_{12}$, gives a substantial stability and sensitivity to the modified sensor. After optimization of the critical parameters by QT-4 run of TSM, the $\mathrm{PMo}_{12} / \mathrm{IL}$ modified CPE was satisfactorily used as a renewable probe electrode to investigate the $\mathrm{Al}(\mathrm{III})$ ion quantity in ultrahigh trace level included in the pharmaceutical and soil matrices, and aqueous samples.

\section{Material and methods}

\subsection{Reagents and materials}


Analytical reagent grade chemicals and doubly distilled water were used for preparing all aqueous solutions. Aluminum (III) nitrate was obtained from Merck. Carbon graphite powder (1-2 $\mu \mathrm{m}$ ), paraffin oil (PO), dioctyl phthalate (DOP) and dibutyl phthalate (DBP) (Fig. 2) were supplied from Aldrich and Fluka. Electrically conductive Ionic liquid (1-n-butyl-3methylimidazolium tetrafluoroborate) $\left(\mathrm{Bmim} . \mathrm{BF}_{4}\right)$ was purchased from Merck. $\mathrm{Na}_{2} \mathrm{HPO}_{4}$ and $\mathrm{Na}_{2} \mathrm{MoO}_{4}$ were purchased from Merck chemical company. The $\mathrm{Cs}_{3}\left[\mathrm{PMo}_{12} \underline{\mathrm{O}}_{40}\right]$ nanocluster was provided at the Inorganic Chemistry Laboratory using a reverse micelles based nanoreactor inspired by reference [34]. Nitrate and chloride salt of metals (all from Merck) were of the highest purity available and used without any further purification. All other chemicals used were of the analytical reagent grade (from Merck, Aldrich, or Fluka). All glassware used in the experiments were washed with freshly prepared aqua regia $3: 1$ (v/v) $\mathrm{HCl}: \mathrm{HNO}_{3}$ ) and rinsed thoroughly with tap water first and then DDW before use.

\subsection{Apparatus}

The potential was measured under constant stirring of the test solution with respect to a double-junction silver/silver chloride reference electrode (Azar electrode, Urmia, Iran) in conjunction with chemically modified carbon paste indicator electrode. All potentiometric measurements and $\mathrm{pH}$ adjustments were accomplished with a digital $\mathrm{pH} / \mathrm{mV}$ meter (Metrohm-827, Switzerland). Some solutions were homogenized by ultrasonic homogenizer (Bandelin UW 3200, Germany) whenever it was required. UV-Vis absorption spectra were recorded with a Perkin-Elmer, Lambda 25 (USA) spectrophotometer. Melting points were also determined with a Barnstead Electrothermal model 9200 apparatus. FT-IR spectra were recorded on Perkin-Elmer Spectrum RXI FT-IR spectrometer using pellets of the materials diluted with $\mathrm{KBr}$. All measurements were carried out at laboratory ambient temperature. The ${ }^{1} \mathrm{HNMR}$ analysis was implemented using BRUKER AVANCE DPX $300 \mathrm{MHz}$ apparatus. Elemental analysis was performed by a Perkin Elmer 2400 series II CHN-O-Rapid elemental analyzer.

\subsection{Preparations}

\subsubsection{Synthesis of Keggin Cs-Nano-PMo ${ }_{12}\left(\mathrm{Cs}_{3}\left[\mathrm{PMo}_{12} \mathrm{O}_{40}\right]\right)$}

The Keggin-type $\mathrm{Cs}_{3}\left[\mathrm{PMo}_{12} \mathrm{O}_{40}\right]$ nanocluster was supplied in accordance to the reference [34] and inspired by literature [35] using microemulsion method. It was formed by direct addition of aqueous solution of hydrochloric acid to reverse micelles containing $\mathrm{Na}_{2} \mathrm{MoO}_{4}$ 
and $\mathrm{Na}_{2} \mathrm{HPO}_{4}$. The product was found to be nearly uniform spherical nanoparticles with 20$30 \mathrm{~nm}$ size. Structure of the prepared nanomaterial was characterized using Fourier Transform Infrared Spectroscopy (FTIR) with $\mathrm{KBr}$ pellet, and surface morphology was also determined by atomic force microscopy (AFM), X-ray diffraction (XRD), and scanning electron microscopy (SEM).

\subsubsection{Electrostatic coupling of Keggin- $\left[\mathrm{PMo}_{12}\right]^{3-}$ with ionic liquid $[\mathrm{Bmim}]^{+}$}

The $[\mathrm{Bmim}]^{+}$moiety of RTIL was electrostatically dispersed throughout the $\alpha$-Keggin$\left[\mathrm{PMo}_{12} \mathrm{O}_{40}\right]^{3-}$ according to the literature [35], briefly by adding $0.5 \mathrm{~g}$ IL into $50 \mathrm{ml}$ $\mathrm{Cs}_{3}\left[\mathrm{PMo}_{12} \mathrm{O}_{40}\right]$ aqueous solution and stirring at room temperature for $6 \mathrm{~h}$ (Scheme 1). Then, the obtained pale yellow sediment was isolated by filtration and washed with deionized water. The resulting solid was dried in vacuum at $50{ }^{\circ} \mathrm{C}$ for $12 \mathrm{~h}$. Eventually, UV-Vis and FT-NMR spectroscopy was successfully used to confirm the PMo 12 /IL Nanocomposite formation. When the $\mathrm{PMo}_{12} / \mathrm{IL}$ Nano-hybrid is formed normally a blue shift of the electronic transitions and splits of the $\mathrm{C}-\mathrm{H}$ stretching modes of the imidazolium ring are observed [36]. As can be conspicuously seen (Fig. 3 ), the neat $\mathrm{Cs}_{3}\left(\mathrm{PMo}_{12}\right)$ exhibits characteristic absorptions at $314 \mathrm{~nm}$, which arise from charge transition from $\mathrm{O}^{2-}$ to $\mathrm{Mo}^{6+}$ in $\mathrm{Mo}=\mathrm{O}$ and $\mathrm{Mo}-\mathrm{O}-\mathrm{Mo}$ bonds. The absorption band at $210 \mathrm{~nm}$ are likely to be associated with $\mathrm{O} \rightarrow \mathrm{P}$ transition [36]. These absorption peaks exhibit a slight blue shift, implies on acceptable interactions between $\mathrm{PMo}_{12}$ anions and imidazolium cations in the mesoporous Nano-cluster matrices.

Along with completion of the characterization analysis, the elemental analysis of the $\mathrm{PMo}_{12} / \mathrm{IL}$ was also performed. According to the results, the experimental values are similar to the calculated values, this suggests that the $\mathrm{PMo}_{12} / \mathrm{IL}$ Nano-hybrid are composed of 3:1 mole ratio of $[\mathrm{Bmim}]^{+}$to Keggin- $\left[\mathrm{Pmo}_{12} \mathrm{O}_{40}\right]^{3-}$. (Anal. Calc. for $\left([\mathrm{Bmim}]_{3}\left[\mathrm{PMo}_{12} \mathrm{O}_{40}\right]\right)$ : C, 12.87; H, 2.03; N, 3.75. Found: C, 12.74; H, 1.96; N, 3.68.)

The FT-IR spectra are quite useful to identify structural and bonding changes in the Keggin unit present in $\mathrm{PMo}_{12}$-based ILs hybrid materials. So, FT-IR spectroscopy was applied to confirm $[\mathrm{Bmim}]_{3}{ }^{+}\left[\mathrm{PMo}_{12} \mathrm{O}_{40}\right]^{3-}$ electrostatic coupling. The FT-IR analysis of $\left[\mathrm{Bmim} . \mathrm{PF}_{4}\right]$, Nano- $\mathrm{Cs}_{3}\left[\mathrm{PMo}_{12} \mathrm{O}_{40}\right]$, and $[\mathrm{Bmim}]_{3}{ }^{+}\left[\mathrm{PMo}_{12} \mathrm{O}_{40}\right]^{3-}$ are in good agreement with the results reported in the literatures [35-38].

\section{3.‥ Electrodes preparation}


The unmodified and chemically modified carbon paste $\mathrm{Al}(\mathrm{III})$ electrodes were prepared as described previously $[3,9,10]$. Concisely, suitable amounts of both carbon graphite (CG) $(\% 67, w / w)$ and pasting agents (binder), PO, DOP, DBP, and or IL (\%33, w/w), were mixed in an agate mortar and exhaustively hand-mixed with an agate pestle. Several different $\mathrm{CG} / \mathrm{IL} / \mathrm{PMo}_{12}$ weight percentage ratios $(\mathrm{w} / \mathrm{w} \%)$ were prepared for each material. After well hand-mixing, to attain maximum uniformity and high electrical conductivity, all the components were dissolved in about $2 \mathrm{ml}$ of acetone and sonicated for $5 \mathrm{~min}$. With this trick, the experimenter easily gets rid of the potential output instability with high tolerance. The resulting solution was then left at ambient temperature to entirely evaporate left-over solvent. A portion of the resulting paste was well packed into the polypropylene tube $\underline{(2.5 \mathrm{~mm} \mathrm{i.d} \text { and }}$ $12 \mathrm{~cm}$ length) with a hole at one end without any air gap, the tip of which had been cut off. Electrical contact was established via a cooper wire with the transversal section previously cleaned, planed and polished. Prior to use, smooth and fresh electrode surfaces were attained by scraping off the over-flow paste and squeezing out $0.5 \mathrm{~mm}$ of the paste from the syringe, polishing it against glossy graph paper until the surface had a shiny appearance without any porosity. The provided electrodes will be ready to use after $12 \mathrm{~h}$ time interval to equilibrium their components. Just before any experiment, the renewed surface of the modified CPEs were preconditioned by putting it into the $1.0 \times 10^{-4} \mathrm{molL}^{-1}$ of $\mathrm{Al}(\mathrm{III})$ ion solution for $30 \mathrm{~min}$. Instantaneously after that, in order to wipe non-specific adsorbed ions off the electrode surface, it was left in DDW for another 15 minutes. And then the electrode active surface was rinsed with distilled water.

\subsection{General procedure}

The electrochemical cell assembly equipped by the proposed carbon paste indicator electrode for potentiometric measurements was as follows [12]:

$$
\mathrm{Ag} / \mathrm{AgCl} \mid \text { sample solution | } \mathrm{CPE}
$$

All potentiometric essay of $\mathrm{Al}(\mathrm{III})$ ion was fulfilled by the proposed carbon paste indicator electrode in contact with $\mathrm{Ag} / \mathrm{AgCl}$ reference electrode connected with the $\mathrm{pH} / \mathrm{mV}$ meter. The reference electrode was a double junction $\mathrm{Ag} / \mathrm{AgCl}, 3 \mathrm{M} \mathrm{KCl} \mid 1 \mathrm{M} \mathrm{KNO}_{3}$ electrode. During all measurements, two electrodes were immersed in the $50 \mathrm{~mL}$ beaker containing $30 \mathrm{~mL}$ deionized water, and the solution was smoothly stirred using a magnetic stirrer. Also, $\mathrm{pH}$ of the test solution was locked in 5.0 by adding $0.1 \mathrm{molL}^{-1}$ solution of either $\mathrm{HNO}_{3}$ or $\mathrm{NaOH}$. The performance of the electrodes was investigated by measuring the cell 
potential of aluminum (III) nitrate solutions in the concentration range of $\underline{4.0} \times 10^{-11}$ to $2.2 \times 10^{-1} \mathrm{molL}^{-1}$ by serial dilution of the $0.1 \mathrm{molL}^{-1}$ stock solution. As the test solution is gently being stirred, the electrode potential was recorded when a steady state value was attained within $\pm 2.0 \mathrm{mVdecade}^{-1}$. The calibration curve was extracted by plotting the potential (E, V vs. $\mathrm{Ag} / \mathrm{AgCl}$ ), versus $\log \mathrm{Al}(\mathrm{III})$ ion concentrations. The activities of the metal ions were calculated based on the Debye-Hückel procedure. All the metal nitrate solutions were freshly prepared by accurate dilution of their stock standard $0.1 \mathrm{molL}^{-1}$ solution with double distilled deionized water.

\subsection{Taguchi design of experiments}

Taguchi method uses a special design of orthogonal arrays that allows to study the whole parameter space with a limited number of experiments. Besides, this method provides other advantages: it reduces economically the variability of the response variable, shows the best way to find out the optimum process conditions during laboratory experiments, it is an important tool for improving the productivity of the R\&D activity and it can be applied to any process $[33,39]$.

In the present study, to achieve maximum efficiency in storage capacity, time or cost with experiments with minimal repetition, some of the effective and determinative factors were optimized applying L-16 array type of QT-4 software of TSM [40]. Successful selection of the factors with favorable outcomes is entirely based on the most critical parameters that can strongly affect the electrochemical response of the proposed sensor. The Nano- $\mathrm{PMo}_{12} / \mathrm{IL}$ modified CPE was established using four different factors such as; the weight percentage ratio of GP and Cs-Nano-PMo $\mathrm{PM}_{12}$ in carbon paste composition, type of binder, and preconcentration time which are mutually exclusive (Table 1). The four parametric levels were selected so that a practical range of parameter variations are included.

Table 1 Different parameters and levels used to design orthogonal array

\begin{tabular}{lllll}
\hline Factors & Level 1 & Level 2 & Level 3 & Level 4 \\
\hline Graphite powder (mg) & 66 & 65 & 64 & 63 \\
Cs-Nano-PMo $_{12}(\mathrm{mg})$ & 0 & 3 & 4 & 5 \\
Binder & PO & DOP & RTIL & DBP \\
PC. time (min) ${ }^{\text {a }}$ & 0 & 15 & 20 & 30 \\
\hline
\end{tabular}


After selecting the effective parameters in four different levels, the L-16 orthogonal array type of QT-4 was used to set up the experiments (Table 2). As can be seen from this table, the 16 manner proposed by QT-4 In this manner, various weigh ratio of the components and type of binder were tested in three replicate experiments $(\mathrm{N}=3)$. Considering the bigger the better, signal to noise $(\mathrm{S} / \mathrm{N})$ was used for the evaluation of the impact rate of the each parameter on the proposed modified electrode response. In the TSM, the terms 'signal' and 'noise' represent the desirable and undesirable values for the output characteristic, respectively. TSM uses the $\mathrm{S} / \mathrm{N}$ ratio to measure the quality characteristic deviating from the desired value. The $\mathrm{S} / \mathrm{N}$ ratios are different according to the type of characteristic. In the cases that the bigger characteristics are better, the $\mathrm{S} / \mathrm{N}$ ratio is defined as;

$$
\frac{\mathrm{S}}{\mathrm{N}}=-10 \log \left[\frac{1}{\mathrm{n}} \sum_{\mathrm{i}=1}^{\mathrm{n}} \frac{1}{\mathrm{y}_{\mathrm{i}}^{2}}\right]
$$

Where, $y_{i}$ is the characteristic property and $n$ is the replication number of the experiment [41].

Indubitably, various parameters are effective on the analytical performance of the generated sensor. Indisputably, the best Nernstian response would be the calibration curve slope close to the $20.0 \mathrm{mV} / \mathrm{decade}$ for $\mathrm{Al}$ (III) ion.

Table 2 Factor settings for Taguchi $\mathrm{L}_{16}$ design of Nano-PMo ${ }_{12} / \mathrm{IL}$ modified CPE.

\begin{tabular}{|c|c|c|c|c|c|c|c|c|}
\hline \multirow{2}{*}{ Exp. } & \multirow{2}{*}{$\begin{array}{l}\text { GP } \\
(\mathrm{mg})\end{array}$} & \multirow{2}{*}{$\begin{array}{l}\text { Nano-PMo }{ }_{12} \\
(\mathrm{mg})\end{array}$} & \multirow{2}{*}{$\begin{array}{l}\text { Binder/Amount } \\
(\mathrm{mg})\end{array}$} & \multirow{2}{*}{$\begin{array}{l}\text { PC. time } \\
(\min )\end{array}$} & \multicolumn{4}{|c|}{ Calibration curve slope $\left(\mathrm{mVdecade}{ }^{-1}\right)$} \\
\hline & & & & & $\begin{array}{l}\text { Sample } \\
\text { (I) }\end{array}$ & $\begin{array}{l}\text { Sample } \\
\text { (II) }\end{array}$ & $\begin{array}{l}\text { Sample } \\
\text { (III) }\end{array}$ & $\mathrm{S} / \mathrm{N}$ \\
\hline L-1 & 66.0 & 0 & $\mathrm{PO} / 34$ & 0 & 4.2 & 3.5 & 3.6 & 11.43 \\
\hline L-2 & 66.0 & 3.0 & $\mathrm{DOP} / 31$ & 15 & 12.4 & 12.5 & 13.0 & 22.02 \\
\hline L-3 & 65.0 & 5.0 & IL/30 & 20 & 19.4 & 19.6 & 19.6 & 25.81 \\
\hline L-4 & 66.0 & 4.0 & $\mathrm{DBP} / 30$ & 30 & 17.5 & 17.0 & 16.8 & 24.65 \\
\hline L-5 & 65.0 & 0 & $\mathrm{DOP} / 35$ & 20 & 8.3 & 8.5 & 8.2 & 18.41 \\
\hline L-6 & 65.0 & 3.0 & $\mathrm{PO} / 32$ & 30 & 15.1 & 14.5 & 15.3 & 23.49 \\
\hline $\mathrm{L}-7$ & 65.0 & 4.0 & $\mathrm{DBP} / 31$ & 0 & 9.1 & 9.5 & 10.0 & 19.56 \\
\hline L-8 & 65.0 & 5.0 & IL/30 & 15 & 18.3 & 18.0 & 18.0 & 25.15 \\
\hline L-9 & 64.0 & 0 & IL/36 & 30 & 8.4 & 7.9 & 8.5 & 18.33 \\
\hline L-10 & 64.0 & 3.0 & DBP/33 & 20 & 14.5 & 14.0 & 14.7 & 23.16 \\
\hline L-11 & 64.0 & 4.0 & $\mathrm{PO} / 32$ & 15 & 15.4 & 15.8 & 16.0 & 23.93 \\
\hline L-12 & 64.0 & 5.0 & DOP/31 & 0 & 7.5 & 7.0 & 7.0 & 17.09 \\
\hline L-13 & 63.0 & 0 & $\mathrm{DBP} / 37$ & 15 & 5.5 & 5.5 & 5.0 & 14.51 \\
\hline L-14 & 63.0 & 3.0 & IL/34 & 0 & 7.3 & 7.0 & 7.1 & 17.06 \\
\hline
\end{tabular}




\begin{tabular}{ccccccccc} 
L-15 & 63.0 & 4.0 & $\mathrm{DOP} / 33$ & 30 & 11.0 & 11.3 & 11.4 & 21.00 \\
$\mathrm{~L}-16$ & 63.0 & 5.0 & $\mathrm{PO} / 32$ & 20 & 17.5 & 18.1 & 17.0 & 24.86 \\
\hline
\end{tabular}

GP: graphite powder, PC time: preconcentration time, PO: paraffin oil, DOP: dioctyl phthalate, DBP: dibutyl phthalate, IL: ionic liquid.

\section{Results}

Admittedly, the analytical performance of ion selective electrodes (ISEs) depends exceedingly on the chemical nature and amount of the modifying additives. Among them, the matrices resistance and uniformity, selectivity, sensitivity and response behavior of the sensors are noteworthy [21]. The ability of POMs to undergo reversible multi-electron redox processes makes them interesting for amperometric sensor applications, such as detection of redox-active industrial and agricultural pollutants. To recite the sensing information and to boost electroanalytical response, the POMs need to be anchored or immobilized on conductive substrates while at the same time maintaining molecular dispersion to reach low analyte detection limits. Therefore, electrically conductive platforms of CNTs, graphene, and RTILs are ideal substrate for this purpose [42]. As far as pursuits confirm, this work, is the first attempt to apply IL-modified $\mathrm{Cs}-\mathrm{PMo}_{12}$ for the selective and sensitive $\mathrm{Al}(\mathrm{III})$ ion determination in the presence of some alkali, alkaline earth and transition metal ions, and some biologically important species. It was found in preliminary evaluations that, compared with PO, DBP, and DOP- PQMM modified CPE, the POM/IL-CPE, influenced by the unique characteristics of IL, generated stable potentials over Al(III) ions, after a conditioning in a $1.0 \times 10^{-4} \mathrm{molL}^{-1} \mathrm{Al}\left(\mathrm{NO}_{3}\right)_{3}$ solution (Fig. 4). As compared to the other traditional electrodes, the clear distinction of the $\mathrm{PMo}_{12} / \mathrm{IL}-\mathrm{CPE}$ are high sensitivity, wider dynamic concentration range, and lower limit of detection._-Furthermore, in preliminary studies, the proposed sensor was successfully examined in potentiometric determination of some alkali, alkaline earth and transition metal ions, and the attained results were graphed in Fig. 5. Among all species tested, the $\mathrm{PMo}_{12} / \mathrm{IL}-\mathrm{CPE}$ revealed outstanding selectivity merely for $\mathrm{Al}$ (III) ion in comparison with more common metal ions. Accordingly, the $\mathrm{PMo}_{12} / \mathrm{IL}$ contributes as an ion exchange platform for design and construction of the $\mathrm{Al}$ (III) selective electrode.

\subsection{Proposal response mechanism of the electrode}

As is well-known, the response characteristics of an ISE depends exceedingly on the chemical nature and amount of both ionophore and plasticizer used [4, 9, 10]. Hereby, in the present study the Keggin type of $\mathrm{Cs}_{3}\left[\mathrm{PMo}_{12} \mathrm{O}_{40}\right]$ Nanocluster (Cs-Nano-PMo $\left.{ }_{12}\right)$ was used as a 
Zeolite-like Nanoporous matrices for sensitive and selective monitoring of $\mathrm{Al}(\mathrm{III})$ ion quantity. Consequently, about the proposed sensor, in the presence of $\mathrm{IL}_{3}\left[\mathrm{PMo}_{12} \mathrm{O}_{40}\right]$, Nanoclusters, the $\left(\mathrm{Al}^{3+}\right)_{\text {solution }} \leftrightarrow\left(\mathrm{Al}^{3+}\right)_{\text {electrode }}$ conditioning process following size-matching theory can be hypothetically the most probable response mechanism in the electrode/solution interface. In the presence of such a compounds, the Keggin clusters also confine target ions in the cavities of framework host matrices as a non-coordinating guests like a zeolite [22].

In order to clarify the most probable response mechanism of the modified sensor, the elemental analysis was implemented over the test solution before and after equilibration with an aluminum solution. Based on the results, no net-charge transfer was performed over electrode surface/solution interface. Accordingly, the most likely mechanism with a Nernstian response characteristic would be as follows:

$\mathrm{Al}^{3+}(\mathrm{aq}) \rightarrow \mathrm{Al}^{3+}($ surface $)$

With this approach, the most likely response mechanisms of the Nano-PMO $\mathrm{PM}_{12} / \mathrm{IL}-\mathrm{CPE}$ over $\mathrm{Al}(\mathrm{III})$ ion is translocation in the octahedral hole of the nanocluster network without net charge-transfer process_(Scheme 2).

3.2. Taguchi design of optimization

The parametric comprehension for design and construction of a sensitive and selective $\mathrm{Al}(\mathrm{III})-\mathrm{CPE}$ and an endeavor for quantitative scrutiny of the impact of individual parameter in sensitive determination of $\mathrm{Al}(\mathrm{III})$ ions has led to the utilization of statistical support system of taguchi design. This design of experiment has got a completely controlled task of selecting the best parameters for sensitive monitoring of the $\mathrm{Al}(\mathrm{III})$ ions (the most Nernstian calibration curve slope would be desirable).

In this study, four four-level process parameters, i.e. GP and $\mathrm{PMo}_{12}$ nanocluster weight percentage ratio, type of binder and preconcentration time were evaluated by L-16 array type of TSM. After fulfillment of the triplicate experiments proposed by the L-16 orthogonal array (Table 2), the obtained results were entered into the Qualitek-4 (QT-4) software. Considering bigger $\mathrm{S} / \mathrm{N}$ ratio is better as criteria for determining the optimum conditions, the software defined and introduced optimized experimental conditions in terms of physical conditions with a statistical estimation based on the mean of $\mathrm{S} / \mathrm{N}$ ratio (bigger $\mathrm{S} / \mathrm{N}$ ratio is better) (Table 3). Consequently, as can be concluded from the Table 4, based on the S/N ratio by three replicate try of each experiment, the best results were obtained in the following 
optimal conditions; GP $65 \mathrm{mg}$ (level 2), $\mathrm{PMo}_{12}$ nanoparticles $5 \mathrm{mg}$ (level 4), IL as binder (level 3) and preconcentration time 20 min (level 3).

Table 3 Taguchi analysis of the electrode response data

\begin{tabular}{lllll}
\hline \multirow{2}{*}{ Factors } & \multicolumn{4}{l}{ Mean S/N ratio } \\
\cline { 2 - 5 } & Level 1 & Level 2 & Level 3 & Level 4 \\
\hline Graphite Powder (mg) & 20.983 & 21.656 & 20.63 & 19.362 \\
Cs-Nano-PMo $_{12}(\mathrm{mg})$ & 15.674 & 21.436 & 22.58 & 22.942 \\
Type of Binder & 20.933 & 19.634 & 21.59 & 20.474 \\
PC. time (min) $^{\text {a }}$ & 16.289 & 21.406 & 23.064 & 21.873 \\
\hline
\end{tabular}

${ }^{a}$ Preconcentration time

Table 4 Optimum conditions and performance proposed by $\underline{L}_{16}$ array run of QT-4 program to provide $\mathrm{Al}$ (III)-CPE.

\begin{tabular}{llll}
\hline Factors & Level Description & Level & Contribution \\
\hline Graphite Powder (mg) & 65 & 2 & 0.998 \\
Cs-Nano-PMo $12(\mathrm{mg})$ & 5 & 4 & 2.284 \\
Type/amount of Binder & $\mathrm{RTIL} / 30^{\mathrm{a}}$ & 3 & 0.932 \\
PC. time (min) & 20 & 3 & 2.406 \\
\hline
\end{tabular}

${ }^{\mathrm{a}}$ Out of PO, DOP, DBP, and RTIL

In the following, to better comprehend, the relative influence of the different critical parameters on the $\mathrm{Al}(\mathrm{III})$-CPE response was inferentially scrutinized by the mean of analysis of variance (ANOVA). Hereby, the relative importance of the experimental parameters in association with construction of the proposed sensor was investigated to discover the optimal data using ANOVA and the outputs were summarized in Table 5.

Table 5 Results of the ANOVA for modified sensor preparation experiments.

\begin{tabular}{lllllll}
\hline Source of Variation & d.f. & SS & MS & F & $\begin{array}{l}\text { Pure Some } \\
\left(\mathrm{S}^{\prime}\right)\end{array}$ & Contribution (\%) \\
\hline Graphite powder $(\mathrm{mg})$ & 3 & 11.127 & 3.709 & 3.379 & 7.834 & 2.927 \\
Cs-Nano-PMo $_{12}(\mathrm{mg})$ & 3 & 137.429 & 45.809 & 41.735 & 134.136 & 50.123 \\
Binder & 3 & 8.109 & 2.703 & 2.462 & 4.816 & 1.799 \\
PC. time (min) & 3 & 107.655 & 35.885 & 32.693 & 104.362 & 38.997 \\
\hline
\end{tabular}




\section{d.f.: degree of freedom, SS: sum of squares, MS: mean of squares (equal to SS/d.f.), $\mathrm{F}: \mathrm{MS}_{\text {effect }} / \mathrm{MS}_{\text {error }}$.}

According to this analysis, the most and least effective factor on the electrochemical behavior of the modified sensor is amount of ionophore (Cs-Nano-PMo $\left.{ }_{12}\right)$ and type of binder respectively. Statistically, F-test provides a decision at some confidence level as to whether these estimates differ significantly from each other [23, 25]. A larger F-value indicates that the variation of the expected parameter makes a bigger change on the proposed sensor performance. In general, the percent contribution indicates the relative ability of a factor to reduce variation. For a factor with high percent contribution, a small variation will have a great influence on the performance. Hereby, the importance of the Cs-Nano-PMo 12 in the electrochemical characteristics of the modified Al (III)-CPE such as Nernstian slope, limit of detection, and response time will be truly understood. Although, the importance of type of the binder is minimal here, it is not dispensable practically. As a priori, conductivity of the carbon paste components depends strongly on the type of the binder, but here this importance located statistically in the shadow of the $\mathrm{PMo}_{12}$ nanoparticles impact. Nevertheless, the preconcentration time have second rank in terms of the impact factor after $\mathrm{PMo}_{12}$ nanoparticles, this mirror the fact that, the electrochemical response of the sensor strongly influenced by the preconcentration period time. Hereby, the observed potential is equal with boundary potential between CPE surface and test solution influenced by ion exchange process arises from concentration gradient of the $\mathrm{Al}$ (III) ions in the CPE surface, this is completely depends on the saturation of the bulk of the carbon paste in the preconcentration period of time.

Eventually, the relative influence of the challenged factors and their interactions obtained by the ANOVA indicated that, the Cs-Nano- $\mathrm{PMo}_{12}$ weight percentage ratio (\%50.12), preconcentration time (\%38.79), graphite powder weight percentage ratio (\%2.92) and Type of binder (\%1.79) respectively have the greatest effect on the potentiometric response of the proposed sensor.

\subsection{Composition and characteristics of the electrodes}

Some variable distinguished features of the carbon paste electrode, such as chemical nature of binder, binder/graphite powder weight ratio, the nature and amount of ionophore, and especially, the nature and amount of the Nano-material used, have been reported to meaningfully influence the sensitivity and selectivity of the ion-selective electrodes $[26,15]$. 
Thus, the efficacy of presence and amount of the modifier (Cs-Nano-PMo $\mathrm{M}_{12}$ ), type of binder (IL, PO, DOP and DBP), and weight ratio of the GP/binder on the electrochemical response of the $\mathrm{Al}$ (III)-CPE were scrutinized by TSM in the 16 trial conditions and the results were summarized in the Table 2. As can be seen overtly, in the absence of the $\mathrm{PMo}_{12}$ nanoparticles the sensor has poor response to $\mathrm{Al}(\mathrm{III})$ ion based on the calibration curve slope. As mentioned earlier, the Cs- $\mathrm{PMo}_{12}$ nanocluster with an appropriate cavity size acts as suitable ionexchange agent for $\mathrm{Al}(\mathrm{III})$. Also, the influence of nature of paste binder on the $\mathrm{CPE}$ response is overtly impressive. As compared to the other types of binders, (PO, DOP and DBP), the Bmim. $\mathrm{BF}_{4}$ as an electrical conductive binder rely on its unique properties, plays a distinguished key role to coherent the carbon paste tissue. This efficiency emanates from the ionic nature of the binder that increases strongly the electrical conductivity of the carbon paste bulk of the electrode while the other binders were incapable just for the sake of nonionic nature. Therefore, despite of $\mathrm{Bmim}_{\mathrm{BF}} \mathrm{BF}_{4}$, the nonconductive binders would not have any influence on the $\mathrm{CPE}$ response while the $\mathrm{Bmim}_{\mathrm{B}} \mathrm{BF}_{4}$ as a solvent mediator not only can act as a liquefying agent, but also enables homogeneous solubilization and modifying the distribution constant of the ionophore used. Also, it was proven experimentally that, reducing the GP/binder weight percentage ratio causes to decrease the sensitivity of the CPE. This is arisen from the fact that by decreasing GP/binder weight ratio, the ohmic resistance of the carbon paste will increase and consequently causes to diminish the CPE sensitivity. Hereto, as shown in Table 4, the Cs-Nano-PMo ${ }_{12}$ modified IL-CPE with the GP/PMo ${ }_{12} / \mathrm{Bmim}$ weigh percentage ratio of 65/5/30 was selected as an optimal paste composition. Such electrode with this features after optimum preconcentration time of $\underline{20} \mathrm{~min}$ exhibits a Nernstian slope of $19.9( \pm 0.2) \mathrm{mVdecade}^{-1}$ in the wide $\mathrm{Al}(\mathrm{III})$ ion concentration range of $\underline{1.0 \times 10^{-9}}$ to $2.2 \times 10^{-1}$ molL ${ }^{-1}$ with a lower limit of detection of $7.94 \times 10^{-10} \mathrm{molL}^{-1}$ (Fig. 6). It is noteworthy that, all of the theoretical optimum conditions proposed by TSM, were perfectly consistent with the experimental data. Therefore, the electrode manufactured under the criteria defined be TSM, represented the best performance and was utilized as an indicator electrode for supplementary electroanalytical operations.

\section{Discussion}

4.1. Analytical characteristics of the modified electrode

\subsubsection{Optimal $\mathrm{pH}$ range}


The $\mathrm{pH}$ dependence of the proposed sensor was scrupulously considered in the range of $1.0 \_-9.0$ at the $2.2 \times 10^{-4}$ and $5.2 \times 10^{-6} \mathrm{molL}^{-1}$ of $\mathrm{Al}\left(\mathrm{NO}_{3}\right)_{3}$ solutions, and the results were depicted in Figure 7. As can be clearly expounded, the observed potential values are wholly freed from the $\mathrm{pH}$ varieties, in the $\mathrm{pH}$ range of 2.0 to 4.5 and 2 to 5.0 in the $2.2 \times 10^{-4}$ and $5.2 \times 10^{-6} \mathrm{molL}^{-1}$ of $\mathrm{Al}(\mathrm{III})$ ion concentration respectively, indicating the applicability of the proposed sensor in this $\mathrm{pH}$ range. The $\mathrm{pH}$ of the test solutions was set in the 1.0 to 9.0 using $0.1 \mathrm{molL}^{-1}$ nitric acid or sodium hydroxide stock solutions. Arguably, the observed potential values are wholly freed from the $\mathrm{pH}$ varieties, in the $\mathrm{pH}$ range of 2.0 to 4.5 and 2.0 to 5.0 in the $2.2 \times 10^{-4}$ and $5.2 \times 10^{-6} \mathrm{molL}^{-1}$ of $\mathrm{Al}(\mathrm{III})$ ion concentration respectively, indicating the applicability of the proposed sensor in this $\mathrm{pH}$ range. Nevertheless, beyond the range, however, relatively drastic drifts in the potential versus $\mathrm{pH}$ behavior were observed. At the $\mathrm{pH}$ values lower than 2.0, the electrode response increased rather irregularly with increasing analyte acidity. At such a high acidic solutions, the observed increasing in the potential can be presumably due to simultaneous response of the sensor to the $\mathrm{Al}^{3+}$ and $\mathrm{H}_{3} \mathrm{O}^{+}$species (protonation of ion-exchange sites of $\underline{\text { Nano-PMo }}{ }_{12}$. In this manner, the significantly protonated surface of the CPE possesses a poor response to the Al (III) ions and instead strong response to $\mathrm{H}_{3} \mathrm{O}^{+}$ions in the solution. On the other hand, at the $\mathrm{pH}$ values higher than 5 , based on thickness of $\mathrm{OH}^{-}$ions throughout the test solution, the potential was found dramatically decreased due to appearance of $\mathrm{Al}(\mathrm{OH})_{3}$ sediment and in consequence diminishing of $\mathrm{Al}$ (III) flux to electrode surface through the solution. It is worth noting that, the experimental results roughly are in entire agreement with what was expected from Ksp relation of the $\mathrm{Al}(\mathrm{OH})_{3}$ precipitation. This means that, the initial concentration of $\mathrm{OH}^{-}$ion required to form $\mathrm{Al}(\mathrm{OH})_{3}$ sediment in presence of $2.2 \times 10^{-4}$ and $5.2 \times 10^{-6}$ molL $^{-1}$ of $\mathrm{Al}(\mathrm{III})$ ion, was nearly proponed by the potentiometric sensor as is anticipated from the Ksp equation of $\mathrm{Al}(\mathrm{OH})_{3}$ precipitation as bellows:

$\mathrm{Ksp}=\left[\mathrm{Al}^{3+}\right]\left[\mathrm{OH}^{-}\right]^{3}=1.9 \times 10^{-33}$, if $\left[\mathrm{Al}^{3+}\right]=2.2 \times 10^{-4} \mathrm{molL}^{-1}$, thus, $\mathrm{pH}=4.31$, and if $\left[\mathrm{Al}^{3+}\right]=$ $5.2 \times 10^{-6} \mathrm{molL}^{-1}$, thus $\mathrm{pH}=4.85$.

\subsubsection{Response time and reversibility}

Arguably, quickness and accuracy are two mostly determinative factors for a quantitative successful analysis. So, dynamic response time is an influential factor for any electrochemical sensors. The electrode response time was assessed rely on the IUPAC recommendation [43]. The average time required for the potentiometric electrode to reach a potential within \pm 1.0 
$\mathrm{mV}$ of the final equilibrium value after successive immersion of $\mathrm{Al}$ (III) ion solutions, each having a 10-fold difference in concentration, was investigated. The measurements of potential (emf, V vs. $\mathrm{Ag} / \mathrm{AgCl}$ ) versus time (sec.) were carried out with the $\mathrm{Al}\left(\mathrm{NO}_{3}\right)_{3}$ solutions from lower $\left(2.2 \times 10^{-7} \mathrm{molL}^{-1}\right)$ to higher $\left(2.2 \times 10^{-4} \mathrm{molL}^{-1}\right)$ concentrations and vice versa (Fig. 8). In this manner, the emf (V)-time (sec.) plot for these concentrations conspicuously indicates that the potentiometric response time of the electrode was 8 seconds. In order to figure out the proposed electrode reversibility, the emf measurements were implemented in the sequence high-to-low sample concentrations as shown in Fig. 8. Rely on the what was achieved, it was found that the response of the electrode was truly reversible. Although the time required reaching equilibrium values (13 sec.) was longer than that for low-to-high sample concentrations ( $8 \mathrm{sec}$.). This is because, residual Aluminum (III) ions will still be adsorbed on the surface of the CPE and acts as an inhibitor shield against dissolved ions; accordingly, leads to high response time due to high contamination of the CPE surface with $\mathrm{Al}(\mathrm{III})$ ions and hereupon due to considerable occupation of the CPE sites.

\subsubsection{Reproducibility, reversibility and lifetime of the electrode}

An important aspect to be considered aiming practical application of carbon paste electrodes is the consistency of the carbon pastes. The consistency of the carbon pastes depends both on the carbon/binder ratio and on the physicochemical properties of the carbonaceous materials, mainly in regard to the kind of carbon/binder interactions. The consistency of the carbon paste is directly associated to the lifetime and reproducibility on the resulting electrodes [44].

Stability of the Nano-PMo $\mathrm{PM}_{12} / \mathrm{IL}-\mathrm{CPE}$ was tested by keeping the electrode in $\mathrm{pH} 4.5$ for 7 days and then the potential were recorded and compared with the data obtained before immersion. The obtained results represented a very slight drop in the modified electrode potential implying on a significant stability of the response. The lifetime of the proposed CPE over time was checked during a period of 3 months within the range of $4.0 \times 10^{-7}$ to $2.2 \times 10^{-3}$ molL ${ }^{-1} \mathrm{Al}^{3+}$ solutions. In between measurements, the sensor should be prudentially kept in the cool, dark and dry place. Examining the figure of merits variety vs. days reveals no significant divergence in the limit of detection, Nernstian slope and response time of the sensor after 2.5 months of storage. These results indicated that $\mathrm{Nano}-\mathrm{PMo}_{12} / \mathrm{IL}-\mathrm{CPE}$ is substantially stable and has quite good capacity to perform repeated measurements within 2.5 months. 
Besides, in order to evaluate repeatability of the electrode manufacturing process, five modified electrodes provided by entirely identical circumstances, were applied for the determination of $6.30 \times 10^{-5} \mathrm{molL}^{-1} \mathrm{Al}$ (III) ion solution. The RSD for the potentiometric response of all the five electrodes (average of three determinations on each electrode) was $3.24 \%$. The operative reproducibility of the proposed method was also checked by determining the RSD for seven potentiometric measurements of aluminum ion quantity. The RSD for each of three concentrations of 1.0, 2.5, and $4.0 \mathrm{ppm}$ of $\mathrm{Al}(\mathrm{III})$, was found out $2.6 \%$, $2.4 \%$ and $1.8 \%$ respectively. These results imply on high repeatability and reproducibility of the preparation procedure and $\mathrm{Al}(\mathrm{III})$ determination respectively.

Eventually, so as to evaluate the reversibility of the proposed $\mathrm{Al}(\mathrm{III})$-sensor, a similar procedure was performed in the sequence of $1.0 \times 10^{-3}$ and $1.0 \times 10^{-4} \mathrm{molL}^{-1} \mathrm{Al}^{3+}$ ion concentrations for 4 times, and the graphical results are shown in Fig. 9. As is evident, by changing the target ion concentration, on account of rapid adaption of the electrode surface with new concentration of target ion, the potentiometric response of the sensor is quite reversible when it was consecutively dipped in two solutions alternatively for 4 times.

\subsubsection{Selectivity potency}

Under optimal experimental conditions the interferences of some coexisting species being $\underline{\text { multi-valent alkali, alkaline earth and transition metal ions, and some biological molecules }}$ have been evaluated utilizing matched potential method (MPM) and fixed interference method (FIM) inspired by IUPAC $[45,46]$.

Firstly, the MPM-based selectivity factor $\left(\mathrm{k}_{\mathrm{A}, \mathrm{B}}^{\mathrm{MPM}}\right)$ was determined as follows;

Succinctly, the potential change $\left(\mathrm{mVdecade}^{-1}\right)$ upon increasing the primary analyte activity by an increment of $\Delta a_{\mathrm{A}}$ in a starting solution is measured $\left(a_{\mathrm{A}}=2.2 \times 10^{-7} \mathrm{molL}^{-1}\right)$. Interfering ions ranging from $2.2 \times 10^{-7}$ to $2.2 \times 10^{-2} \mathrm{molL}^{-1}$ are then added to an identical starting solution of primary ion until the same potential change is observed. The selectivity factor $\left(\mathrm{k}_{\mathrm{A}, \mathrm{B}}^{\mathrm{MPM}}\right)$ is then obtained as the ratio of the changes in the activity of the analyte, $\Delta a_{\mathrm{A}}$. $\underline{\text { and interfering ion, } a_{\mathrm{B}} \text { as below; }}$

$$
k_{\mathrm{A}, \mathrm{B}}^{\mathrm{MPM}}=\frac{\Delta a_{\mathrm{A}}}{a_{\mathrm{B}}}=\frac{a_{\mathrm{A}}^{\prime}-a_{\mathrm{A}}}{a_{\mathrm{B}}} \text {, where, } a_{\mathrm{A}}=2.2 \times 10^{-7} \text { and } a^{\prime}{ }_{\mathrm{A}}=2.2 \times 10^{-4} \mathrm{molL}^{-1}
$$


$\underline{\text { In subsequence, the selectivity coefficients were worked out as per instructions of FIM. In }}$ practice, incremental amounts of primary ions are added to a solution encompassing a constant concentration of an interfering substance until a Nernstian response slope to the primary ion is observed. This linear response region is extrapolated to the emf for the background interference only, and the primary ion activity $a_{\mathrm{A}}(\mathrm{DL})$ at this detection limit is, together with the interfering ion activity in the background $a_{\mathrm{B}}(\mathrm{BG})$, inserted into the following equation:

$$
\mathrm{K}_{\mathrm{A}, \mathrm{B}}^{\mathrm{FIM}}=\frac{a_{\mathrm{A}}(\mathrm{DL})}{a_{\mathrm{B}}(\mathrm{BG})^{\mathrm{Z}_{\mathrm{A}} / \mathrm{Z}_{\mathrm{B}}}}
$$

Where, $a_{\mathrm{A}}(\mathrm{DL})$ is the primary ion activity in detection limit, $a_{\mathrm{B}}=2.2 \times 10^{-2}$ molL $^{-1}$ is the interfering ion activity, $\underline{Z}_{\underline{A}}$ and $\mathrm{Z}_{\underline{B}}$ are the primary and interfering ions charge, respectively. All the MPM and FIM outcomes were summarized in Table 6.

As is conspicuous, some common interfering species of $\mathrm{Co}(\mathrm{II}), \mathrm{Cu}(\mathrm{II}), \mathrm{Zn}$ (II) and somewhat $\mathrm{Cr}(\mathrm{III})$ and $\mathrm{Fe}(\mathrm{III})$, have partly interfering contribution over potentiometric response of the electrode. This can be likely because of size-matching selection of the target species. According to this hypothesis, the Zeolite-like Nano-PMo ${ }_{12}$ in the electrode composition acts as a size-fitting network and by trapping the target ions cause to alter the boundary potential of the CPE which is directly proportional to the target ion activity. Therefore, the mentioned interfering ions with the closest ionic radius to the $\mathrm{Al}(\mathrm{III})$, show the greatest interfering effect in the determination process of the $\mathrm{Al}(\mathrm{III})$ concentration. On the contrary, the species with larger ionic radius than $\mathrm{Al}(\mathrm{III})$, are repelled from the electrode surface and in consequence don't shows a significant interfering effect.

It should be pointed out that, the rather substantial selectivity coefficients of the $\operatorname{Ag}(\mathrm{I})$ and $\mathrm{Hg}$ (II) ions is justified by instinctive response of the bare (unmodified) CPE to these ions not due to presence of modifying additives in the paste composition [29]. According to IUPAC [45], if the selectivity coefficient is less than 1.0, the ISE responds to primary ion more selectively than the interfering species. As is conspicuous, the results in the Table 6 are much smaller than 1.0, signifying a substantial selectivity of the sensor considered.

Potentiometric response and selectivity of the proposed sensor has also been challenged by coexisting of some biological species being cysteine, glucose, fructose, ascorbic acid, uric 
acid, and urea. For this propose, the selectivity behavior of the mentioned compounds were examined using MPM. As can be seen, just like most of interfering ions, these species don't cause any considerable interference over $\mathrm{Al}(\mathrm{III})$ ion detection process.

The interfering species larger than $\mathrm{Al}^{3+}$ in ionic radius terms, will be fully repelled from the electrode surface and those smaller than $\mathrm{Al}^{3+}$, will be non-specifically adsorbed on the electrode surface. So, both types of interfering ions will be wiped out from the electrode surface by a gentle whirling flow of the solution surrounding the electrode surface without any significant interference against the target ion. This hypothesis is fully consistent with what was proposed for the electrode response mechanism (Scheme 2).

All in all, the obtained results in the Table 6 well proved that the proposed sensor has an acceptable performance in potentiometric determination of $\mathrm{Al}(\mathrm{III})$ ion in coexisting of some biological species and multi-valent cations.

Table 6 The selectivity coefficients of various interfering species; extracted using proposed Al(III)-CPE calculated by FIM and MPM.

\begin{tabular}{lll}
\hline Interference species & $\left(\mathrm{K}_{\mathrm{Al}, \mathrm{M}^{\mathrm{n}+}}^{\mathrm{FIM}}\right)$ & $\left(\mathrm{k}_{\mathrm{Al}, \mathrm{M}^{\mathrm{n}+}}^{\mathrm{MPM}}\right)$ \\
\hline $\mathrm{Ag}^{+}$ & $6.4( \pm 0.3) \times 10^{-3}$ & $7.3( \pm 0.4) \times 10^{-4}$ \\
$\mathrm{Hg}^{2+}$ & $1.1( \pm 0.2) \times 10^{-4}$ & $1.0( \pm 0.2) \times 10^{-4}$ \\
$\mathrm{Cu}^{2+}$ & $5.4( \pm 0.4) \times 10^{-3}$ & $8.1( \pm 0.3) \times 10^{-4}$ \\
$\mathrm{Co}^{2+}$ & $3.5( \pm 0.3) \times 10^{-4}$ & $9.1( \pm 0.5) \times 10^{-5}$ \\
$\mathrm{Zn}^{2+}$ & $1.5( \pm 0.1) \times 10^{-4}$ & $3.7( \pm 0.2) \times 10^{-4}$ \\
$\mathrm{~Pb}^{2+}$ & $2.1( \pm 0.3) \times 10^{-5}$ & $2.7( \pm 0.2) \times 10^{-5}$ \\
$\mathrm{Cd}^{2+}$ & $2.5( \pm 0.4) \times 10^{-5}$ & $8.8( \pm 0.1) \times 10^{-5}$ \\
$\mathrm{Cr}^{3+}$ & $1.5( \pm 0.4) \times 10^{-5}$ & $2.1( \pm 0.2) \times 10^{-5}$ \\
$\mathrm{La}^{3+}$ & $2.8( \pm 0.2) \times 10^{-6}$ & $7.1( \pm 0.3) \times 10^{-5}$ \\
$\mathrm{Ca}^{2+}$ & $1.5( \pm 0.2) \times 10^{-6}$ & $4.5( \pm 0.2) \times 10^{-5}$ \\
$\mathrm{Fe}^{3+}$ & $8.4( \pm 0.3) \times 10^{-4}$ & $3.2( \pm 0.3) \times 10^{-5}$ \\
$\mathrm{Na}^{+}$ & $7.8( \pm 0.1) \times 10^{-6}$ & $2.2( \pm 0.4) \times 10^{-5}$ \\
$\mathrm{Mg}^{2+}$ & $1.8( \pm 0.2) \times 10^{-5}$ & $1.1( \pm 0.5) \times 10^{-5}$ \\
$\mathrm{Mn}^{2+}$ & $2.4( \pm 0.3) \times 10^{-7}$ & $3.1( \pm 0.2) \times 10^{-6}$ \\
$\mathrm{NH}_{4}^{+}$ & $1.3( \pm 0.4) \times 10^{-5}$ & $1.5( \pm 0.3) \times 10^{-5}$ \\
$\mathrm{~K}^{+}$ & $5.3( \pm 0.3) \times 10^{-6}$ & $1.2( \pm 0.3) \times 10^{-6}$ \\
Cysteine & - & No Response \\
$\mathrm{Glucose}_{\text {Fructose }}$ & - & No Response \\
Ascorbic acid & - & No Response \\
Uric acid & - & No Response \\
Urea & - & No Response \\
\hline & - & No Response \\
\hline
\end{tabular}




\section{a Values in parentheses are SDs based on three replicate analyses}

\subsection{Comparative survey}

Response characteristics of the proposed sensor being Nernstian slope, selectivity, limit of detection, linear range and response time were carefully weighed up against some previously reported $\mathrm{Al}(\mathrm{III})$-selective electrochemical sensors (Table 7). As can be visibly seen, in more aspects such as limit of detection, linearity, selectivity, and response time, the proposed sensor illustrates a superior behavior in comparison with the best previously reported $\mathrm{Al}$ (III) sensors $[3,44, \underline{47}-\underline{53}]$. Although in some aspects, some of the previously reported electrodes have rather enhanced performance than the presented electrode, but overall, evaluation indicates that, this electrode is more useful in such applications.

Table 7 Comparative performance of the Nano-PMo ${ }_{12} / \mathrm{IL}-\mathrm{CPE}$ in competition with some previously reported $\mathrm{Al}(\mathrm{III})$-sensor

\begin{tabular}{|c|c|c|c|c|c|c|}
\hline Ref. & $\begin{array}{l}\text { Slope } \\
\text { (mV/decade) }\end{array}$ & $\begin{array}{l}\mathrm{LOD} \\
\left(\mathrm{molL}^{-1}\right)\end{array}$ & $\begin{array}{l}\mathrm{LR} \\
\left(\mathrm{molL}^{-1}\right)\end{array}$ & $\begin{array}{l}\mathrm{pH} \\
\text { range }\end{array}$ & $\begin{array}{l}\text { RT } \\
\text { (sec.) }\end{array}$ & $\left(-\log \mathrm{K}_{\mathrm{Al}, \mathrm{M}}^{\mathrm{pot}}\right)$ \\
\hline [3] & $20.0( \pm 0.1)$ & $2.0 \times 10^{-10}$ & $\begin{array}{l}5.0 \times 10^{-10} \\
\text { to } \\
5.0 \times 10^{-2}\end{array}$ & $\begin{array}{l}3.0 \\
\text { to } \\
7.0\end{array}$ & 5.0 & $\begin{array}{l}\mathrm{Hg}(\mathrm{NR}), \mathrm{Cu}(3.1), \mathrm{Ag}(4.0), \mathrm{Cd}(4.0), \\
\mathrm{Pb}(5.0), \mathrm{Ca}(3.4), \mathrm{Zn}(4.0), \mathrm{Mg}(3.8), \\
\mathrm{Mn}(3.6), \mathrm{Co}(4.0), \mathrm{Fe}(3.0), \mathrm{Cr}(3.1), \\
\mathrm{K}(5.0), \mathrm{Na}(4.3)\end{array}$ \\
\hline [44] & $19.5( \pm \ldots)$ & $3.2 \times 10^{-6}$ & $\begin{array}{l}1.0 \times 10^{-5} \\
\text { to } \\
1.0 \times 10^{-1}\end{array}$ & $\begin{array}{l}2.2 \\
\text { to } \\
3.2\end{array}$ & $\sim 20$ & $\begin{array}{l}\mathrm{Hg}(2.7), \mathrm{Cu}(2.0), \mathrm{Ag}(1.4), \mathrm{Cd}(4.5), \\
\mathrm{Pb}(1.7), \mathrm{Ca}(4.3), \mathrm{Zn}(1.1), \mathrm{Mg}(4.9), \\
\mathrm{Mn}(4.4), \mathrm{Co}(4.7), \mathrm{Fe}(3.2), \mathrm{Cr}(\mathrm{NR}), \\
\mathrm{K}(1.0), \mathrm{Na}(1.9)\end{array}$ \\
\hline [47] & $19.6( \pm 0.4)$ & $6.3 \times 10^{-7}$ & $\begin{array}{l}1.0 \times 10^{-6} \\
\text { to } \\
1.0 \times 10^{-1}\end{array}$ & $\begin{array}{l}3.0 \\
\text { to } \\
6.0\end{array}$ & $\sim 10$ & $\begin{array}{l}\mathrm{Hg}(2.5), \mathrm{Cu}(3.0), \mathrm{Ag}(\mathrm{NR}), \mathrm{Cd}(3.1), \\
\mathrm{Pb}(2.7), \mathrm{Ca}(1.9), \mathrm{Zn}(2.1), \mathrm{Mg}(2.0), \\
\mathrm{Mn}(2.5), \mathrm{Co}(\mathrm{NR}), \mathrm{Fe}(2.5), \mathrm{Cr}(3.0), \\
\mathrm{K}(3.1), \mathrm{Na}(3.0)\end{array}$ \\
\hline [48] & $19.3( \pm 0.8)$ & $2.5 \times 10^{-6}$ & $\begin{array}{l}5.0 \times 10^{-6} \\
\text { to } \\
1.0 \times 10^{-2}\end{array}$ & $\begin{array}{l}2.9 \\
\text { to } \\
5.0\end{array}$ & $\sim 10$ & $\begin{array}{l}\mathrm{Hg}(2.4), \mathrm{Cu}(2.7), \mathrm{Ag}(2.1), \mathrm{Cd}(3.2), \\
\mathrm{Pb}(2.5), \mathrm{Ca}(2.5), \mathrm{Zn}(2.6), \mathrm{Mg}(2.1), \\
\mathrm{Mn}(3.1), \mathrm{Co}(2.9), \mathrm{Fe}(2.4), \mathrm{Cr}(3.2), \\
\mathrm{K}(2.8), \mathrm{Na}(2.5)\end{array}$ \\
\hline [49] & $19.7( \pm 0.1)$ & $3.2 \times 10^{-7}$ & $\begin{array}{l}5.0 \times 10^{-7} \\
\text { to } \\
1.0 \times 10^{-1}\end{array}$ & $\begin{array}{l}3.5 \\
\text { to } \\
5.0\end{array}$ & $\sim 5.0$ & $\begin{array}{l}\mathrm{Hg}(4.0), \mathrm{Cu}(3.9), \mathrm{Ag}(\mathrm{NR}), \mathrm{Cd}(3.3), \\
\mathrm{Pb}(3.1), \mathrm{Ca}(\mathrm{NR}), \mathrm{Zn}(3.5), \mathrm{Mg}(\mathrm{NR}), \\
\mathrm{Mn}(3.6), \mathrm{Co}(3.4), \mathrm{Fe}(2.4), \mathrm{Cr}(2.7), \\
\mathrm{K}(3.0), \mathrm{Na}(2.7)\end{array}$ \\
\hline [50] & $19.4( \pm 0.3)$ & $4.6 \times 10^{-7}$ & $\begin{array}{l}7.9 \times 10^{-7} \\
\text { to } \\
1.0 \times 10^{-1}\end{array}$ & $\begin{array}{l}2.5 \\
\text { to } \\
4.0\end{array}$ & 8.0 & $\begin{array}{l}\mathrm{Hg}(\mathrm{NR}), \mathrm{Cu}(1.6), \mathrm{Ag}(\mathrm{NR}), \mathrm{Cd}(2.2), \\
\mathrm{Pb}(2.1), \mathrm{Ca}(2.3), \mathrm{Zn}(2.4), \mathrm{Mg}(2.2), \\
\mathrm{Mn}(2.1), \mathrm{Co}(2.0), \mathrm{Fe}(2.9), \mathrm{Cr}(2.8), \\
\mathrm{K}(4.9), \mathrm{Na}(4.9)\end{array}$ \\
\hline [51] & $20.0( \pm 0.2)$ & $6.0 \times 10^{-7}$ & $\begin{array}{l}1.0 \times 10^{-6} \\
\text { to } \\
1.6 \times 10^{-1}\end{array}$ & $\begin{array}{l}3.0 \\
\text { to } \\
8.5\end{array}$ & $<5.0$ & $\begin{array}{l}\mathrm{Hg}(1.2), \mathrm{Cu}(2.6), \mathrm{Ag}(0.9), \mathrm{Cd}(2.3), \\
\mathrm{Pb}(2.3), \mathrm{Ca}(3.0), \mathrm{Zn}(2.2), \mathrm{Mg}(2.8), \\
\mathrm{Mn}(2.6), \mathrm{Co}(2.2), \mathrm{Fe}(3.7), \mathrm{Cr}(4.3), \\
\mathrm{K}(0.9), \mathrm{Na}(0.3)\end{array}$ \\
\hline [52] & $20.1( \pm \ldots)$ & $8.7 \times 10^{-6}$ & $1.8 \times 10^{-5}$ & 2.5 & 10 & $\mathrm{Hg}(\mathrm{NR}), \mathrm{Cu}(1.0), \mathrm{Ag}(\mathrm{NR}), \mathrm{Cd}(1.2)$, \\
\hline
\end{tabular}




\begin{tabular}{|c|c|c|c|c|c|c|}
\hline & & & $\begin{array}{l}\text { to } \\
1.0 \times 10^{-1}\end{array}$ & $\begin{array}{l}\text { to } \\
4.5\end{array}$ & & $\begin{array}{l}\mathrm{Pb}(\mathrm{NR}), \mathrm{Ca}(\mathrm{NR}), \mathrm{Zn}(1.2), \mathrm{Mg}(1.3), \\
\mathrm{Mn}(\mathrm{NR}), \mathrm{Co}(1.1), \mathrm{Fe}(1.4), \mathrm{Cr}(1.1), \\
\mathrm{K}(2.4), \mathrm{Na}(2.2)\end{array}$ \\
\hline [53] & $19.8( \pm 0.4)$ & $4.6 \times 10^{-7}$ & $\begin{array}{l}1.0 \times 10^{-1} \\
\text { to } \\
1.0 \times 10^{-6}\end{array}$ & $\begin{array}{l}2.0 \\
\text { to } \\
6.0\end{array}$ & $\sim 8.0$ & $\begin{array}{l}\mathrm{Hg}(\mathrm{NR}), \mathrm{Cu}(2.6), \mathrm{Ag}(\mathrm{NR}), \mathrm{Cd}(1.5), \\
\mathrm{Pb}(0.2), \mathrm{Ca}(\mathrm{NR}), \mathrm{Zn}(1.7), \mathrm{Mg}(2.0), \\
\mathrm{Mn}(1.2), \mathrm{Co}(2.2), \mathrm{Fe}(1.4), \mathrm{Cr}(0.4), \\
\mathrm{K}(2.9), \mathrm{Na}(1.6)\end{array}$ \\
\hline $\begin{array}{l}\text { This } \\
\text { work }\end{array}$ & $19.9( \pm 0.2)$ & $\underline{7.9} \times 10^{-10}$ & $\begin{array}{l}\frac{1.0}{\text { to }} \times 10^{-9} \\
2.2 \times 10^{-1}\end{array}$ & $\begin{array}{l}2.0 \\
\text { to } \\
5.0\end{array}$ & 8.0 & $\begin{array}{l}\mathrm{Hg}(1.0), \mathrm{Cu}(8.1), \mathrm{Ag}(7.3), \mathrm{Cd}(8.8), \\
\mathrm{Pb}(2.7), \mathrm{Ca}(4.5), \mathrm{Zn}(3.7), \mathrm{Mg}(1.1), \\
\mathrm{Mn}(5.5), \mathrm{Co}(9.1), \mathrm{Fe}(3.2), \mathrm{Cr}(2.1), \\
\mathrm{K}(1.2), \mathrm{Na}(2.2)\end{array}$ \\
\hline
\end{tabular}

LOD: limit of detection, LR: linear range, RT: response time

\subsection{Practical efficiency}

To qualify the hands-on applicability of the proposed $\mathrm{Al}(\mathrm{III})$-sensor under practical conditions, it was applied as an indicator electrode for potentiometric assessment of $\mathrm{Al}(\mathrm{III})$ ion quantity in some real samples with different matrices using standard addition method (SAM). The real samples evaluated by $\mathrm{Al}(\mathrm{III})-\mathrm{CPE}$ consist of black tea leaves, Aluminum-Mg oral suspension (antacid drug) containing $4.5 \times 10^{-4} \mathrm{mgL}^{-1}$ of the aluminum hydroxide (Toliddaru pharma Co., Tehran, Iran), Basalt and Andesite ores, mineral water (Aquafina, bottled by Eram Noush soft drink Co., Tehran, Iran). Prior to carrying out the quantitative electroanalysis, preparation of the real samples of tea leaves, $\mathrm{Al}-\mathrm{Mg}$ syrup, basalt and andesite ore samples, and mineral water were fulfilled exactly in accordance with the methods presented in the Refs [50], [54], and [55] respectively. The data summarized in the Table 8 , evidently represent that, the accuracy of aluminum determination in different aqueous samples is in entirely acceptable agreement with those obtained by flame atomic absorption spectroscopy (FAAS) method, signifying the satisfactory practical performance of the proposed $\mathrm{Al}$ (III)-electrode.

Table 8 Determination of $\mathrm{Al}^{3+}$ ion quantity in some real samples by the proposed sensor; approved by FAAS method.

\begin{tabular}{l|lll|lc}
\hline \multirow{2}{*}{ Real samples } & $\mathrm{Al}^{3+}\left(\mathrm{molL}^{-1}\right)^{\mathrm{a}}$ & & & \multicolumn{2}{c}{ Adaptability (\%) } \\
\cline { 2 - 6 } & Added (SAM) & Found by ISE & Found by FAAS & ISE & FASS \\
\hline \multirow{2}{*}{ Mineral water } & 0.0 & $\mathrm{Nd}^{\mathrm{b}}$ & - & - & - \\
& $3.2 \times 10^{-3}$ & $2.9( \pm 0.5) \times 10^{-3}$ & $3.1( \pm 0.5) \times 10^{-3}$ & 90.6 & 96.8 \\
\hline \multirow{2}{*}{ Al-Mg syrup } & 0.0 & $\mathrm{Nd}$ & - & - & - \\
& $9.3 \times 10^{-3}$ & $9.0( \pm 0.2) \times 10^{-3}$ & $9.7( \pm 0.2) \times 10^{-3}$ & 96.7 & 104.3 \\
\hline Black tea leaves $\left(\mathrm{mgg}^{-1}\right)$ & 0.0 & $\mathrm{Nd}$ & - & - & - \\
\hline
\end{tabular}




\begin{tabular}{l|l|llllll}
\multicolumn{2}{l|}{} & $5.5 \times 10^{-3}$ & $6.2( \pm 0.3) \times 10^{-3}$ & $6.5( \pm 0.3) \times 10^{-3}$ & 112.7 & 118.2 \\
\hline \multirow{3}{*}{$\begin{array}{l}\text { Ore samples } \\
\left(\mathrm{mgg}^{-1}\right)\end{array}$} & Basalt & 0.0 & $\mathrm{Nd}$ & - & - & - \\
\cline { 2 - 7 } & & $5.0 \times 10^{-3}$ & $4.7( \pm 0.6) \times 10^{-3}$ & $5.2( \pm 0.6) \times 10^{-3}$ & 94.0 & 104.0 \\
\cline { 2 - 7 } & Andesite & 0.0 & $\mathrm{Nd}$ & - & - & - \\
& $6.0 \times 10^{-3}$ & $5.5( \pm 0.5) \times 10^{-3}$ & $5.8( \pm 0.5) \times 10^{-3}$ & 91.6 & 96.6 \\
\hline
\end{tabular}

${ }^{\mathrm{a}}$ Values in parentheses are SDs based on three replicate analyses.

${ }^{\mathrm{b}}$ Not Detected

Moreover, the potentio-titrimetric analysis of $\mathrm{Al}(\mathrm{III})$ containing sample solution was performed with a known concentration of EDTA utilizing the proposed indicator electrode in conjunction with an $\mathrm{Ag} / \mathrm{AgCl}$ reference electrode. To do so, $30.0 \mathrm{~mL}$ of $1.0 \times 10^{-4} \mathrm{molL}^{-1}$ of $\mathrm{Al}\left(\mathrm{NO}_{3}\right)_{3}$ solution was titrated by $1.0 \times 10^{-2}$ molL $^{-1}$ EDTA solution at the $\mathrm{pH}$ of about 4.0. The resulting titration curve and the corresponding first derivative ( $\mathrm{dE} / \mathrm{dV}$ vs. titrant volume) graph for the direct titration of $\mathrm{Al}^{3+}$ cation solution with EDTA are shown in Fig. 10. As can be evidently seen, a sharp potential change and break at the endpoint of titration illustrates that, the proposed sensor is well adapted to the determination of aluminium in solutions, where the direct titration with EDTA is satisfactorily practicable.

\section{Conclusion}

Relying on the achieved results, the Cs-Nano-polyoxomolybdate (Cs-Nano-PMo $\mathrm{Mo}_{12}$ ) can be deservedly considered as a suitable ion-sensitive agent for construction of a carbon paste based selective electrode for the potentiometric assessment of $\mathrm{Al}(\mathrm{III})$ ion in aqueous samples. It was also found that, among various pasting agents being paraffin oil (PO), dioctyl phthalate (DOP) and dibutyl phthalate (DBP), room temperature ionic liquid (RTIL), the last one based on its extraordinary physicochemical features, is surprisingly able to promote the sensitivity, response time, and stability of the modified electrode. In particular, IL along with Nano$\mathrm{PMo}_{12}$ makes an exceptional approach to have a robust and sensitive sensor. With this expounding, the inherent advantages of the Nano-PMo $\mathrm{M}_{12} / \mathrm{IL}-\mathrm{CPE}$ are its hyper-sensitivity and selectivity, simple operation, high stability, wide dynamic range, low detection limit and fast response time as compared to bare CPE. Moreover, amount of graphite powder (GP), $\mathrm{PMo}_{12} / \mathrm{GP}$ weigh percentage ratio, type of binder and preconcentration time, were considered as process critical parameters to be optimized using Taguchi statistical method. As the result of taguchi analysis in this study, $\mathrm{PMo}_{12} / \mathrm{GP}$ weigh percentage ratio and type of binder were the most influencing parameters respectively on the electrochemical performance of the 
proposed sensor. With this approach, the provided sensor possess an acceptable practical applicability for the determination of $\mathrm{Al}$ (III) content in the ore, pharmaceutical and aqueous sample matrices. By the way, such an electrode compared with the previously reported similar sensors, illustrates the best performance in some crucial aspects.

\section{Acknowledgement}

Our research group are kindly appreciative of all the supports given by Chairman of Faculty of Chemistry, general chemistry (I, II) laboratory staffs, and especially sincere cooperation of staffs and supervisor of the inorganic chemistry research lab.

\section{Figure captions:}

Scheme 1 Portrayal representation of the $[\mathrm{Bmim}]_{3}{ }^{+}\left[\mathrm{PMo}_{12} \mathrm{O}_{40}\right]^{3-}$ synthesis process

Scheme 2 Depiction of potentiometric response mechanism of $\mathrm{Al}(\mathrm{III})$-selective $\mathrm{PMo}_{12} / \mathrm{IL}$ CPE

Fig. 1 a) Chemical structure of RTIL [Bmim]. $\mathrm{BF}_{4}$ as a carbon paste binder, b) Electrostatic coupling of imidazolium moiety (positive moiety) of IL with $\left[\mathrm{PMo}_{12}\right]^{3-}[22-24,26,33]$

Fig. 2 Chemical structure of $\mathrm{DOPh}$ and $\mathrm{DBPh}$ as nonconductive pasting agent

Fig. 3 UV-Vis spectra of $\mathrm{PMo}_{12} \mathrm{O}_{40}$ and $[\mathrm{Bmim}]_{3}\left[\mathrm{PMo}_{12} \mathrm{O}_{40}\right]$ in methanol solution

Fig. 4 Potentiometric response of various modified CPEs to Al(III) ion

Fig. 5 Potentiometric calibration curves of the various cations afforded by Nano-PMo ${ }_{12} / \mathrm{IL}-$ CPE

Fig. 6 Calibration curve for $\mathrm{Al}$ (III) Nano-PMo ${ }_{12} / \mathrm{IL}-\mathrm{CPE}$ at $\mathrm{pH}$ 4.0. Inset: Practical working range with Nernstian slope of $19.9( \pm 0.2) \mathrm{mVdecade}^{-1}$.

Fig. 7 The effect of $\mathrm{pH}$ solution varieties on the cell potential drawn out by the modified sensor at A) $2.2 \times 10^{-4}$ and B) $5.2 \times 10^{-6} \mathrm{molL}^{-1}$ of $\mathrm{Al}$ (III) solutions

Fig. 8 Dynamic response of the Nano-PMo $\mathrm{PM}_{12} / \mathrm{IL}-\mathrm{CPE}$ for step changes in concentrations from low to high and vice versa. A) $2.2 \times 10^{-7}$, B) $2.2 \times 10^{-6}$, C) $2.2 \times 10^{-5}$, and D) $2.2 \times 10^{-4} \mathrm{molL}^{-1}$

Fig. 9 Reversibility of Nano-PMo $12 / \mathrm{IL}-\mathrm{CPE}$ for $\underline{\mathrm{Al}(\mathrm{III})} \underline{\text { ion }}$ step-change of concentration from (a) $1.0 \times 10^{-3}$ to (b) $1.0 \times 10^{-4} \mathrm{molL}^{-1}$ and vice versa 
Fig. 10 Potentiometric direct titration and first derivative $\left(\mathrm{dE} \cdot \mathrm{dV}^{-1}\right.$ vs. titrant volume $)$ curves of $30.0 \mathrm{~mL} 1.0 \times 10^{-4} \mathrm{molL}^{-1} \underline{\mathrm{Al}(\mathrm{III})}$ solution with $1.0 \times 10^{-2} \mathrm{molL}^{-1}$ EDTA at $\mathrm{pH} \sim 4.0$ using the proposed sensor as an indicator electrode

\section{References}

[1] H.X. Jiang, L.S. Chen, J.G. Zheng, S. Han, N. Tang, B.R. Smith, Aluminum-induced effects on Photosystem II photochemistry in citrus leaves assessed by the chlorophyll a fluorescence transient, Tree Physiol. 28 (2008) 1863-71.

[2] S.V. Verstraeten, L. Aimo, P.I. Oteiza, Aluminium and lead: molecular mechanisms of brain toxicity, Arch Toxicol 82 (2008) 789-802.

[3] M.H. Mashhadizadeh, H. Khani, Sol-Gel-Au nano-particle modified carbon paste electrode for potentiometric determination of sub ppb level of $\mathrm{Al}(\mathrm{III})$, Anal. Methods 2 (2010) 24-31.

[4] P. Buhlmann, Li.D. Chen, Ion-Selective electrodes with ionophore-doped sensing membranes, John Wiley \& Sons 5 (2012) 2539-2576.

[5] M.B. Gholivand, F. Ahmadi, E. Rafiee, A Novel Al(III)-Selective Electrochemical Sensor Based on N,N'-Bis(salicylidene)-1,2-phenylenediamine Complexes, Electroanalysis 18 (2006) 1620-1626.

[6] E. Nossol, A.J.G. Zarbin, Carbon paste electrodes made from novel carbonaceous materials: Preparation and electrochemical characterization, Electrochim. Acta 54 (2008) $582-589$.

[7] D. Gligor, F. Balaj, A. Maicaneanu, R. Gropeanu, I. Grosu, L. Muresan, I.C. Popescu, Carbon paste electrodes modified with a new phenothiazine derivative adsorbed on zeolite and on mineral clay for NADH oxidation, Mater. Chem. Phys. 113 (2009) 283-289.

[8] A. Babaei, M. Zendehdel, B. Khalilzadeh, A. Taheri, Simultaneous determination of tryptophan, uric acid and ascorbic acid at Iron(III) doped zeolite modified carbon paste electrode, Colloid Surf. B 66 (2008) 226-232.

[9] S. Ramezani, M. Ghobadi, B. Nemati Bideh, Voltammetric monitoring of Cd (II) by nano- $\mathrm{TiO}_{2}$ modified carbon paste electrode sensitized using 1,2-bis-[o-aminophenyl thio] ethane as a new ion receptor, Sens. Actuat. B 192 (2014) 648-657. 
[10] S. Ramezani, M.H. Mashhadizadeh, S. Jalilian, M. Aghili, Structure-switching of an organothiol neutral carrier by gold nanoparticles decorated on SH-MWCNTs for ultra-trace voltammetric assay of $\mathrm{Hg}$ (II) using a carbon paste electrode, Anal. Methods 7 (2015) $7765-7775$.

[11] S. Ramezani, M. H. Mashhadizadeh, M. Ghobadi, S. Jalilian, Silica gel/gold nanoparticles/(NS) $)_{2}$ ligand Nanoporous platform-modified ionic liquid carbon paste electrode for potentiometric ultra-trace assessment of $\mathrm{Ag}(\mathrm{I})$, Int. J. Environ. Sci. Technol. 13 (2016) $2175-2188$.

[12] M.H. Mashhadizadeh, S. Ramezani, M.K. Rofouei, Development of a novel MWCNTstriazene-modified carbon paste electrode for potentiometric assessment of $\mathrm{Hg}(\mathrm{II})$ in the aquatic environments, Mater. Sci. Eng. C 47 (2015) 273-280.

[13] I. Švancara, A. Walcarius, K. Kalcher, K. Vytřas, Carbon paste electrodes in the new millennium, Cent. Eur. J. Chem. 7 (2009) 598-656.

[14] M.H. Mashhadizadeh, S. Ramezani, A. Shockravi, M. Kamali, Comparative study of carbon paste electrodes modified by new pentaaza macrocyclic ligands and gold nanoparticles embedded in three-dimensional sol-gel network for determination of trace amounts of Ag(I), J Incl. Phenom. Macrocycl. Chem. 76 (2013) 283-291.

[15] H. Liu, P. He, Z. Li, C. Sun, L. Shi, Y. Liu, G. Zhu, J. Li, An ionic liquid-type carbon paste electrode and its polyoxometalate-modified properties, Electrochem. Commun. 7 (2005) $1357-1363$.

[16] Z-K. Qu, K. Yu, Z-F. Zhao, Z-h. Su, J-Q. Sha, C-M. Wang, B-B. Zhou, An organicinorganic hybrid semiconductor material based on Lindqvist polyoxomolybdate and a tetranuclear copper complex containing two different ligands, Dalton Trans. 43 (2014) 6744-6751.

[17] Y. Liang, P. He, Y. Ma, Y. Zhou, C. Pei, X. Li, A novel bacterial cellulose-based carbon paste electrode and its polyoxometalate-modified properties, Electrochem. Commun. 11 (2009) 1018-1021.

[18] I.V. Kozhevnikov, Catalysis by heteropoly acids and multi-component Polyoxometalates in liquid-phase reactions. Chem. Rev. 98 (1998) 171-198. 
[19] M. Opallo, A. Lesniewski, Review: A review on electrodes modified with ionic liquids, J. Electroanal. Chem. 656 (2011) 2-16.

[20] Z.C. Zhang, Catalysis in ionic liquids. Adv. Catal. 49 (2006) 153-237.

[21] C.P. Mehnert, Supported ionic liquid catalysis. Chem. Eur. J. 11(2005) 50-56.

[22] K. Yamaguchi, C. Yoshida, S. Uchida, N. Mizuno, Peroxotungstate immobilized on ionic liquid-modified silica as a heterogeneous epoxidation catalyst with hydrogen peroxide. J. Am. Chem. Soc. 127 (2005) 530-531.

[23] W. Jiang, D. Zheng, S. Xun, Y. Qin, Q. Lu, W. Zhu, H. Li, Polyoxometalate-based ionic liquid supported on graphite carbon induced solvent-free ultra-deep oxidative desulfurization of model fuels, Fuel 190 (2017) 1-9.

[24] X. Wu, W. Wu, Q. Wu, W. Yan, Thermoresponsive polyoxometalate/ionic liquid supramolecular gel electrolytes for supercapacitors: fabrication, structure, and heteropolyanion structure effect, Langmuir 33 (2017) 4242-4249.

[25] T. Huang, N. Tian, Q. Wu, W. Yan, Keggin-type polyoxometalate-based ionic liquid gels, Soft Matter. 11 (2015) 4481-4486.

[26] J. Casamada Ribot, C. Guerrero-Sanchez, R. Hoogenboom, U.S. Schubert, Aqueous gelation of ionic liquids: Reverse thermos-responsive ion gels, Chem. Commun. 46 (2010) 6971-6973.

[27] Z.F. He, H.B. Wang, Y.L. Wang, Y. Wu, H.L. Li, L.H. Bi, L.X. Wu, Substitution effect in reversible gel-liquid phase transformation polyoxometalate ionic liquid compounds, Soft Matter. 8 (2012) 3315-3321.

[28] P. He, B. Xu, X. Xu, L. Song, X. Wang, Surfactant encapsulated palladium Polyoxometalates: controlled assembly and their application as single-atom catalysts, Chem. Sci. 7 (2016) 1-5.

[29] M. Shamsipur, J. Tashkhourian, B. Hemmateenejad, H. Sharghi, Application of artificial neural network to simultaneous potentiometric determination of silver(I), mercury(II) and copper(II) ions by an unmodified carbon paste electrode, Talanta 64 (2004) 590. 
[30] L. Zhang, W. Yang, X. Kuang, X. Wua, C. Lu, pH-dependent assembly of two polyoxometalate host-guest structural isomers based on Keggin polyoxoanion templates, Dalton Trans. 43 (2014) 16328-34.

[31] R.C, Van Nostrand, Design of experiments using the taguchi approach: 16 steps to product and process improvement, Technometrics 44 (2002) 289.

[32] J. Rutherford, Practical experiment designs for engineers and scientists, Technometrics 44 (2002) 400-401.

[33] J.L. Rosa, A. Robin, M.B. Silva, C.A. Baldan, M.P. Peres, Electrodeposition of copper on titanium wires: Taguchi experimental design approach, J. Matter. Process. Technol. 209 (2009) 1181-1188.

[34] M. Masteri-Farahani, S. Shahbazi, Preparation of Keggin-type polyoxometalate hybrid nanomaterial with one pot multicomponent reaction in reverse micelle nanoreactors, Inorganic Chem. Commu.15 (2012) 297-300.

[35] P. Swetha, A. S. Kumar, Phosphomolybdic acid Nano-aggregates immobilized nafion membrane modified electrode for selective cysteine electrocatalytic oxidation and antidermatophytic activity, Electrochimica Acta 98 (2013) 54- 65.

[36] W. Zhu, W. Huang, H. Li, M. Zhang, W. Jiang, G. Chen, C. Han, Polyoxometalatebased ionic liquids as catalysts for deep desulfurization of fuels, Fuel Process. Technol. 92 (2011) 1842-1848.

[37] M. Ammamz, J. Fransaer, Ionic liquid-heteropolyacid: Synthesis, characterization, and supercapacitor study of films deposited by electrophoresis, J. Electrochem. Soc. (2011) $14-21$

[38] R. Wang, D. Jia, Y. Cao, Facile synthesis and enhanced electrocatalytic activities of organic-inorganic hybrid ionic liquid polyoxometalate nanomaterials by solid-state chemical reaction, Electrochimica Acta 72 (2012)101-107.

[39] P.J. Ross, Taguchi Techniques for Quality Engineering. Second edition, Mc. Graw-Hill, USA, 1996.

[40] A. Bendell, J. Disney, W.A. Pridmore, Taguchi Methods: Applications in world industry, IFS Publications, UK, 1989. 
[41] S.T. Kim, M.S. Park, H.M. Kim, Systematic approach for the evaluation of the optimal fabrication conditions of a $\mathrm{H}_{2} \mathrm{~S}$ gas sensor with Taguchi method, Sens. Actuators B 102 (2004) 253-260.

[42] Y. Ji, L. Huang, J. Hu, C. Streb, Y-F. Song, Polyoxometalate-functionalized Nano carbon materials for energy conversion, energy storage and sensor systems, Energy Environ. Sci. 8 (2015) 776-789.

[43] IUPAC, Analytical chemistry division, commission on analytical electrodes, Pure Appl. Chem. 48 (1979) 127-131.

[44] M.B. Saleh, S.S. M. Hassan, A.A. Abdel Gaber, N.A. Abdel Kream, Novel potentiometric membrane sensor for selective determination of aluminum (III) ions, Anal. Chim. Acta 434 (2001) 247-253.

[45] Y. Umezawa, P. Buhlmann, K. Umezawa, K. Tohda, S. Amemiya, Potentiometric selectivity coefficients of ion-selective electrodes, Pure Appl. Chem. 72 (2000) 1851-2082.

[46] E. Bakker, E. Pretsch, P. Buhlmann, Selectivity of Potentiometric Ion Sensors, Anal. Chem. $72(2000) \underline{1127-1133 .}$

[47] M. Arvand, S.A. Asadollahzadeh, Ion-selective electrode for aluminum determination in pharmaceutical substances, tea leaves and water samples, Talanta 75 (2008) 1046-1054.

[48] A. Abbaspour, A.R. Esmaeilbeig, A.A. Jarrahpour, B. Khajeh, R. Kia, Aluminium(III)selective electrode based on a newly synthesized tetradentate Schiff base, Talanta 58 (2002) 397-403.

[49] V.K. Gupta, A.K. Jain, G. Maheshwari, Aluminum(III) selective potentiometric sensor based on Morin in poly(vinyl chloride) matrix, Talanta 72 (2007) 1469-1473.

[50] Y-H. Ma, R. Yuan, Y-Q. Chai, X-L. Liu, A new aluminum(III)-selective potentiometric sensor based on N,N'-propanediamide bis-(2-salicylideneimine) as a neutral carrier, Mat. Sci. Eng. C 30 (2010) 209-213.

[51] A. Yari, L. Darvishi, M. Shamsipur, Al(III)-selective electrode based on newly synthesized xanthone derivative as neutral ionophore, Anal. Chim. Acta 555 (2006) 329-335. 
[52] Y. Li, Y. Chai, R. Yuan, W. Liang, L. Zhang, G. Ye, Aluminium(III)-Selective Electrode Based on a Newly Synthesized Glyoxal-bis-Thiosemicarbazone Schiff Base, J. Anal. Chem. 63 (2008) 1090-1093.

[53] M. Arvand, M. Kermanian, Potentiometric Determination of Aluminum in Foods, Pharmaceuticals, and Alloys by AlMCM-41-Modified Carbon Paste Electrode, Food Anal. Methods 6 (2013) 578-586.

[54] M. Esmaelpourfarkhani, Gh.H. Rounaghi, M.H. Arbab-Zavar, Construction of a New Aluminum(III) Cation Selective Electrode Based on 12-Crown-4 as an Ionophore, J. Braz. Chem. Soc. 26 (2015) 963-969.

[55] A.D. Eaton, L.S. Glesceri, A.E. Greenberg, Standard methods for the examination of water and wastewater, American Public Health Association, Washington, 1995, Part 3000, pp. 3-43.

\section{Figures}

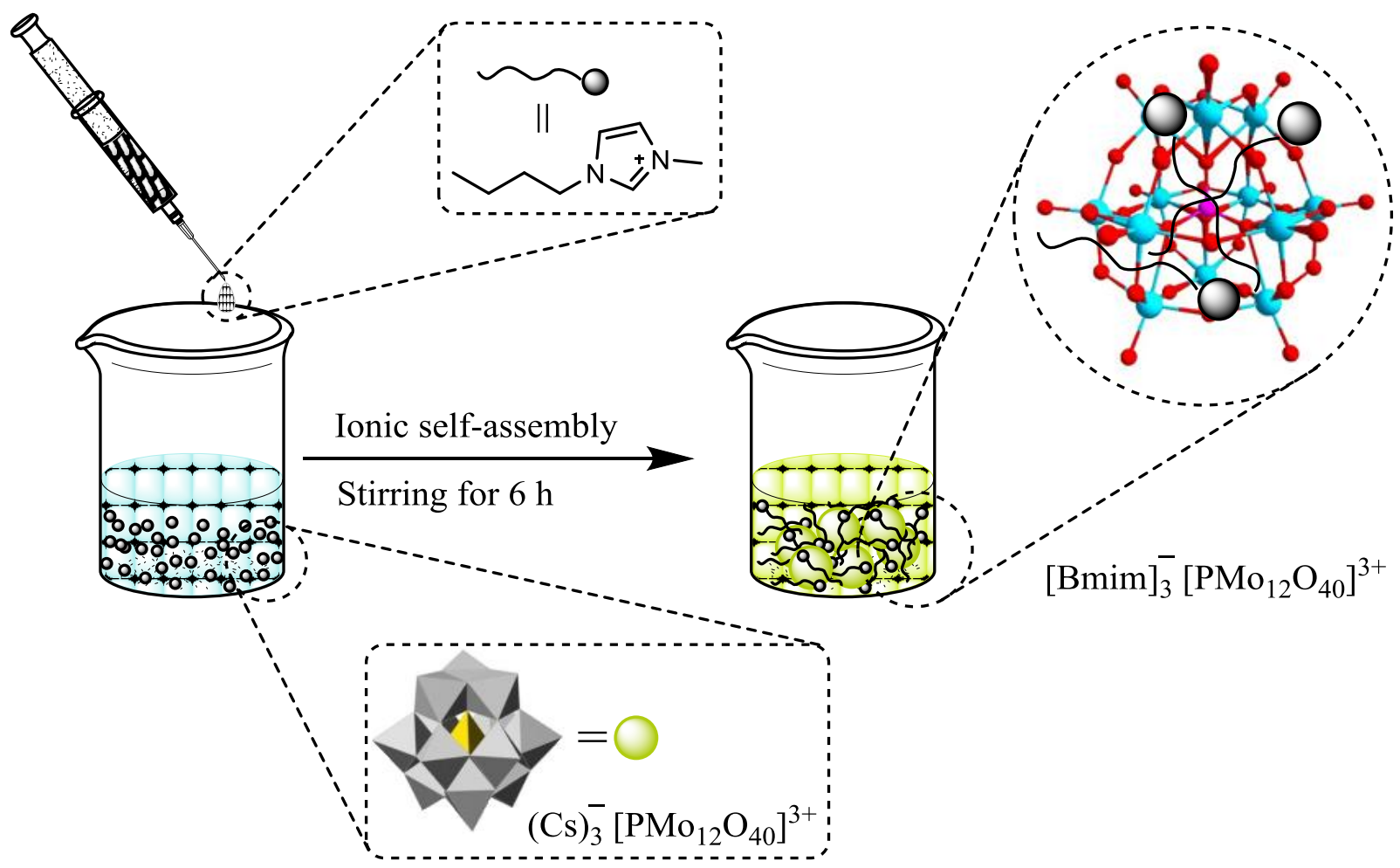




\section{Scheme 1}

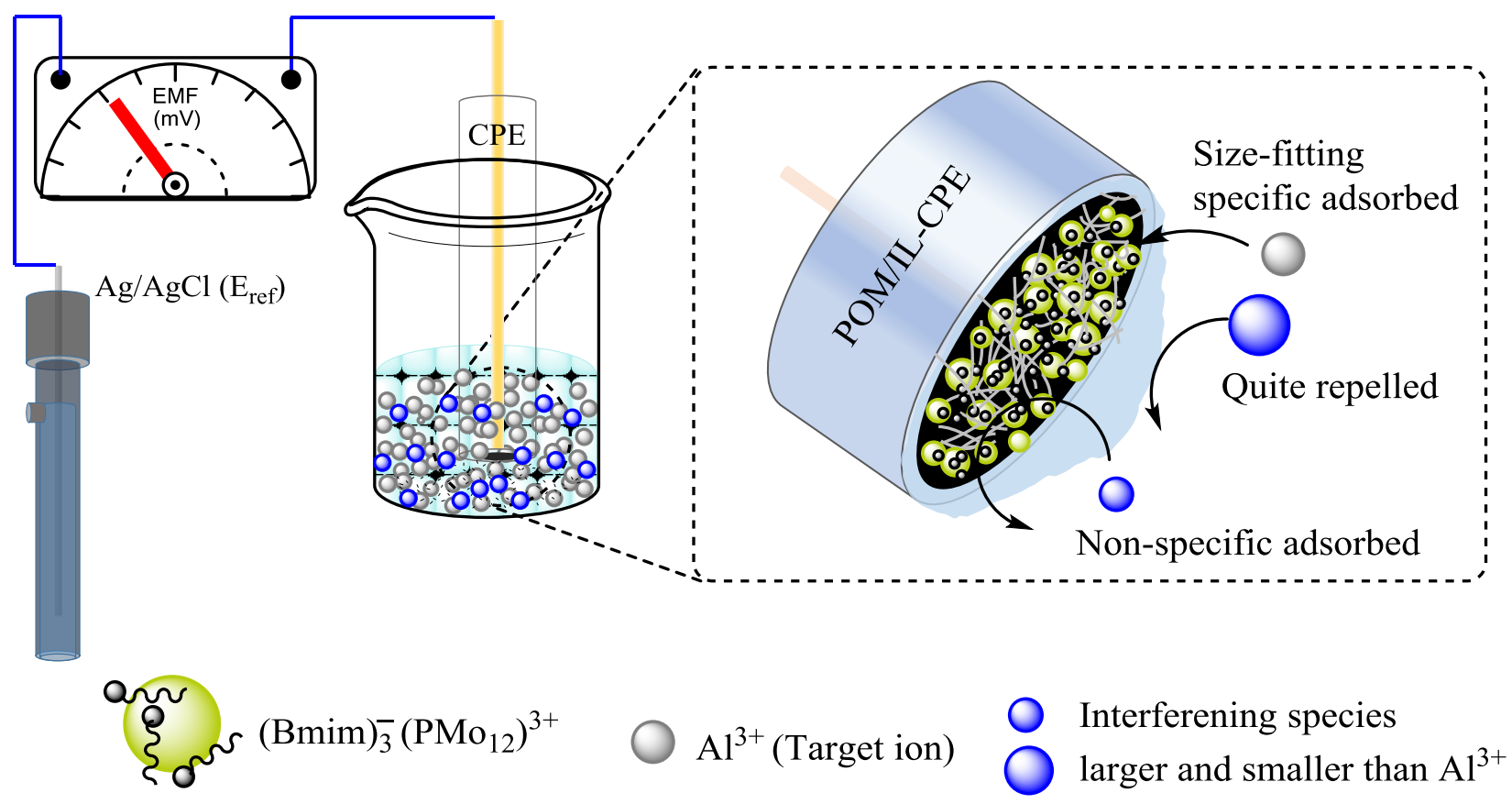

Scheme 2 
(a)<smiles>CCCCn1cc[n+](C)c1</smiles><smiles>F[B-](F)(F)F</smiles>

1-n-butyl-3-methylimidazolium tetrafluoroborate $\left(\mathrm{Bmim} \mathrm{BF}_{4}\right)$

(b)<smiles>CCCCCn1cc[n+](C(C)(C)[N+]([O])O[Al])c1</smiles>

POM-IL

Fig. 1<smiles>CCCCCCCCCOC(=O)c1ccccc1C(=O)OCCCCCCC</smiles>

dioctyl phthalate (DOP)<smiles>CCCCOC(=O)c1ccccc1C(=O)OCCCC</smiles>

dibutyl phthalate (DBP)

Fig. 2 


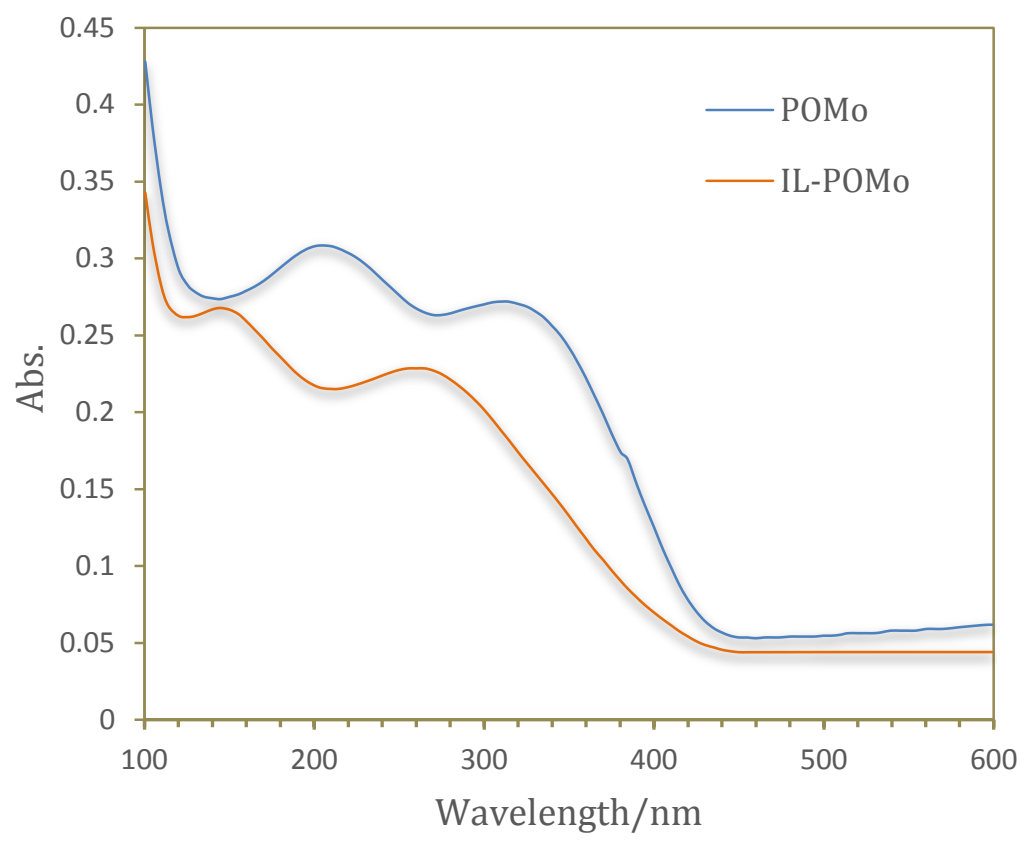

Fig. 3

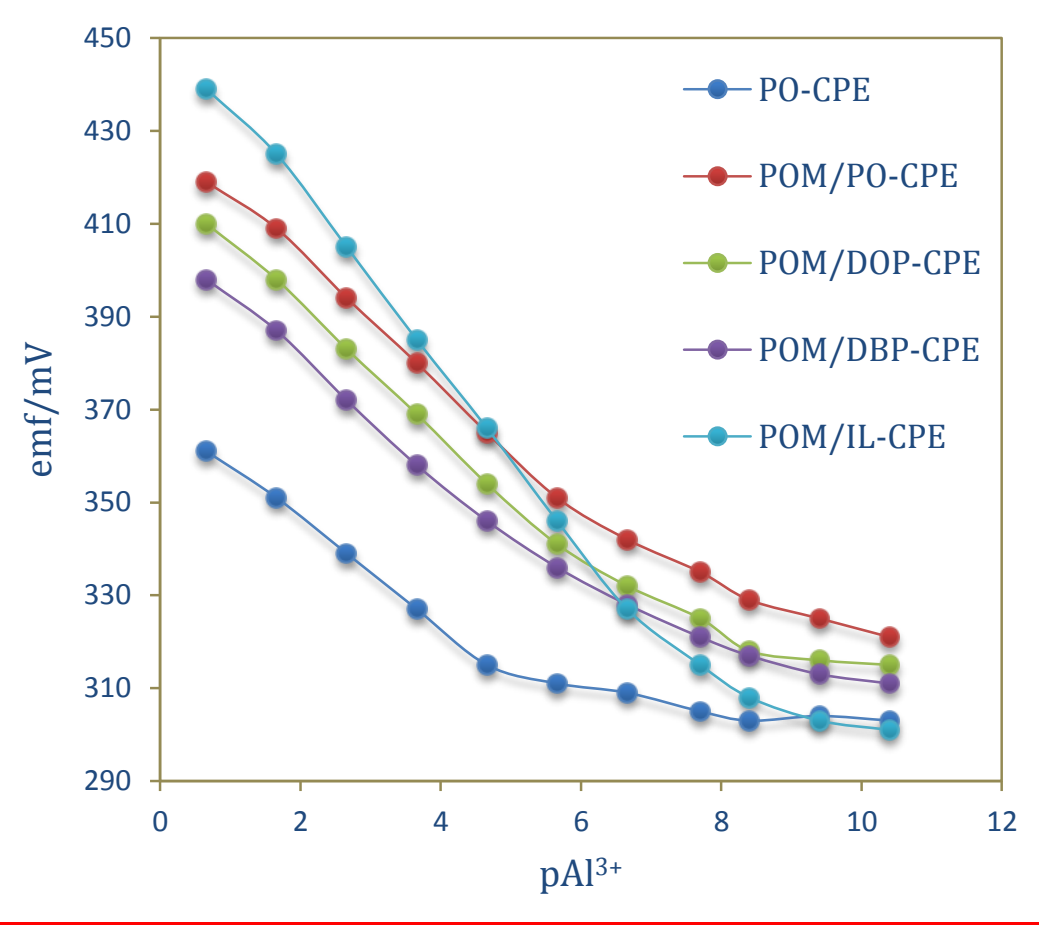

Fig. 4 


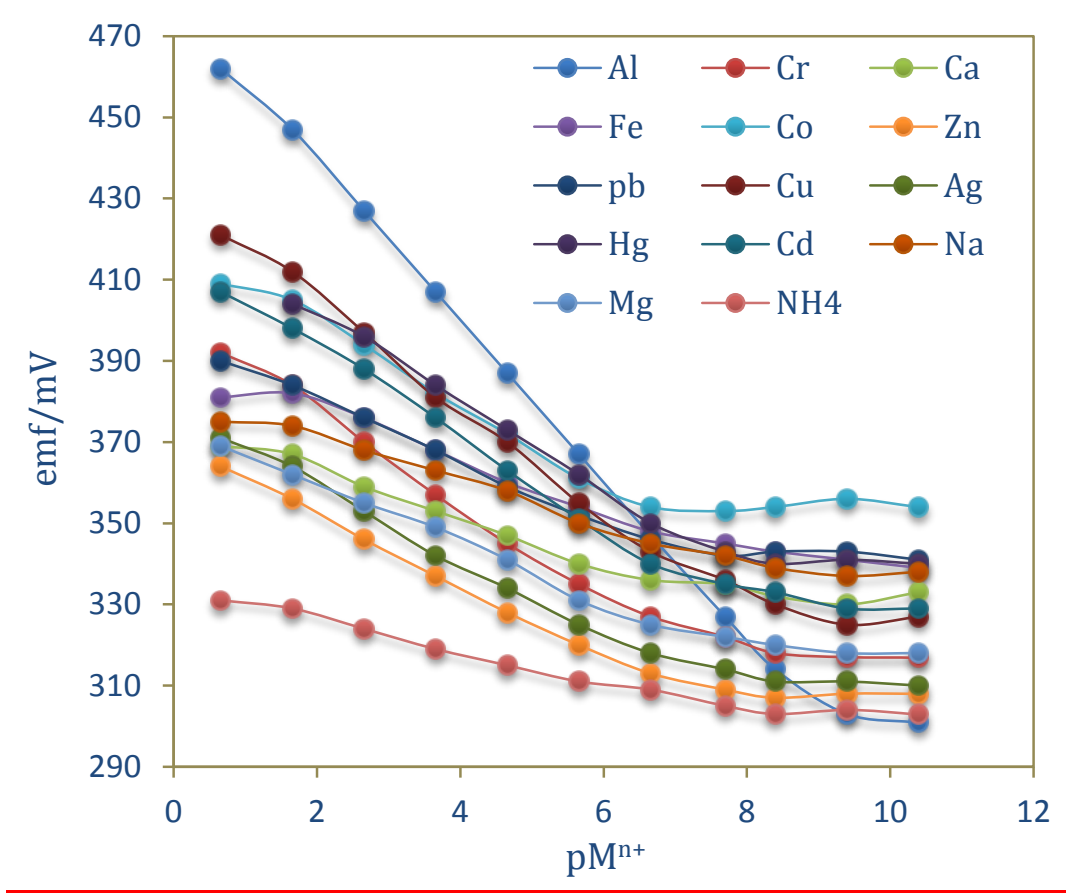

Fig. 5

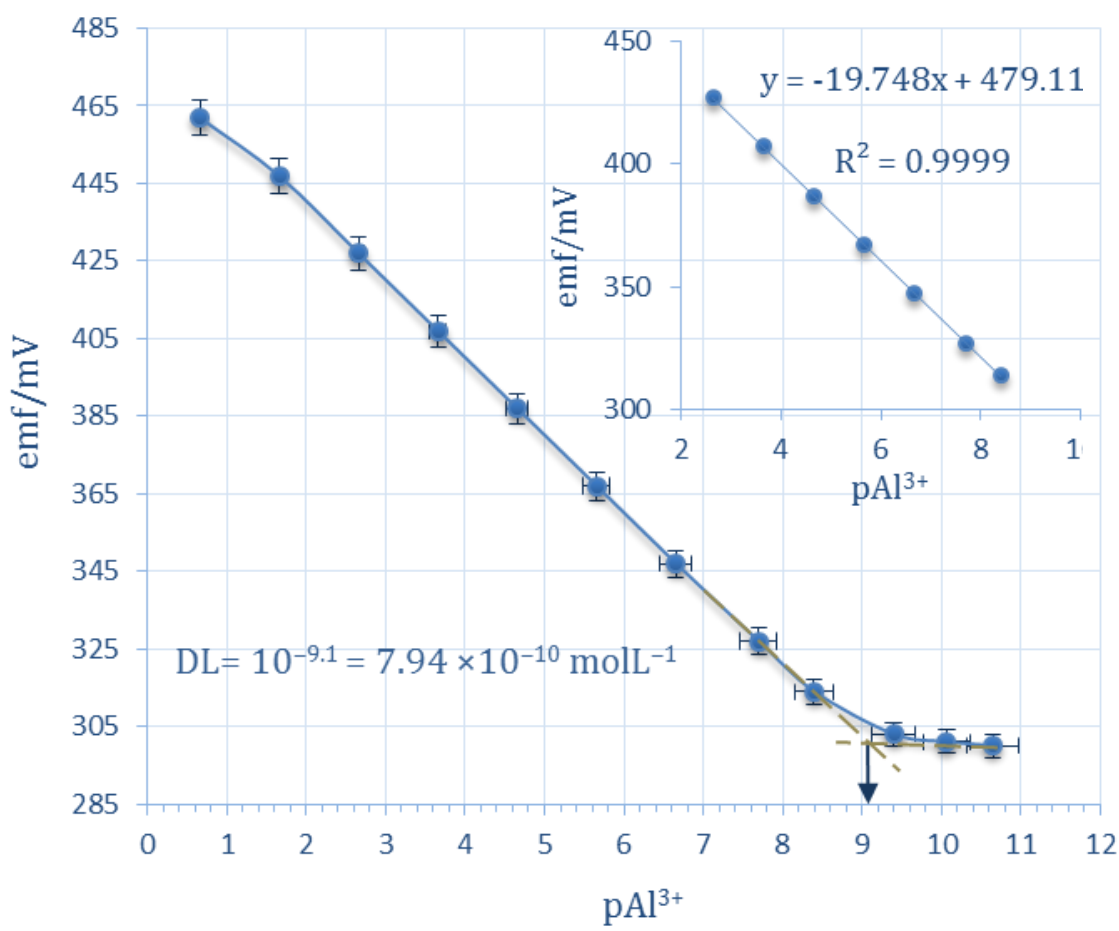

Fig. 6 


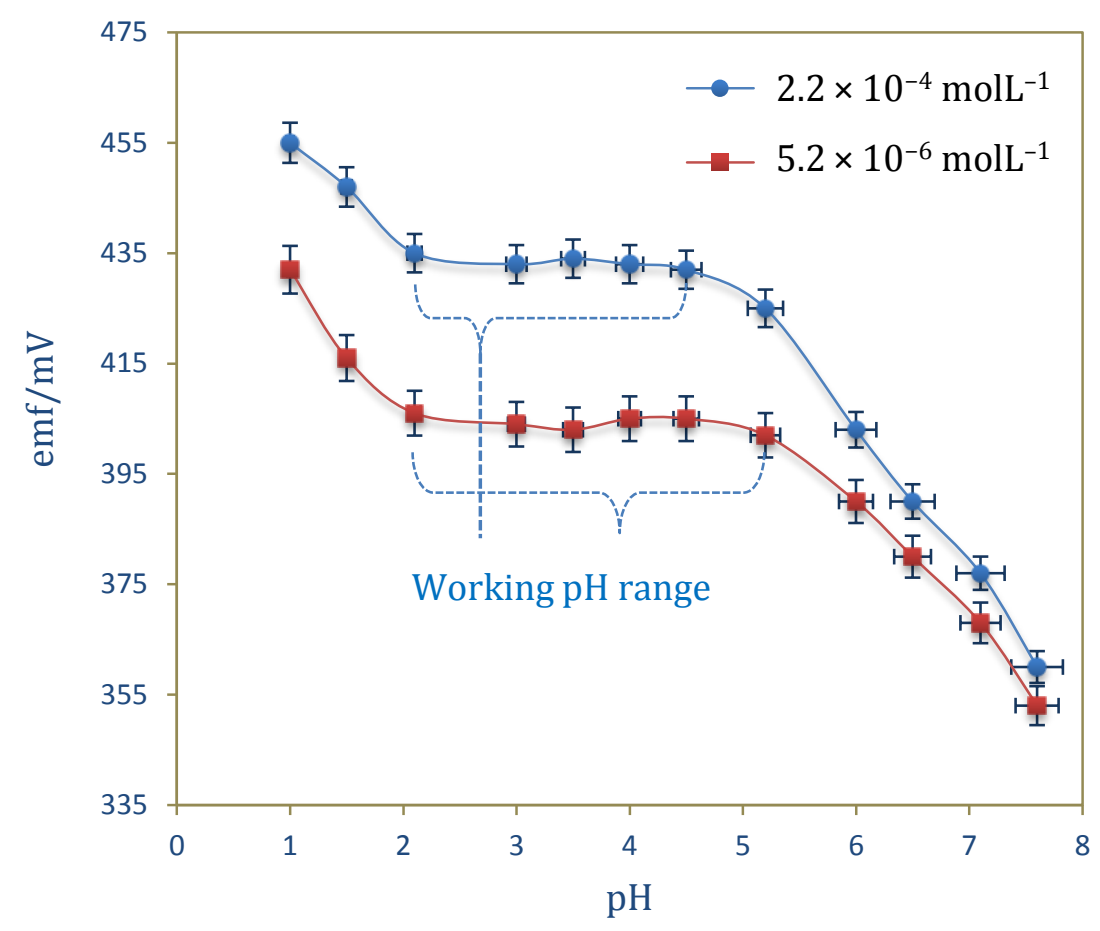

Fig. 7

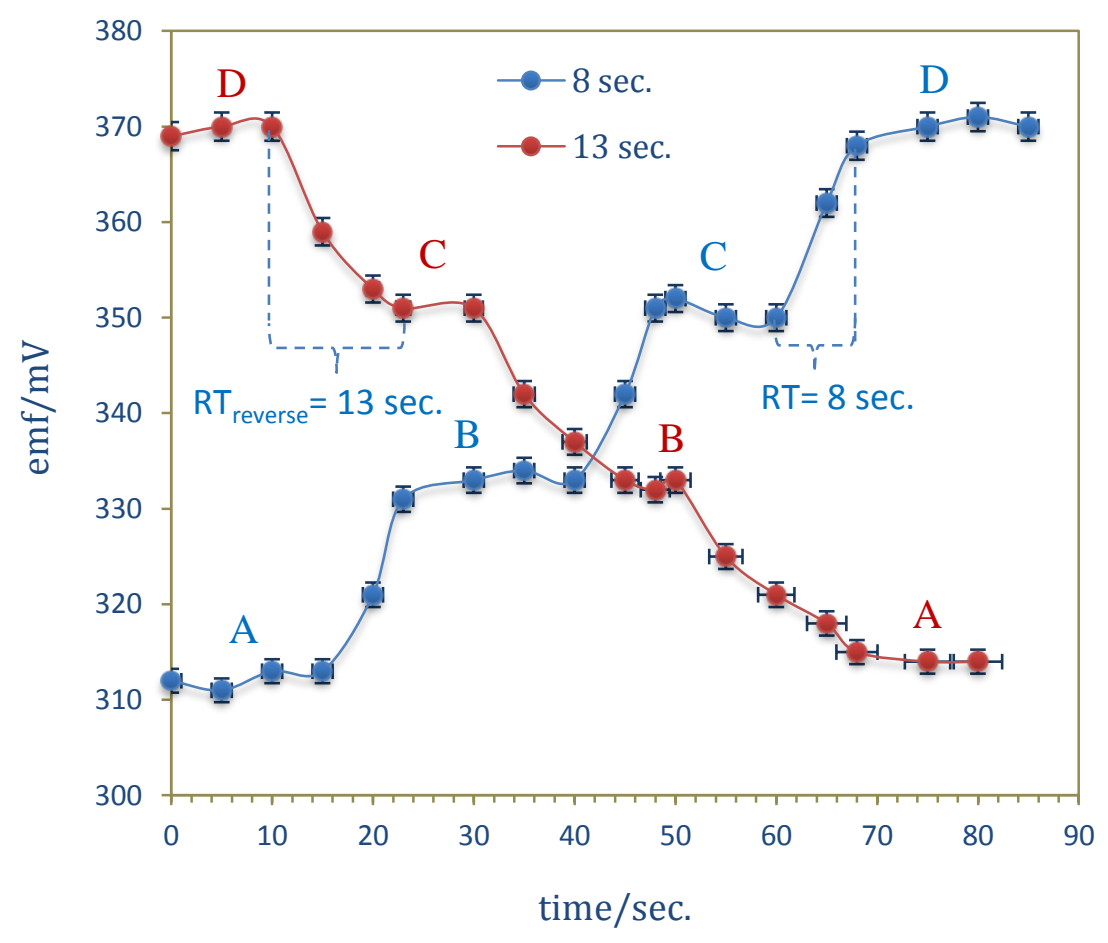

Fig. 8 


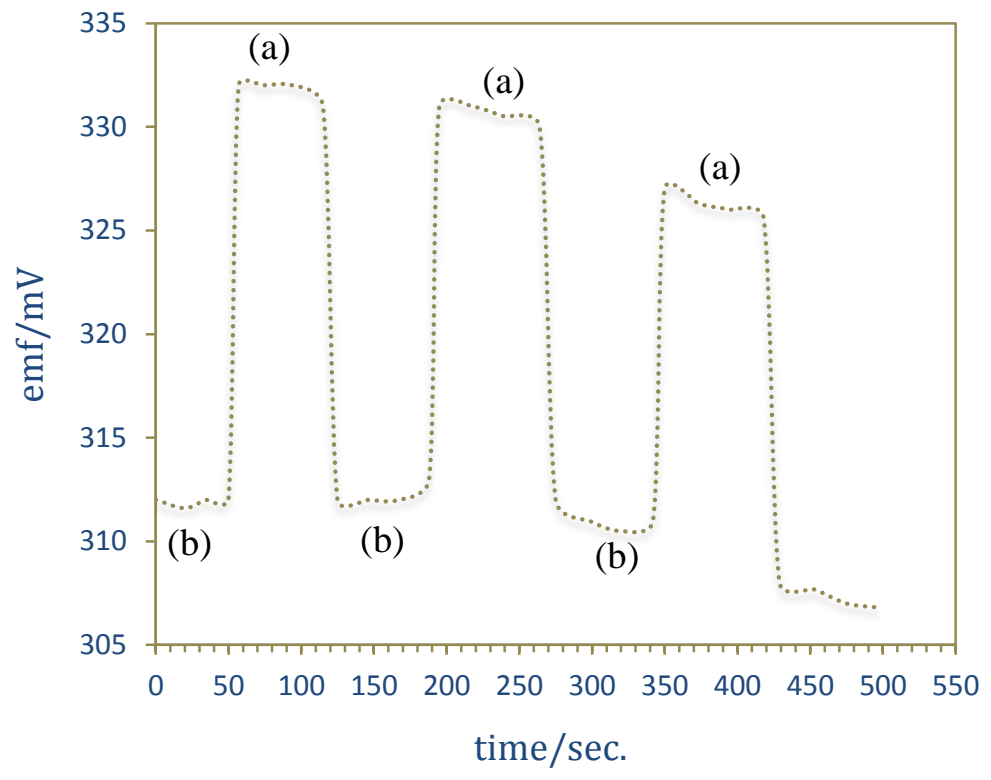

Fig. 9

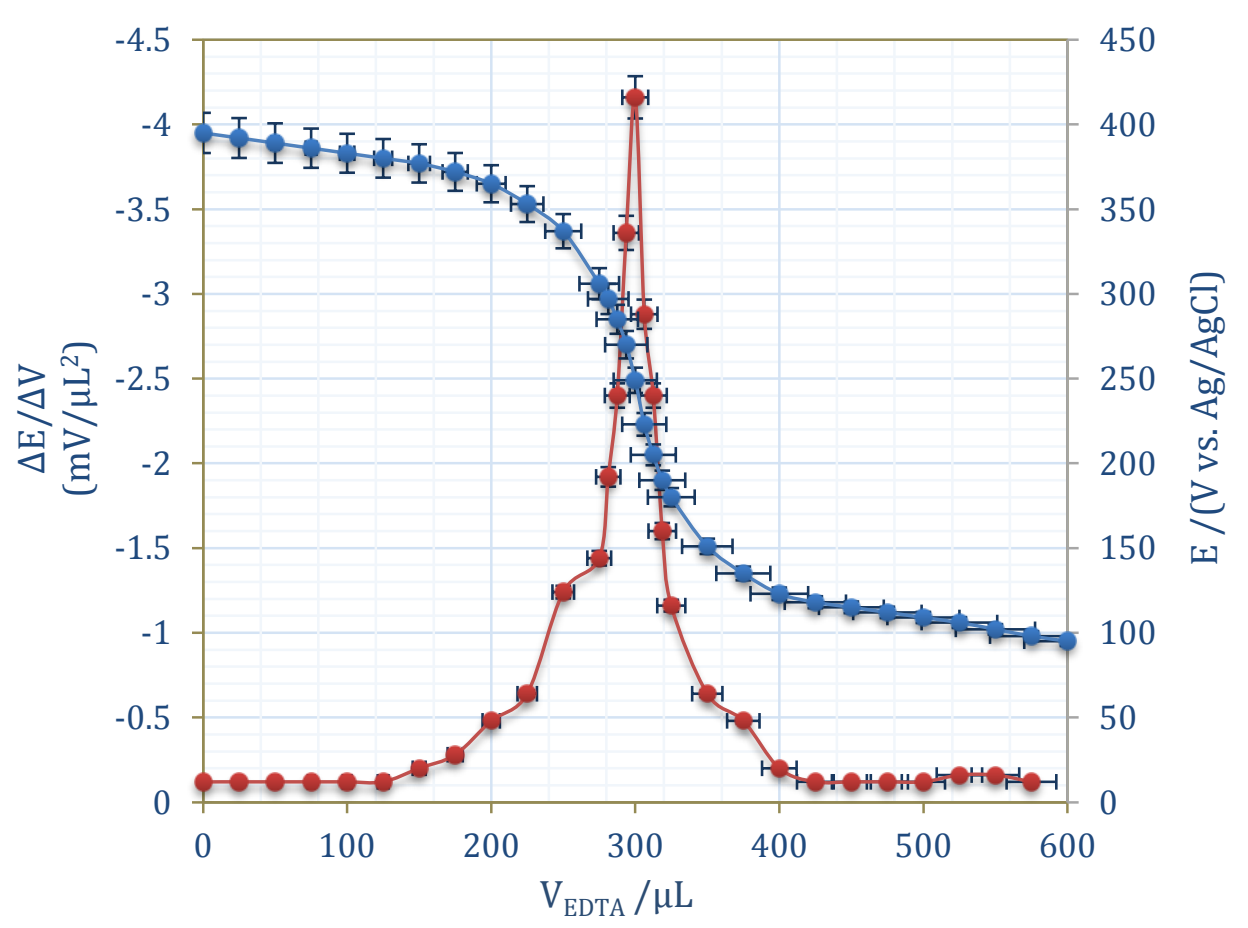

Fig. 10 
A novel polyoxomolybdate/ionic liquid based sensor for ultra-high sensitive monitoring of Al(III): Optimization by Taguchi statistical design

Soleyman Ramezani ${ }^{\text {a, } * \text {, Rana Jahani }}{ }^{\text {b }}$, Mohammad Hossein Mashhadizadeh ${ }^{\text {a }}$, Saeed Shahbazi $^{\text {a }}$, Sajad Jalilian ${ }^{\mathrm{c}}$

${ }^{a}$ Faculty of Chemistry, Kharazmi University, Tehran, Iran

${ }^{\mathrm{b}}$ Department of Applied Chemistry, Faculty of Science, University of Mohaghegh Ardabili, Ardabil, Iran

${ }^{\mathrm{c}}$ Material Physic Center (CFM), University of Basque Country (EHU-UPV), San Sebastian 20018, Spain

Email: Soleyman.ramezani@yahoo.com 


\begin{abstract}
A novel ionic liquid electrostatically supported Nano-Cs-polyoxomolybdate modified carbon paste electrode (Nano-PMo ${ }_{12} / \mathrm{IL}-\mathrm{CPE}$ ) has been developed by using 1-n-butyl-3methylimidazolium tetrafluoroborate $\left(\mathrm{Bmim}_{\mathrm{B}} \mathrm{BF}_{4}\right)$ as a hydrophobic binder. The supramolecular gel $\left(\mathrm{PMo}_{12} / \mathrm{IL}\right)$ exhibits an ordered structure, various physicochemical properties, and specifically as a result of its substantial reversible self-assembly, it can be used as an intelligent ion-exchange smart platform in the carbon paste bulk of the electrode. As expected, a significant linear correspondence was found between the sensor output signal $(\mathrm{emf} / \mathrm{mV})$ and logarithm of $\mathrm{Al}(\mathrm{III})$ ion activity with a Nernstian slope of $19.9( \pm 0.2)$ mVdecade ${ }^{-1}$ over a wide concentration range of $1.0 \times 10^{-9}$ to $2.2 \times 10^{-1} \mathrm{molL}^{-1}\left(\mathrm{R}^{2}=0.9999\right)$. The sensor considered, exploits an astounding lower limit of detection and short response time of $7.94 \times 10^{-10} \mathrm{molL}^{-1}$ and $8.0 \mathrm{sec}$. respectively within the working $\mathrm{pH}$ range of 2.0 to 5.0. A statistical design of experimental (Taguchi method with Qualitek-4 software and $\mathrm{L}_{16}$ orthogonal array robust design) was implemented in this work to optimize the process to achieve the least number of experimental runs as much as possible. Ultimately, practical capability of the sensor was investigated successfully by assessment of $\mathrm{Al}(\mathrm{III})$ ion quantity in some aqueous samples namely mineral water, Al-Mg syrup, black tea extract, and ore samples (Basalt and Andesite), in perfect agreement with flame atomic absorption spectroscopy (FAAS).
\end{abstract}

Keywords: Ionic liquid/polyoxomolybdate supramolecular gel, Taguchi statistical method, potentiometric sensor, $\mathrm{Al}(\mathrm{III})$ ion 


\section{Introduction}

Due to the important roles of Aluminum in the pathology of Parkinson's disease (PD), Alzheimer's disease and diseases of dialysis (dialysis encephalopathy or dialysis dementia), also it's toxicological effects on living system, especially on human beings and because of its utility as an aggregating agent in potable water treatment units [1-4], there is an increasing necessity for aluminum monitoring in real samples. So, a sensitive, fast, and specific methods for the determination of this element in different biological and physiological matrices and in environmental and food samples are needed. Up to date, various methods comprising different sorts of spectrophotometry, spectrofluorimetry, and chromatography have been successfully applied for determination of aluminum ion quantity in trace levels [5]. In spite of their intrinsic assets, this method has some inherent shortcomings such as time-consuming, involving tedious pre-treatment procedures, or too expensive $[3,5]$.

As an appropriate and reliable alternative, electrochemical methods utilizing chemically modified carbon paste electrodes (CMCPEs) are the most reliable methods for the determination of some biologically important molecules, medicines and toxic metal ions [36]. CPEs characterized of many properties such as low background current, easy renewal surface, rich surface chemistry, facile fabrication and modification with desired properties via incorporating different substances during the paste preparation, and above all, suitability for various sensing and detection applications [7-14].

Polyoxometalates (POMs) as mediators shuttling the redox equivalents between the substrate and the electrode for indirect electrochemical processes have attracted much attention in recent years [15-18]. Owing to the strong Brønsted acidity and special structural properties, Keggin-type POMs, as a non-coordinating templates have attracted much attention. They especially have some very useful and interesting properties including high stability, tunable ability of their redox potentials, and the possibility of their reversible multielectron transfer [18].

The unique properties of ionic liquids, including high thermal stability, tunability of their acidities, and excellent retention of polar or charged catalysts, make them appealing media for a broad range of catalytic applications [19]. Supported ionic liquid catalysis is a concept that combines the advantages of ionic liquids with those of heterogeneous support materials. The catalytically active polyoxometalate anion $\left[\mathrm{PMo}_{12} \mathrm{O}_{40}\right]^{3-}$ was immobilized onto the IL support by stoichiometric anion exchange via a very simple preparation procedure under 
relatively benign and easy-to-handle conditions (Fig. 1) [20-22]. Contrary to its bulk form, Nano-sized POMs possess some intrinsic preferences of high electrical conductivity, high specific surface area, low solubility in aqueous media (metal salt form), and in consequence high stability [23, 24]. In this context, the combination of room temperature ionic liquid (RTIL) with Cs-Nano-PMo ${ }_{12}$ [PMo $\left.{ }_{12} / \mathrm{ILs}\right]$ can be concluded to be a novel kind of supramolecular gel. The results indicate that it's properties (i.e., transformation points and conductivities) can be tuned by the design of the organic part. The features of unique Nanosized space and functional surface of metal-organic frameworks, enable them to efficiently serve as host materials for various species (target species) [15, 25-30].

Design of Experiments (DOE) using Taguchi approach can economically satisfy the needs of problem solving and product/process design optimization complex projects to study the effect of multiple factors (i.e. variables, parameters, ingredients, etc.) simultaneously [3133]. To complete planning of experiments and evaluation criteria before conducting experiments, steps for analysis are standardized (main effect, ANOVA and Optimum), using taguchi statistical method (TSM) executed by Qualitek-4 (QT-4) software. A L 16 orthogonal array type of QT-4 possessing four factors of control at four levels has been employed at the present study. The analysis of variance (ANOVA) of the mean electrode response and signalto-noise ratio showed the great influence of $\mathrm{PMo}_{12} / \mathrm{GP}$ weigh percentage ratio on the electrode potentiometric response. On the contrary, the other factors revealed low or no significant effect.

$\mathrm{PMo}_{12}$ is a Keggin type of anionic complex that has several applications in fuel cells, catalysis, molecular materials, electrochromism, super capacitors, medicine and some antibacterial activity against Escherichia coli and Bacillus subtilis [34]. As a unique class of metal oxide clusters, Keggin-type $\left[\mathrm{PMo}_{12} \mathrm{O}_{40}\right]^{3-}\left(\mathrm{PMo}_{12}\right)$ would represents as an IL supported building block to play key role of an ion-exchange or size-matching selective agent on the CPE assemblies. Due to its synergetic physicochemical properties, IL impregnated Nano$\mathrm{PMo}_{12}$, gives a substantial stability and sensitivity to the modified sensor. After optimization of critical parameters by QT-4 run of TSM, the $\mathrm{PMo}_{12} / \mathrm{IL}$ modified CPE was satisfactorily used as a renewable probe electrode to investigate the $\mathrm{Al}(\mathrm{III})$ ion quantity in ultrahigh trace level included in the pharmaceutical and soil matrices, and aqueous samples.

\section{Material and methods}

\subsection{Reagents and materials}


Analytical reagent grade chemicals and doubly distilled water were used for preparing all aqueous solutions. Aluminum (III) nitrate was obtained from Merck. Carbon graphite powder (1-2 $\mu \mathrm{m}$ ), paraffin oil (PO), dioctyl phthalate (DOP) and dibutyl phthalate (DBP) (Fig. 2) were supplied from Aldrich and Fluka. Electrically conductive Ionic liquid (1-n-butyl-3methylimidazolium tetrafluoroborate) $\left(\mathrm{Bmim} . \mathrm{BF}_{4}\right)$ was purchased from Merck. $\mathrm{Na}_{2} \mathrm{HPO}_{4}$ and $\mathrm{Na}_{2} \mathrm{MoO}_{4}$ were purchased from Merck chemical company. The $\mathrm{Cs}_{3}\left[\mathrm{PMo}_{12} \mathrm{O}_{40}\right]$ nanocluster was provided at the Inorganic Chemistry Laboratory using a reverse micelles based nanoreactor inspired by reference [34]. Nitrate and chloride salt of metals (all from Merck) were of the highest purity available and used without any further purification. All other chemicals used were of the analytical reagent grade (from Merck, Aldrich, or Fluka). All glassware used in the experiments were washed with freshly prepared aqua regia $(3: 1$ (v/v) $\mathrm{HCl}: \mathrm{HNO}_{3}$ ) and rinsed thoroughly with tap water first and then DDW before use.

\subsection{Apparatus}

The potential was measured under constant stirring of the test solution with respect to a double-junction silver/silver chloride reference electrode (Azar electrode, Urmia, Iran) in conjunction with chemically modified carbon paste indicator electrode. All potentiometric measurements and $\mathrm{pH}$ adjustments were accomplished with a digital $\mathrm{pH} / \mathrm{mV}$ meter (Metrohm-827, Switzerland). Some solutions were homogenized by ultrasonic homogenizer (Bandelin UW 3200, Germany) whenever it was required. UV-Vis absorption spectra were recorded with a Perkin-Elmer, Lambda 25 (USA) spectrophotometer. Melting points were also determined with a Barnstead Electrothermal model 9200 apparatus. FT-IR spectra were recorded on Perkin-Elmer Spectrum RXI FT-IR spectrometer using pellets of the materials diluted with $\mathrm{KBr}$. All measurements were carried out at laboratory ambient temperature. The ${ }^{1} \mathrm{HNMR}$ analysis was implemented using BRUKER AVANCE DPX $300 \mathrm{MHz}$ apparatus. Elemental analysis was performed by a Perkin Elmer 2400 series II CHN-O-Rapid elemental analyzer.

\subsection{Preparations}

\subsubsection{Synthesis of Keggin Cs-Nano-PMo ${ }_{12}\left(\mathrm{Cs}_{3}\left[\mathrm{PMo}_{12} \mathrm{O}_{40}\right]\right)$}

The Keggin-type $\mathrm{Cs}_{3}\left[\mathrm{PMo}_{12} \mathrm{O}_{40}\right]$ nanocluster was supplied in accordance to the reference [34] and inspired by literature [35] using microemulsion method. It was formed by direct addition of aqueous solution of hydrochloric acid to reverse micelles containing $\mathrm{Na}_{2} \mathrm{MoO}_{4}$ 
and $\mathrm{Na}_{2} \mathrm{HPO}_{4}$. The product was found to be nearly uniform spherical nanoparticles with 20 $30 \mathrm{~nm}$ size. Structure of the prepared nanomaterial was characterized using Fourier Transform Infrared Spectroscopy (FTIR) with $\mathrm{KBr}$ pellet, and surface morphology was also determined by atomic force microscopy (AFM), X-ray diffraction (XRD), and scanning electron microscopy (SEM).

\subsubsection{Electrostatic coupling of Keggin- $\left[\mathrm{PMo}_{12}\right]^{3-}$ with ionic liquid $[\mathrm{Bmim}]^{+}$}

The $[\mathrm{Bmim}]^{+}$moiety of RTIL was electrostatically dispersed throughout the $\alpha$-Keggin$\left[\mathrm{PMo}_{12} \mathrm{O}_{40}\right]^{3-}$ according to the literature [35], briefly by adding $0.5 \mathrm{~g}$ IL into $50 \mathrm{ml}$ $\mathrm{Cs}_{3}\left[\mathrm{PMo}_{12} \mathrm{O}_{40}\right]$ aqueous solution and stirring at room temperature for $6 \mathrm{~h}$ (Scheme 1). Then, the obtained pale yellow sediment was isolated by filtration and washed with deionized water. The resulting solid was dried in vacuum at $50{ }^{\circ} \mathrm{C}$ for $12 \mathrm{~h}$. Eventually, UV-Vis and FT-NMR spectroscopy was successfully used to confirm the $\mathrm{PMo}_{12} / \mathrm{IL}$ Nanocomposite formation. When the $\mathrm{PMo}_{12} / \mathrm{IL}$ Nano-hybrid is formed normally a blue shift of the electronic transitions and splits of the $\mathrm{C}-\mathrm{H}$ stretching modes of the imidazolium ring are observed [36]. As can be conspicuously seen (Fig. 3), the neat $\mathrm{Cs}_{3}\left(\mathrm{PMo}_{12}\right)$ exhibits characteristic absorptions at 314 $\mathrm{nm}$, which arise from charge transition from $\mathrm{O}^{2-}$ to $\mathrm{Mo}^{6+}$ in $\mathrm{Mo}=\mathrm{O}$ and $\mathrm{Mo}-\mathrm{O}-\mathrm{Mo}$ bonds. The absorption band at $210 \mathrm{~nm}$ are likely to be associated with $\mathrm{O} \rightarrow \mathrm{P}$ transition [36]. These absorption peaks exhibit a slight blue shift, implies on acceptable interactions between $\mathrm{PMo}_{12}$ anions and imidazolium cations in the mesoporous Nano-cluster matrices.

Along with completion of the characterization analysis, the elemental analysis of the $\mathrm{PMo}_{12} / \mathrm{IL}$ was also performed. According to the results, the experimental values are similar to the calculated values, this suggests that the $\mathrm{PMo}_{12} / \mathrm{IL}$ Nano-hybrid are composed of 3:1 mole ratio of $[\mathrm{Bmim}]^{+}$to Keggin- $\left[\mathrm{Pmo}_{12} \mathrm{O}_{40}\right]^{3-}$. (Anal. Calc. for $\left([\mathrm{Bmim}]_{3}\left[\mathrm{PMo}_{12} \mathrm{O}_{40}\right]\right)$ : C, 12.87; H, 2.03; N, 3.75. Found: C, 12.74; H, 1.96; N, 3.68.)

The FT-IR spectra are quite useful to identify structural and bonding changes in the Keggin unit present in $\mathrm{PMo}_{12}$-based ILs hybrid materials. So, FT-IR spectroscopy was applied to confirm $[\mathrm{Bmim}]_{3}{ }^{+}\left[\mathrm{PMo}_{12} \mathrm{O}_{40}\right]^{3-}$ electrostatic coupling. The FT-IR analysis of $\left[\mathrm{Bmim} . \mathrm{PF}_{4}\right]$, Nano- $\mathrm{Cs}_{3}\left[\mathrm{PMo}_{12} \mathrm{O}_{40}\right]$, and $[\mathrm{Bmim}]_{3}{ }^{+}\left[\mathrm{PMo}_{12} \mathrm{O}_{40}\right]^{3-}$ are in good agreement with the results reported in the literatures [35-38].

\subsubsection{Electrodes preparation}


The unmodified and chemically modified carbon paste $\mathrm{Al}(\mathrm{III})$ electrodes were prepared as described previously $[3,9,10]$. Concisely, suitable amounts of both carbon graphite (CG) (\%67, w/w) and pasting agents (binder), PO, DOP, DBP, and or IL (\%33, w/w), were mixed in an agate mortar and exhaustively hand-mixed with an agate pestle. Several different $\mathrm{CG} / \mathrm{IL} / \mathrm{PMo}_{12}$ weight percentage ratios $(\mathrm{w} / \mathrm{w} \%)$ were prepared for each material. After well hand-mixing, to attain maximum uniformity and high electrical conductivity, all the components were dissolved in about $2 \mathrm{ml}$ of acetone and sonicated for $5 \mathrm{~min}$. With this trick, the experimenter easily gets rid of the potential output instability with high tolerance. The resulting solution was then left at ambient temperature to entirely evaporate left-over solvent. A portion of the resulting paste was well packed into the polypropylene tube $(2.5 \mathrm{~mm}$ i.d and $12 \mathrm{~cm}$ length) with a hole at one end without any air gap, the tip of which had been cut off. Electrical contact was established via a cooper wire with the transversal section previously cleaned, planed and polished. Just prior to use, smooth and fresh electrode surfaces were attained by scraping off the over-flow paste and squeezing out $0.5 \mathrm{~mm}$ of the paste from the syringe, polishing it against glossy graph paper until the surface had a shiny appearance without any porosity. The provided electrodes will be ready to use after $12 \mathrm{~h}$ time interval to equilibrium their components. Just before any experiment, the renewed surface of the modified CPEs were preconditioned by putting it into the $1.0 \times 10^{-4} \mathrm{molL}^{-1}$ of $\mathrm{Al}$ (III) ion solution for $30 \mathrm{~min}$. Instantaneously after that, in order to wipe non-specific adsorbed ions off the electrode surface, it was left in DDW for another 15 minutes. And then the electrode active surface was rinsed with distilled water.

\subsection{General procedure}

The electrochemical cell assembly equipped by the proposed carbon paste indicator electrode for potentiometric measurements was as follows [12]:

$$
\mathrm{Ag} / \mathrm{AgCl} \mid \text { sample solution | } \mathrm{CPE}
$$

All potentiometric essay of $\mathrm{Al}(\mathrm{III})$ ion was fulfilled by the proposed carbon paste indicator electrode in contact with $\mathrm{Ag} / \mathrm{AgCl}$ reference electrode connected with the $\mathrm{pH} / \mathrm{mV}$ meter. The reference electrode was a double junction $\mathrm{Ag} / \mathrm{AgCl}, 3 \mathrm{M} \mathrm{KCl} \mid 1 \mathrm{M} \mathrm{KNO}_{3}$ electrode. During all measurements, two electrodes were immersed in the $50 \mathrm{~mL}$ beaker containing $30 \mathrm{~mL}$ deionized water, and the solution was smoothly stirred using a magnetic stirrer. Also, $\mathrm{pH}$ of the test solution was locked in 5.0 by adding $0.1 \mathrm{molL}^{-1}$ solution of either $\mathrm{HNO}_{3}$ or $\mathrm{NaOH}$. The performance of the electrodes was investigated by measuring the cell 
potential of aluminum nitrate solutions in the concentration range of $4.0 \times 10^{-11}$ to $2.2 \times 10^{-1}$ molL ${ }^{-1}$ by serial dilution of the $0.1 \mathrm{molL}^{-1}$ stock solution. As the test solution is gently being stirred, the electrode potential was recorded when a steady state value was attained within $\pm 2.0 \mathrm{mVdecade}{ }^{-1}$. The calibration curve was extracted by plotting the potential (emf, $\mathrm{mV}$ vs. $\mathrm{Ag} / \mathrm{AgCl}$ ), versus $\log \mathrm{Al}(\mathrm{III})$ ion concentrations. The activities of the metal ions were calculated based on the Debye-Hückel procedure. All the metal nitrate solutions were freshly prepared by accurate dilution of their stock standard $0.1 \mathrm{molL}^{-1}$ solution with double distilled deionized water.

\subsection{Taguchi design of experiments}

Taguchi method uses a special design of orthogonal arrays that allows to study the whole parameter space with a limited number of experiments. Besides, this method provides other advantages: it reduces economically the variability of the response variable, shows the best way to find out the optimum process conditions during laboratory experiments, it is an important tool for improving the productivity of the R\&D activity and it can be applied to any process $[33,39]$.

In the present study, to achieve maximum efficiency in storage capacity, time or cost with experiments with minimal repetition, some of the effective and determinative factors were optimized applying L-16 array type of QT-4 software of TSM [40]. Successful selection of the factors with favorable outcomes is entirely based on the most critical parameters that can strongly affect the electrochemical response of the proposed sensor. The Nano- $\mathrm{PMo}_{12} / \mathrm{IL}$ modified CPE was established using four different factors such as; the weight percentage ratio of GP and Cs-Nano-PMo $\mathrm{PM}_{12}$ in carbon paste composition, type of binder, and preconcentration time which are mutually exclusive (Table 1). The four parametric levels were selected so that a practical range of parameter variations are included.

Table 1 Different parameters and levels used to design orthogonal array

\begin{tabular}{lllll}
\hline Factors & Level 1 & Level 2 & Level 3 & Level 4 \\
\hline Graphite powder (mg) & 66 & 65 & 64 & 63 \\
Cs-Nano-PMo $_{12}(\mathrm{mg})$ & 0 & 3 & 4 & 5 \\
Binder & PO & DOP & RTIL & DBP \\
PC. time (min) $^{\text {a }}$ & 0 & 15 & 20 & 30 \\
\hline
\end{tabular}

${ }^{a}$ Preconcentration time 
After selecting the effective parameters in four different levels, the L-16 orthogonal array type of QT-4 was used to set up the experiments (Table 2). As can be seen from this table, the 16 manner proposed by QT-4. In this manner, various weigh ratio of the components and type of binder were tested in three replicate experiments $(\mathrm{N}=3)$. Considering the bigger the better, signal to noise $(\mathrm{S} / \mathrm{N})$ was used for the evaluation of the impact rate of the each parameter on the proposed modified electrode response. In the TSM, the terms 'signal' and 'noise' represent the desirable and undesirable values for the output characteristic, respectively. TSM uses the $\mathrm{S} / \mathrm{N}$ ratio to measure the quality characteristic deviating from the desired value. The $\mathrm{S} / \mathrm{N}$ ratios are different according to the type of characteristic. In the cases that the bigger characteristics are better, the $\mathrm{S} / \mathrm{N}$ ratio is defined as;

$$
\frac{\mathrm{S}}{\mathrm{N}}=-10 \log \left[\frac{1}{\mathrm{n}} \sum_{\mathrm{i}=1}^{\mathrm{n}} \frac{1}{\mathrm{y}_{\mathrm{i}}^{2}}\right]
$$

Where, $y_{i}$ is the characteristic property and $n$ is the replication number of the experiment [41].

Indubitably, various parameters are effective on the analytical performance of the generated sensor. Indisputably, the best Nernstian response would be the calibration curve slope close to the $20.0 \mathrm{mV} / \mathrm{decade}$ for $\mathrm{Al}$ (III) ion.

Table 2 Factor settings for Taguchi $\mathrm{L}_{16}$ design of Nano- $\mathrm{PMo}_{12} / \mathrm{IL}$ modified CPE.

\begin{tabular}{|c|c|c|c|c|c|c|c|c|}
\hline \multirow{2}{*}{ Exp. } & \multirow{2}{*}{$\begin{array}{l}\text { GP } \\
(\mathrm{mg})\end{array}$} & \multirow{2}{*}{$\begin{array}{l}\text { Nano-PMo }{ }_{12} \\
(\mathrm{mg})\end{array}$} & \multirow{2}{*}{$\begin{array}{l}\text { Binder/Amount } \\
(\mathrm{mg})\end{array}$} & \multirow{2}{*}{$\begin{array}{l}\text { PC. time } \\
(\min )\end{array}$} & \multicolumn{4}{|c|}{ Calibration curve slope $\left(\mathrm{mVdecade}{ }^{-1}\right)$} \\
\hline & & & & & $\begin{array}{l}\text { Sample } \\
\text { (I) }\end{array}$ & $\begin{array}{l}\text { Sample } \\
\text { (II) }\end{array}$ & $\begin{array}{l}\text { Sample } \\
\text { (III) }\end{array}$ & $\mathrm{S} / \mathrm{N}$ \\
\hline L-1 & 66.0 & 0 & $\mathrm{PO} / 34$ & 0 & 4.2 & 3.5 & 3.6 & 11.43 \\
\hline L-2 & 66.0 & 3.0 & $\mathrm{DOP} / 31$ & 15 & 12.4 & 12.5 & 13.0 & 22.02 \\
\hline L-3 & 65.0 & 5.0 & IL/30 & 20 & 19.4 & 19.6 & 19.6 & 25.81 \\
\hline L-4 & 66.0 & 4.0 & $\mathrm{DBP} / 30$ & 30 & 17.5 & 17.0 & 16.8 & 24.65 \\
\hline L-5 & 65.0 & 0 & $\mathrm{DOP} / 35$ & 20 & 8.3 & 8.5 & 8.2 & 18.41 \\
\hline L-6 & 65.0 & 3.0 & $\mathrm{PO} / 32$ & 30 & 15.1 & 14.5 & 15.3 & 23.49 \\
\hline $\mathrm{L}-7$ & 65.0 & 4.0 & $\mathrm{DBP} / 31$ & 0 & 9.1 & 9.5 & 10.0 & 19.56 \\
\hline L-8 & 65.0 & 5.0 & IL/30 & 15 & 18.3 & 18.0 & 18.0 & 25.15 \\
\hline L-9 & 64.0 & 0 & IL/36 & 30 & 8.4 & 7.9 & 8.5 & 18.33 \\
\hline L-10 & 64.0 & 3.0 & DBP/33 & 20 & 14.5 & 14.0 & 14.7 & 23.16 \\
\hline L-11 & 64.0 & 4.0 & $\mathrm{PO} / 32$ & 15 & 15.4 & 15.8 & 16.0 & 23.93 \\
\hline L-12 & 64.0 & 5.0 & DOP/31 & 0 & 7.5 & 7.0 & 7.0 & 17.09 \\
\hline L-13 & 63.0 & 0 & $\mathrm{DBP} / 37$ & 15 & 5.5 & 5.5 & 5.0 & 14.51 \\
\hline L-14 & 63.0 & 3.0 & IL/34 & 0 & 7.3 & 7.0 & 7.1 & 17.06 \\
\hline
\end{tabular}




\begin{tabular}{|c|c|c|c|c|c|c|c|c|}
\hline L-15 & 63.0 & 4.0 & $\mathrm{DOP} / 33$ & 30 & 11.0 & 11.3 & 11.4 & 21.00 \\
\hline L-16 & 63.0 & 5.0 & $\mathrm{PO} / 32$ & 20 & 17.5 & 18.1 & 17.0 & 24.86 \\
\hline
\end{tabular}

\section{Results}

Admittedly, the analytical performance of ion selective electrodes (ISEs) depends exceedingly on the chemical nature and amount of the modifying additives. Among them, the matrices resistance and uniformity, selectivity, sensitivity and response behavior of the sensors are noteworthy [21]. The ability of POMs to undergo reversible multi-electron redox processes makes them interesting for amperometric sensor applications, such as detection of redox-active industrial and agricultural pollutants. To recite the sensing information and to boost electroanalytical response, the POMs need to be anchored or immobilized on conductive substrates while at the same time maintaining molecular dispersion to reach low analyte detection limits. Therefore, electrically conductive platforms of CNTs, graphene, and RTILs are ideal substrate for this purpose [42]. As far as pursuits confirm, this work, is the first attempt to apply IL-modified $\mathrm{Cs}-\mathrm{PMo}_{12}$ for the selective and sensitive $\mathrm{Al}(\mathrm{III})$ ion determination in the presence of some alkali, alkaline earth and transition metal ions, and some biologically important species. It was found in preliminary evaluations that, compared with PO, DBP, and DOP- POM modified CPE, the POM/IL-CPE, influenced by the unique characteristics of IL, generated stable potentials over Al(III) ions, after a conditioning in a $1.0 \times 10^{-4} \mathrm{molL}^{-1} \mathrm{Al}\left(\mathrm{NO}_{3}\right)_{3}$ solution (Fig. 4). As compared to the other traditional electrodes, the clear distinction of the $\mathrm{PMo}_{12} / \mathrm{IL}-\mathrm{CPE}$ are high sensitivity, wider dynamic concentration range, and lower limit of detection. Furthermore, in preliminary studies, the proposed sensor was successfully examined in potentiometric determination of some alkali, alkaline earth and transition metal ions, and the attained results were graphed in Fig. 5. Among all species tested, the $\mathrm{PMo}_{12} / \mathrm{IL}-\mathrm{CPE}$ revealed outstanding selectivity merely for $\mathrm{Al}$ (III) ion in comparison with more common metal ions. Accordingly, the $\mathrm{PMo}_{12} / \mathrm{IL}$ contributes as an ion exchange platform for design and construction of the $\mathrm{Al}$ (III) selective electrode.

\subsection{Proposal response mechanism of the electrode}

As is well-known, the response characteristics of an ISE depends exceedingly on the chemical nature and amount of both ionophore and plasticizer used [4, 9, 10]. Hereby, in the present study the Keggin type of $\mathrm{Cs}_{3}\left[\mathrm{PMo}_{12} \mathrm{O}_{40}\right]$ Nanocluster $\left(\mathrm{Cs}-\mathrm{Nano}-\mathrm{PMo}_{12}\right.$ ) was used as a 
Zeolite-like Nanoporous matrices for sensitive and selective monitoring of $\mathrm{Al}(\mathrm{III})$ ion quantity. Consequently, about the proposed sensor, in the presence of $\mathrm{IL}_{3}\left[\mathrm{PMo}_{12} \mathrm{O}_{40}\right]$, Nanoclusters, the $\left(\mathrm{Al}^{3+}\right)_{\text {solution }} \leftrightarrow\left(\mathrm{Al}^{3+}\right)_{\text {electrode }}$ conditioning process following size-matching theory can be hypothetically the most probable response mechanism in the electrode/solution interface. In the presence of such a compounds, the Keggin clusters also confine target ions in the cavities of framework host matrices as a non-coordinating guests like a zeolite [22].

In order to clarify the most probable response mechanism of the modified sensor, the elemental analysis was implemented over the test solution before and after equilibration with an aluminum solution. Based on the results, no net-charge transfer was performed over electrode surface/solution interface. Accordingly, the most likely mechanism with a Nernstian response characteristic would be as follows:

$$
\mathrm{Al}^{3+}(\mathrm{aq}) \rightarrow \mathrm{Al}^{3+}(\text { surface })
$$

With this approach, the most likely response mechanisms of the Nano-PMo ${ }_{12} / \mathrm{IL}-\mathrm{CPE}$ over $\mathrm{Al}(\mathrm{III})$ ion is translocation in the octahedral hole of the nanocluster network without net charge-transfer process (Scheme 2).

\subsection{Taguchi design of optimization}

The parametric comprehension for design and construction of a sensitive and selective $\mathrm{Al}(\mathrm{III})-\mathrm{CPE}$ and an endeavor for quantitative scrutiny of the impact of individual parameter in sensitive determination of $\mathrm{Al}(\mathrm{III})$ ions has led to the utilization of statistical support system of taguchi design. This design of experiment has got a completely controlled task of selecting the best parameters for sensitive monitoring of the $\mathrm{Al}(\mathrm{III})$ ions (the most Nernstian calibration curve slope would be desirable).

In this study, four four-level process parameters, i.e. GP and $\mathrm{PMo}_{12}$ nanocluster weight percentage ratio, type of binder and preconcentration time were evaluated by L-16 array type of TSM. After fulfillment of the triplicate experiments proposed by the L-16 orthogonal array (Table 2), the obtained results were entered into the Qualitek-4 (QT-4) software. Considering bigger $\mathrm{S} / \mathrm{N}$ ratio is better as criteria for determining the optimum conditions, the software defined and introduced optimized experimental conditions in terms of physical conditions with a statistical estimation based on the mean of $\mathrm{S} / \mathrm{N}$ ratio (bigger $\mathrm{S} / \mathrm{N}$ ratio is better) (Table 3). Consequently, as can be concluded from the Table 4, based on the $\mathrm{S} / \mathrm{N}$ ratio by three replicate try of each experiment, the best results were obtained in the following 
optimal conditions; GP $65 \mathrm{mg}$ (level 2), $\mathrm{PMo}_{12}$ nanoparticles $5 \mathrm{mg}$ (level 4), IL as binder (level 3) and preconcentration time 20 min (level 3).

Table 3 Taguchi analysis of the electrode response data

\begin{tabular}{lllll}
\hline \multirow{2}{*}{ Factors } & \multicolumn{4}{l}{ Mean S/N ratio } \\
\cline { 2 - 5 } & Level 1 & Level 2 & Level 3 & Level 4 \\
\hline Graphite Powder (mg) & 20.983 & 21.656 & 20.63 & 19.362 \\
Cs-Nano-PMo $_{12}(\mathrm{mg})$ & 15.674 & 21.436 & 22.58 & 22.942 \\
Type of Binder & 20.933 & 19.634 & 21.59 & 20.474 \\
PC. time (min) $^{\text {a }}$ & 16.289 & 21.406 & 23.064 & 21.873 \\
\hline
\end{tabular}

${ }^{\mathrm{a}}$ Preconcentration time

Table 4 Optimum conditions and performance proposed by $\mathrm{L}_{16}$ array run of QT-4 program to provide $\mathrm{Al}$ (III)-CPE.

\begin{tabular}{llll}
\hline Factors & Level Description & Level & Contribution \\
\hline Graphite Powder $(\mathrm{mg})$ & 65 & 2 & 0.998 \\
Cs-Nano-PMo $_{12}(\mathrm{mg})$ & 5 & 4 & 2.284 \\
Type/amount of Binder & $\mathrm{RTIL} / 30^{\mathrm{a}}$ & 3 & 0.932 \\
PC. time (min) & 20 & 3 & 2.406 \\
\hline
\end{tabular}

${ }^{\mathrm{a}}$ Out of PO, DOP, DBP, and RTIL

In the following, to better comprehend, the relative influence of the different critical parameters on the $\mathrm{Al}(\mathrm{III})-\mathrm{CPE}$ response was inferentially scrutinized by the mean of analysis of variance (ANOVA). Hereby, the relative importance of the experimental parameters in association with construction of the proposed sensor was investigated to discover the optimal data using ANOVA and the outputs were summarized in Table 5.

Table 5 Results of the ANOVA for modified sensor preparation experiments.

\begin{tabular}{lllllll}
\hline Source of Variation & d.f. & SS & MS & F & $\begin{array}{l}\text { Pure Some } \\
\left(\mathrm{S}^{\prime}\right)\end{array}$ & Contribution (\%) \\
\hline Graphite powder (mg) & 3 & 11.127 & 3.709 & 3.379 & 7.834 & 2.927 \\
Cs-Nano-PMo 12 (mg) & 3 & 137.429 & 45.809 & 41.735 & 134.136 & 50.123 \\
Binder & 3 & 8.109 & 2.703 & 2.462 & 4.816 & 1.799 \\
PC. Time (min) & 3 & 107.655 & 35.885 & 32.693 & 104.362 & 38.997 \\
\hline d.f.: degree of freedom, SS: sum of squares, MS: mean of squares (equal to SS/d.f.), \\
F: $\mathrm{MS}_{\text {effect }} / \mathrm{MS}_{\text {error. }}$
\end{tabular}


According to this analysis, the most and least effective factor on the electrochemical behavior of the modified sensor is amount of ionophore (Cs-Nano-PMo $\left.{ }_{12}\right)$ and type of binder respectively. Statistically, F-test provides a decision at some confidence level as to whether these estimates differ significantly from each other [23, 25]. A larger F-value indicates that the variation of the expected parameter makes a bigger change on the proposed sensor performance. In general, the percent contribution indicates the relative ability of a factor to reduce variation. For a factor with high percent contribution, a small variation will have a great influence on the performance. Hereby, the importance of the Cs-Nano-PMo $\mathrm{PM}_{12}$ in the electrochemical characteristics of the modified Al (III)-CPE such as Nernstian slope, limit of detection, and response time will be truly understood. Although, the importance of type of the binder is minimal here, it is not dispensable practically. As a priori, conductivity of the carbon paste components depends strongly on the type of the binder, but here this importance located statistically in the shadow of the $\mathrm{PMo}_{12}$ nanoparticles impact. Nevertheless, the preconcentration time have second rank in terms of the impact factor after $\mathrm{PMo}_{12}$ nanoparticles, this mirror the fact that, the electrochemical response of the sensor strongly influenced by the preconcentration period time. Hereby, the observed potential is equal with boundary potential between CPE surface and test solution influenced by ion exchange process arises from concentration gradient of the $\mathrm{Al}(\mathrm{III})$ ions in the $\mathrm{CPE}$ surface, this is completely depends on the saturation of the bulk of the carbon paste in the preconcentration period of time.

Eventually, the relative influence of the challenged factors and their interactions obtained by the ANOVA indicated that, the Cs-Nano- $\mathrm{PMo}_{12}$ weight percentage ratio (\%50.12), preconcentration time (\%38.79), graphite powder weight percentage ratio (\%2.92) and Type of binder (\%1.79) respectively have the greatest effect on the potentiometric response of the proposed sensor.

\subsection{Composition and characteristics of the electrodes}

Some variable distinguished features of the carbon paste electrode, such as chemical nature of binder, binder/graphite powder weight ratio, the nature and amount of ionophore, and especially, the nature and amount of the Nano-material used, have been reported to meaningfully influence the sensitivity and selectivity of the ion-selective electrodes $[26,15]$. Thus, the efficacy of presence and amount of the modifier (Cs-Nano-PMo ${ }_{12}$ ), type of binder (IL, PO, DOP and DBP), and weight ratio of the GP/binder on the electrochemical response 
of the $\mathrm{Al}$ (III)-CPE were scrutinized by TSM in the 16 trial conditions and the results were summarized in the Table 2. As can be seen overtly, in the absence of the $\mathrm{PMo}_{12}$ nanoparticles the sensor has poor response to $\mathrm{Al}$ (III) ion based on the calibration curve slope. As mentioned earlier, the $\mathrm{Cs}-\mathrm{PMo}_{12}$ nanocluster with an appropriate cavity size acts as suitable ionexchange agent for $\mathrm{Al}(\mathrm{III})$. Also, the influence of nature of paste binder on the $\mathrm{CPE}$ response is overtly impressive. As compared to the other types of binders, (PO, DOP and DBP), the Bmim. $\mathrm{BF}_{4}$ as an electrical conductive binder rely on its unique properties, plays a distinguished key role to coherent the carbon paste tissue. This efficiency emanates from the ionic nature of the binder that increases strongly the electrical conductivity of the carbon paste bulk of the electrode while the other binders were incapable just for the sake of nonionic nature. Therefore, despite of $\mathrm{Bmim}_{\mathrm{BF}} \mathrm{BF}_{4}$, the nonconductive binders would not have any influence on the CPE response while the $\mathrm{Bmim}_{\mathrm{B}} \mathrm{BF}_{4}$ as a solvent mediator not only can act as a liquefying agent, but also enables homogeneous solubilization and modifying the distribution constant of the ionophore used. Also, it was proven experimentally that, reducing the GP/binder weight percentage ratio causes to decrease the sensitivity of the CPE. This is arisen from the fact that by decreasing GP/binder weight ratio, the ohmic resistance of the carbon paste will increase and consequently causes to diminish the CPE sensitivity. Hereto, as shown in Table 4, the Cs-Nano-PMo $\mathrm{PM}_{12}$ modified IL-CPE with the GP/PMo $\mathrm{PM}_{12} / \mathrm{Bmim}$ weigh percentage ratio of 65/5/30 was selected as an optimal paste composition. Such electrode with this features after optimum preconcentration time of 20 min exhibits a Nernstian slope of $19.9( \pm 0.2) \mathrm{mVdecade}^{-1}$ in the wide $\mathrm{Al}(\mathrm{III})$ ion concentration range of $1.0 \times 10^{-9}$ to $2.2 \times 10^{-1}$ molL ${ }^{-1}$ with a lower limit of detection of $7.94 \times 10^{-10} \mathrm{molL}^{-1}$ (Fig. 6). It is noteworthy that, all of the theoretical optimum conditions proposed by TSM, were perfectly consistent with the experimental data. Therefore, the electrode manufactured under the criteria defined be TSM, represented the best performance and was utilized as an indicator electrode for supplementary electroanalytical operations.

\section{Discussion}

4.1. Analytical characteristics of the modified electrode

\subsubsection{Optimal $\mathrm{pH}$ range}

The $\mathrm{pH}$ dependence of the proposed sensor was scrupulously considered in the range of $1.0-9.0$ at the $2.2 \times 10^{-4}$ and $5.2 \times 10^{-6} \mathrm{molL}^{-1}$ of $\mathrm{Al}\left(\mathrm{NO}_{3}\right)_{3}$ solutions, and the results were depicted in Figure 7. As can be plainly expounded, the observed potential values are wholly 
freed from the $\mathrm{pH}$ varieties, in the $\mathrm{pH}$ range of 2.0 to 4.5 and 2 to 5.0 in the $2.2 \times 10^{-4}$ and $5.2 \times 10^{-6} \mathrm{molL}^{-1}$ of $\mathrm{Al}(\mathrm{III})$ ion concentration respectively, indicating the applicability of the proposed sensor in this $\mathrm{pH}$ range. The $\mathrm{pH}$ of the test solutions was set in the 1.0 to 9.0 using $0.1 \mathrm{molL}^{-1}$ nitric acid or sodium hydroxide stock solutions. Arguably, the observed potential values are wholly freed from the $\mathrm{pH}$ varieties, in the $\mathrm{pH}$ range of 2.0 to 4.5 and 2.0 to 5.0 in the $2.2 \times 10^{-4}$ and $5.2 \times 10^{-6} \mathrm{molL}^{-1}$ of $\mathrm{Al}(\mathrm{III})$ ion concentration respectively, indicating the applicability of the proposed sensor in this $\mathrm{pH}$ range. Nevertheless, beyond the range, however, relatively drastic drifts in the potential versus $\mathrm{pH}$ behavior were observed. At the $\mathrm{pH}$ values lower than 2.0 , the electrode response increased rather irregularly with increasing analyte acidity. At such a high acidic solutions, the observed increasing in the potential can be presumably due to simultaneous response of the sensor to the $\mathrm{Al}^{3+}$ and $\mathrm{H}_{3} \mathrm{O}^{+}$species (protonation of ion-exchange sites of Nano- $\mathrm{PMo}_{12}$ ). In this manner, the significantly protonated surface of the CPE possesses a poor response to the Al (III) ions and instead strong response to $\mathrm{H}_{3} \mathrm{O}^{+}$ions in the solution. On the other hand, at the $\mathrm{pH}$ values higher than 5 , based on thickness of $\mathrm{OH}^{-}$ions throughout the test solution, the potential was found dramatically decreased due to appearance of $\mathrm{Al}(\mathrm{OH})_{3}$ sediment and in consequence diminishing of $\mathrm{Al}(\mathrm{III})$ flux to electrode surface through the solution. It is worth noting that, the experimental results roughly are in entire agreement with what was expected from Ksp relation of the $\mathrm{Al}(\mathrm{OH})_{3}$ precipitation. This means that, the initial concentration of $\mathrm{OH}^{-}$ion required to form $\mathrm{Al}(\mathrm{OH})_{3}$ sediment in presence of $2.2 \times 10^{-4}$ and $5.2 \times 10^{-6} \mathrm{molL}^{-1}$ of $\mathrm{Al}(\mathrm{III})$ ion, was nearly proponed by the potentiometric sensor as is anticipated from the Ksp equation of $\mathrm{Al}(\mathrm{OH})_{3}$ precipitation as bellows:

$\mathrm{Ksp}=\left[\mathrm{Al}^{3+}\right]\left[\mathrm{OH}^{-}\right]^{3}=1.9 \times 10^{-33}$, if $\left[\mathrm{Al}^{3+}\right]=2.2 \times 10^{-4} \mathrm{molL}^{-1}$, thus, $\mathrm{pH}=4.31$, and if $\left[\mathrm{Al}^{3+}\right]=$ $5.2 \times 10^{-6} \mathrm{molL}^{-1}$, thus $\mathrm{pH}=4.85$.

\subsubsection{Response time and reversibility}

Arguably, quickness and accuracy are two mostly determinative factors for a quantitative successful analysis. So, dynamic response time is an influential factor for any electrochemical sensors. The electrode response time was assessed rely on the IUPAC recommendation [43]. The average time required for the potentiometric electrode to reach a potential within \pm 1.0 $\mathrm{mV}$ of the final equilibrium value after successive immersion of $\mathrm{Al}$ (III) ion solutions, each having a 10-fold difference in concentration, was investigated. The measurements of potential (emf, V vs. $\mathrm{Ag} / \mathrm{AgCl}$ ) versus time (sec.) were carried out with the $\mathrm{Al}\left(\mathrm{NO}_{3}\right)_{3}$ 
solutions from lower $\left(2.2 \times 10^{-7} \mathrm{molL}^{-1}\right)$ to higher $\left(2.2 \times 10^{-4} \mathrm{molL}^{-1}\right)$ concentrations and vice versa (Fig. 8). In this manner, the emf (V)-time (sec.) plot for these concentrations conspicuously indicates that the potentiometric response time of the electrode was 8 seconds. In order to figure out the proposed electrode reversibility, the emf measurements were implemented in the sequence high-to-low sample concentrations as shown in Fig. 8. Rely on the what was achieved, it was found that the response of the electrode was truly reversible. Although the time required reaching equilibrium values (13 sec.) was longer than that for low-to-high sample concentrations ( $8 \mathrm{sec}$.). This is because, residual Aluminum (III) ions will still be adsorbed on the surface of the CPE and acts as an inhibitor shield against dissolved ions; accordingly, leads to high response time due to high contamination of the CPE surface with $\mathrm{Al}(\mathrm{III})$ ions and hereupon due to considerable occupation of the CPE sites.

\subsubsection{Reproducibility, reversibility and lifetime of the electrode}

An important aspect to be considered aiming practical application of carbon paste electrodes is the consistency of the carbon pastes. The consistency of the carbon pastes depends both on the carbon/binder ratio and on the physicochemical properties of the carbonaceous materials, mainly in regard to the kind of carbon/binder interactions. The consistency of the carbon paste is directly associated to the lifetime and reproducibility on the resulting electrodes [44].

Stability of the Nano-PMo $\mathrm{PM}_{12} / \mathrm{IL}-\mathrm{CPE}$ was tested by keeping the electrode in $\mathrm{pH} 4.5$ for 7 days and then the potential were recorded and compared with the data obtained before immersion. The obtained results represented a very slight drop in the modified electrode potential implying on a significant stability of the response. The lifetime of the proposed CPE over time was checked during a period of 3 months within the range of $4.0 \times 10^{-7}$ to $2.2 \times 10^{-3}$ molL ${ }^{-1} \mathrm{Al}^{3+}$ solutions. In between measurements, the sensor should be prudentially kept in the cool, dark and dry place. Examining the figure of merits variety vs. days reveals no significant divergence in the limit of detection, Nernstian slope and response time of the sensor after 2.5 months of storage. These results indicated that Nano-PMo ${ }_{12} / \mathrm{IL}-\mathrm{CPE}$ is substantially stable and has quite good capacity to perform repeated measurements within 2.5 months.

Besides, in order to evaluate repeatability of the electrode manufacturing process, five modified electrodes provided by entirely identical circumstances, were applied for the determination of $6.30 \times 10^{-5} \mathrm{molL}^{-1} \mathrm{Al}(\mathrm{III})$ ion solution. The RSD for the potentiometric 
response of all the five electrodes (average of three determinations on each electrode) was $3.2 \%$. The operative reproducibility of the proposed method was also checked by determining the RSD for seven potentiometric measurements of aluminum ion quantity. The RSD for each of three concentrations of 1.0, 2.5, and $4.0 \mathrm{ppm}$ of $\mathrm{Al}(\mathrm{III})$, was found out $2.6 \%, 2.4 \%$ and $1.8 \%$ respectively. These results imply on high repeatability and reproducibility of the preparation procedure and $\mathrm{Al}(\mathrm{III})$ determination respectively.

Eventually, so as to evaluate the reversibility of the proposed $\mathrm{Al}(\mathrm{III})$-sensor, a similar procedure was performed in the sequence of $1.0 \times 10^{-3}$ and $1.0 \times 10^{-4} \mathrm{molL}^{-1} \mathrm{Al}^{3+}$ ion concentrations for 4 times, and the graphical results are shown in Fig. 9. As is evident, by changing the target ion concentration, on account of rapid adaption of the electrode surface with new concentration of target ion, the potentiometric response of the sensor is quite reversible when it was consecutively dipped in two solutions alternatively for 4 times.

\subsubsection{Selectivity potency}

Under optimal experimental conditions the interferences of some coexisting species being multi-valent alkali, alkaline earth and transition metal ions, and some biological molecules have been evaluated utilizing matched potential method (MPM) and fixed interference method (FIM) inspired by IUPAC $[45,46]$.

Firstly, the MPM-based selectivity factor $\left(\mathrm{k}_{\mathrm{A}, \mathrm{B}}^{\mathrm{MPM}}\right)$ was determined as follows;

Succinctly, the potential change $\left(\mathrm{mVdecade}^{-1}\right)$ upon increasing the primary analyte activity by an increment of $\Delta a_{\mathrm{A}}$ in a starting solution is measured $\left(a_{\mathrm{A}}=2.2 \times 10^{-7} \mathrm{molL}^{-1}\right)$. Interfering ions ranging from $2.2 \times 10^{-7}$ to $2.2 \times 10^{-2} \mathrm{molL}^{-1}$ are then added to an identical starting solution of primary ion until the same potential change is observed. The selectivity factor $\left(\mathrm{k}_{\mathrm{A}, \mathrm{B}}^{\mathrm{MPM}}\right)$ is then obtained as the ratio of the changes in the activity of the analyte, $\Delta a_{\mathrm{A}}$, and interfering ion, $a_{\mathrm{B}}$ as below;

$$
\mathrm{k}_{\mathrm{A}, \mathrm{B}}^{\mathrm{MPM}}=\frac{\Delta a_{\mathrm{A}}}{a_{\mathrm{B}}}=\frac{a_{\mathrm{A}}^{\prime}-a_{\mathrm{A}}}{a_{\mathrm{B}}} \text {, where, } a_{\mathrm{A}}=2.2 \times 10^{-7} \text { and } a_{\mathrm{A}}^{\prime}=2.2 \times 10^{-4} \mathrm{molL}^{-1}
$$

In subsequence, the selectivity coefficients were worked out as per instructions of FIM. In practice, incremental amounts of primary ions are added to a solution encompassing a 
constant concentration of an interfering substance until a Nernstian response slope to the primary ion is observed. This linear response region is extrapolated to the emf for the background interference only, and the primary ion activity $a_{\mathrm{A}}(\mathrm{DL})$ at this detection limit is, together with the interfering ion activity in the background $a_{\mathrm{B}}(\mathrm{BG})$, inserted into the following equation:

$$
\mathrm{K}_{\mathrm{A}, \mathrm{B}}^{\mathrm{FIM}}=\frac{a_{\mathrm{A}}(\mathrm{DL})}{a_{\mathrm{B}}(\mathrm{BG})^{\mathrm{Z}_{\mathrm{A}} / \mathrm{Z}_{\mathrm{B}}}}
$$

Where, $a_{\mathrm{A}}(\mathrm{DL})$ is the primary ion activity in detection limit, $a_{\mathrm{B}}=2.2 \times 10^{-2} \mathrm{molL}^{-1}$ is the interfering ion activity, $\mathrm{Z}_{\mathrm{A}}$ and $\mathrm{Z}_{\mathrm{B}}$ are the primary and interfering ions charge, respectively. All the MPM and FIM outcomes were summarized in Table 6.

As is conspicuous, some common interfering species of $\mathrm{Co}(\mathrm{II}), \mathrm{Cu}(\mathrm{II}), \mathrm{Zn}$ (II) and somewhat $\mathrm{Cr}(\mathrm{III})$ and $\mathrm{Fe}(\mathrm{III})$, have partially interfering contribution over potentiometric response of the electrode. This can be most likely on account of size-matching based single out of the target species. As per this hypothesis, the Zeolite-like Nano-PMo $\mathrm{PM}_{12}$ in the electrode composition acts as a size-fitting smart platform trapping the target ions cause to alter the boundary potential of the CPE which is directly proportional to the target ion activity. Therefore, the mentioned interfering ions with the closest ionic radius to the $\mathrm{Al}(\mathrm{III})$, show the greatest interfering effect in $\mathrm{Al}(\mathrm{III})$ determination process. On the contrary, the species with larger ionic radius than $\mathrm{Al}(\mathrm{III})$, are fully repelled from the electrode surface and in consequence can't trigger any significant interfering effect.

It should be pointed out that, the rather substantial selectivity coefficients of the $\operatorname{Ag}(\mathrm{I})$ and $\mathrm{Hg}$ (II) ions is justified by instinctive response of the bare (unmodified) CPE to these ions not due to the presence of modifying additives in the carbon paste composition [29]. According to IUPAC [45], if the selectivity coefficient is less than 1.0, the ISE responds to primary ion more selectively than the interfering species. As is conspicuous, the results in the Table 6 are much smaller than 1.0, signifying a substantial selectivity of the sensor considered.

Potentiometric response and selectivity of the proposed sensor has also been challenged by coexisting of some biologically important species being cysteine, glucose, fructose, ascorbic acid, uric acid, and urea. For this propose, the selectivity behavior of the mentioned 
compounds were examined using MPM. As can be seen, just like most of interfering ions, these species don't cause any considerable interference over Al(III) ion detection process.

The interfering species larger than $\mathrm{Al}^{3+}$ in ionic radius terms, will be fully repelled from the electrode surface and those smaller than $\mathrm{Al}^{3+}$, will be non-specifically adsorbed on the electrode surface. So, both types of interfering ions will be wiped out from the electrode surface by a gentle whirling flow of the solution surrounding the electrode surface without any significant interference against the target ion. This hypothesis is fully consistent with what was proposed for the electrode response mechanism (Scheme 2).

All in all, the obtained results in the Table 6 well proved that the proposed sensor has an acceptable performance in potentiometric determination of $\mathrm{Al}(\mathrm{III})$ ion in coexisting of some biological species and multi-valent cations.

Table 6 The selectivity coefficients of various interfering species; extracted using proposed $\mathrm{Al}(\mathrm{III})$ CPE calculated by FIM and MPM.

\begin{tabular}{|c|c|c|}
\hline Interfering species & $\left(\mathrm{K}_{\mathrm{Al}^{3+}, \mathrm{M}^{\mathrm{n+}}}^{\mathrm{FIM}}\right.$ & $\left(\mathrm{k}_{\mathrm{Al}^{3+}, \mathrm{M}^{\mathrm{n}+}}^{\mathrm{MPM}}\right.$ \\
\hline $\mathrm{Ag}^{+}$ & $6.4( \pm 0.3) \times 10^{-3}$ & $7.3( \pm 0.4) \times 10^{-4}$ \\
\hline $\mathrm{Hg}^{2+}$ & $1.1( \pm 0.2) \times 10^{-4}$ & $1.0( \pm 0.2) \times 10^{-4}$ \\
\hline $\mathrm{Cu}^{2+}$ & $5.4( \pm 0.4) \times 10^{-3}$ & $8.1( \pm 0.3) \times 10^{-4}$ \\
\hline $\mathrm{Co}^{2+}$ & $3.5( \pm 0.3) \times 10^{-4}$ & $9.1( \pm 0.5) \times 10^{-5}$ \\
\hline $\mathrm{Zn}^{2+}$ & $1.5( \pm 0.1) \times 10^{-4}$ & $3.7( \pm 0.2) \times 10^{-4}$ \\
\hline $\mathrm{Pb}^{2+}$ & $2.1( \pm 0.3) \times 10^{-5}$ & $2.7( \pm 0.2) \times 10^{-5}$ \\
\hline $\mathrm{Cd}^{2+}$ & $2.5( \pm 0.4) \times 10^{-5}$ & $8.8( \pm 0.1) \times 10^{-5}$ \\
\hline $\mathrm{Cr}^{3+}$ & $1.5( \pm 0.4) \times 10^{-5}$ & $2.1( \pm 0.2) \times 10^{-5}$ \\
\hline $\mathrm{La}^{3+}$ & $2.8( \pm 0.2) \times 10^{-6}$ & $7.1( \pm 0.3) \times 10^{-5}$ \\
\hline $\mathrm{Ca}^{2+}$ & $1.5( \pm 0.2) \times 10^{-6}$ & $4.5( \pm 0.2) \times 10^{-5}$ \\
\hline $\mathrm{Fe}^{3+}$ & $8.4( \pm 0.3) \times 10^{-4}$ & $3.2( \pm 0.3) \times 10^{-5}$ \\
\hline $\mathrm{Na}^{+}$ & $7.8( \pm 0.1) \times 10^{-6}$ & $2.2( \pm 0.4) \times 10^{-5}$ \\
\hline $\mathrm{Mg}^{2+}$ & $1.8( \pm 0.2) \times 10^{-5}$ & $1.1( \pm 0.5) \times 10^{-5}$ \\
\hline $\mathrm{Mn}^{2+}$ & $2.4( \pm 0.3) \times 10^{-7}$ & $3.1( \pm 0.2) \times 10^{-6}$ \\
\hline $\mathrm{NH}_{4}^{+}$ & $1.3( \pm 0.4) \times 10^{-5}$ & $1.5( \pm 0.3) \times 10^{-5}$ \\
\hline $\mathrm{K}^{+}$ & $5.3( \pm 0.3) \times 10^{-6}$ & $1.2( \pm 0.3) \times 10^{-6}$ \\
\hline Cysteine & - & No Response \\
\hline Glucose & - & No Response \\
\hline Fructose & - & No Response \\
\hline Ascorbic acid & - & No Response \\
\hline Uric acid & - & No Response \\
\hline Urea & - & No Response \\
\hline
\end{tabular}

${ }^{a}$ Values in parentheses are SDs based on three replicate analyses 


\subsection{Comparative survey}

Response characteristics of the proposed sensor being Nernstian slope, selectivity, limit of detection, linear range and response time were carefully weighed up against some previously reported $\mathrm{Al}(\mathrm{III})$-selective electrochemical sensors (Table 7). As can be visibly seen, in more aspects such as limit of detection, linearity, selectivity, and response time, the proposed sensor illustrates a superior behavior in comparison with the best previously reported Al(III) sensors [3, 44, 47-53]. Although in some aspects, some of the previously reported electrodes have rather enhanced performance than the presented electrode, but overall, evaluation indicates that, this electrode is more useful in such applications.

Table 7 Comparative performance of the Nano-PMo ${ }_{12} / \mathrm{IL}-\mathrm{CPE}$ in competition with some previously reported $\mathrm{Al}(\mathrm{III})$-sensor

\begin{tabular}{|c|c|c|c|c|c|c|}
\hline Ref. & $\begin{array}{l}\text { Slope } \\
\text { (mV/decade) }\end{array}$ & $\begin{array}{l}\mathrm{LOD} \\
\left(\mathrm{molL}^{-1}\right)\end{array}$ & $\begin{array}{l}\mathrm{LR} \\
\left(\mathrm{molL}^{-1}\right)\end{array}$ & $\begin{array}{l}\mathrm{pH} \\
\text { range }\end{array}$ & $\begin{array}{l}\text { RT } \\
\text { (sec.) }\end{array}$ & $\left(-\log \mathrm{K}_{\mathrm{Al}^{3+}, \mathrm{M}^{\mathrm{n}+}}^{\mathrm{pot}}\right)$ \\
\hline [3] & $20.0( \pm 0.1)$ & $2.0 \times 10^{-10}$ & $\begin{array}{l}5.0 \times 10^{-10} \\
\text { to } \\
5.0 \times 10^{-2}\end{array}$ & $\begin{array}{l}3.0 \\
\text { to } \\
7.0\end{array}$ & 5.0 & $\begin{array}{l}\mathrm{Hg}(\mathrm{NR}), \mathrm{Cu}(3.1), \mathrm{Ag}(4.0), \mathrm{Cd}(4.0), \\
\mathrm{Pb}(5.0), \mathrm{Ca}(3.4), \mathrm{Zn}(4.0), \mathrm{Mg}(3.8), \\
\mathrm{Mn}(3.6), \mathrm{Co}(4.0), \mathrm{Fe}(3.0), \mathrm{Cr}(3.1), \\
\mathrm{K}(5.0), \mathrm{Na}(4.3)\end{array}$ \\
\hline [44] & $19.5( \pm \ldots)$ & $3.2 \times 10^{-6}$ & $\begin{array}{l}1.0 \times 10^{-5} \\
\text { to } \\
1.0 \times 10^{-1}\end{array}$ & $\begin{array}{l}2.2 \\
\text { to } \\
3.2\end{array}$ & $\sim 20$ & $\begin{array}{l}\mathrm{Hg}(2.7), \mathrm{Cu}(2.0), \mathrm{Ag}(1.4), \mathrm{Cd}(4.5), \\
\mathrm{Pb}(1.7), \mathrm{Ca}(4.3), \mathrm{Zn}(1.1), \mathrm{Mg}(4.9), \\
\mathrm{Mn}(4.4), \mathrm{Co}(4.7), \mathrm{Fe}(3.2), \mathrm{Cr}(\mathrm{NR}), \\
\mathrm{K}(1.0), \mathrm{Na}(1.9)\end{array}$ \\
\hline [47] & $19.6( \pm 0.4)$ & $6.3 \times 10^{-7}$ & $\begin{array}{l}1.0 \times 10^{-6} \\
\text { to } \\
1.0 \times 10^{-1}\end{array}$ & $\begin{array}{l}3.0 \\
\text { to } \\
6.0\end{array}$ & $\sim 10$ & $\begin{array}{l}\mathrm{Hg}(2.5), \mathrm{Cu}(3.0), \mathrm{Ag}(\mathrm{NR}), \mathrm{Cd}(3.1), \\
\mathrm{Pb}(2.7), \mathrm{Ca}(1.9), \mathrm{Zn}(2.1), \mathrm{Mg}(2.0), \\
\mathrm{Mn}(2.5), \mathrm{Co}(\mathrm{NR}), \mathrm{Fe}(2.5), \mathrm{Cr}(3.0), \\
\mathrm{K}(3.1), \mathrm{Na}(3.0)\end{array}$ \\
\hline [48] & $19.3( \pm 0.8)$ & $2.5 \times 10^{-6}$ & $\begin{array}{l}5.0 \times 10^{-6} \\
\text { to } \\
1.0 \times 10^{-2}\end{array}$ & $\begin{array}{l}2.9 \\
\text { to } \\
5.0\end{array}$ & $\sim 10$ & $\begin{array}{l}\mathrm{Hg}(2.4), \mathrm{Cu}(2.7), \mathrm{Ag}(2.1), \mathrm{Cd}(3.2), \\
\mathrm{Pb}(2.5), \mathrm{Ca}(2.5), \mathrm{Zn}(2.6), \mathrm{Mg}(2.1), \\
\mathrm{Mn}(3.1), \mathrm{Co}(2.9), \mathrm{Fe}(2.4), \mathrm{Cr}(3.2), \\
\mathrm{K}(2.8), \mathrm{Na}(2.5)\end{array}$ \\
\hline [49] & $19.7( \pm 0.1)$ & $3.2 \times 10^{-7}$ & $\begin{array}{l}5.0 \times 10^{-7} \\
\text { to } \\
1.0 \times 10^{-1}\end{array}$ & $\begin{array}{l}3.5 \\
\text { to } \\
5.0\end{array}$ & $\sim 5.0$ & $\begin{array}{l}\mathrm{Hg}(4.0), \mathrm{Cu}(3.9), \mathrm{Ag}(\mathrm{NR}), \mathrm{Cd}(3.3), \\
\mathrm{Pb}(3.1), \mathrm{Ca}(\mathrm{NR}), \mathrm{Zn}(3.5), \mathrm{Mg}(\mathrm{NR}), \\
\mathrm{Mn}(3.6), \mathrm{Co}(3.4), \mathrm{Fe}(2.4), \mathrm{Cr}(2.7), \\
\mathrm{K}(3.0), \mathrm{Na}(2.7)\end{array}$ \\
\hline [50] & $19.4( \pm 0.3)$ & $4.6 \times 10^{-7}$ & $\begin{array}{l}7.9 \times 10^{-7} \\
\text { to } \\
1.0 \times 10^{-1}\end{array}$ & $\begin{array}{l}2.5 \\
\text { to } \\
4.0\end{array}$ & 8.0 & $\begin{array}{l}\mathrm{Hg}(\mathrm{NR}), \mathrm{Cu}(1.6), \mathrm{Ag}(\mathrm{NR}), \mathrm{Cd}(2.2), \\
\mathrm{Pb}(2.1), \mathrm{Ca}(2.3), \mathrm{Zn}(2.4), \mathrm{Mg}(2.2), \\
\mathrm{Mn}(2.1), \mathrm{Co}(2.0), \mathrm{Fe}(2.9), \mathrm{Cr}(2.8), \\
\mathrm{K}(4.9), \mathrm{Na}(4.9)\end{array}$ \\
\hline [51] & $20.0( \pm 0.2)$ & $6.0 \times 10^{-7}$ & $\begin{array}{l}1.0 \times 10^{-6} \\
\text { to } \\
1.6 \times 10^{-1}\end{array}$ & $\begin{array}{l}3.0 \\
\text { to } \\
8.5\end{array}$ & $<5.0$ & $\begin{array}{l}\mathrm{Hg}(1.2), \mathrm{Cu}(2.6), \mathrm{Ag}(0.9), \mathrm{Cd}(2.3), \\
\mathrm{Pb}(2.3), \mathrm{Ca}(3.0), \mathrm{Zn}(2.2), \mathrm{Mg}(2.8), \\
\mathrm{Mn}(2.6), \mathrm{Co}(2.2), \mathrm{Fe}(3.7), \mathrm{Cr}(4.3), \\
\mathrm{K}(0.9), \mathrm{Na}(0.3)\end{array}$ \\
\hline [52] & $20.1( \pm \ldots)$ & $8.7 \times 10^{-6}$ & $\begin{array}{l}1.8 \times 10^{-5} \\
\text { to } \\
1.0 \times 10^{-1}\end{array}$ & $\begin{array}{l}2.5 \\
\text { to } \\
4.5\end{array}$ & 10 & $\begin{array}{l}\mathrm{Hg}(\mathrm{NR}), \mathrm{Cu}(1.0), \mathrm{Ag}(\mathrm{NR}), \mathrm{Cd}(1.2), \\
\mathrm{Pb}(\mathrm{NR}), \mathrm{Ca}(\mathrm{NR}), \mathrm{Zn}(1.2), \mathrm{Mg}(1.3), \\
\mathrm{Mn}(\mathrm{NR}), \mathrm{Co}(1.1), \mathrm{Fe}(1.4), \mathrm{Cr}(1.1), \\
\mathrm{K}(2.4), \mathrm{Na}(2.2)\end{array}$ \\
\hline
\end{tabular}




\begin{tabular}{|c|c|c|c|c|c|c|}
\hline [53] & $19.8( \pm 0.4)$ & $4.6 \times 10^{-7}$ & $\begin{array}{l}1.0 \times 10^{-1} \\
\text { to } \\
1.0 \times 10^{-6}\end{array}$ & $\begin{array}{l}2.0 \\
\text { to } \\
6.0\end{array}$ & $\sim 8.0$ & $\begin{array}{l}\mathrm{Hg}(\mathrm{NR}), \mathrm{Cu}(2.6), \mathrm{Ag}(\mathrm{NR}), \mathrm{Cd}(1.5), \\
\mathrm{Pb}(0.2), \mathrm{Ca}(\mathrm{NR}), \mathrm{Zn}(1.7), \mathrm{Mg}(2.0), \\
\mathrm{Mn}(1.2), \mathrm{Co}(2.2), \mathrm{Fe}(1.4), \mathrm{Cr}(0.4), \\
\mathrm{K}(2.9), \mathrm{Na}(1.6)\end{array}$ \\
\hline $\begin{array}{l}\text { This } \\
\text { work }\end{array}$ & $19.9( \pm 0.2)$ & $7.9 \times 10^{-10}$ & $\begin{array}{l}1.0 \times 10^{-9} \\
\text { to } \\
2.2 \times 10^{-1}\end{array}$ & $\begin{array}{l}2.0 \\
\text { to } \\
5.0\end{array}$ & 8.0 & $\begin{array}{l}\mathrm{Hg}(1.0), \mathrm{Cu}(8.1), \mathrm{Ag}(7.3), \mathrm{Cd}(8.8), \\
\mathrm{Pb}(2.7), \mathrm{Ca}(4.5), \mathrm{Zn}(3.7), \mathrm{Mg}(1.1) \\
\mathrm{Mn}(5.5), \mathrm{Co}(9.1), \mathrm{Fe}(3.2), \mathrm{Cr}(2.1) \\
\mathrm{K}(1.2), \mathrm{Na}(2.2)\end{array}$ \\
\hline
\end{tabular}

LOD: limit of detection, LR: linear range, RT: response time

\subsection{Practical efficiency}

To qualify the hands-on applicability of the proposed $\mathrm{Al}(\mathrm{III})$-sensor under practical conditions, it was applied as an indicator electrode for potentiometric assessment of $\mathrm{Al}$ (III) ion quantity in some real samples with different matrices using standard addition method (SAM). The real samples evaluated by $\mathrm{Al}(\mathrm{III})-\mathrm{CPE}$ consist of black tea leaves, Aluminum-Mg oral suspension (antacid drug) containing $4.5 \times 10^{-4} \mathrm{mgL}^{-1}$ of the aluminum hydroxide (Toliddaru pharma Co., Tehran, Iran), Basalt and Andesite ores, mineral water (Aquafina, bottled by Eram Noush soft drink Co., Tehran, Iran). Prior to carrying out the quantitative electroanalysis, preparation of the real samples of tea leaves, $\mathrm{Al}-\mathrm{Mg}$ syrup, basalt and andesite ore samples, and mineral water were fulfilled exactly in accordance with the methods presented in the Refs [50], [54], and [55] respectively. The data summarized in the Table 8 , evidently represent that, the accuracy of aluminum determination in different aqueous samples is in entirely acceptable agreement with those obtained by flame atomic absorption spectroscopy (FAAS) method, signifying the satisfactory practical performance of the proposed $\mathrm{Al}(\mathrm{III})$-electrode.

Table 8 Determination of $\mathrm{Al}^{3+}$ ion quantity in some real samples by the proposed sensor; approved by FAAS method.

\begin{tabular}{|c|c|c|c|c|c|c|}
\hline \multirow{2}{*}{\multicolumn{2}{|c|}{ Real samples }} & \multicolumn{3}{|l|}{$\mathrm{Al}^{3+}\left(\mathrm{molL}^{-1}\right)^{\mathrm{a}}$} & \multicolumn{2}{|c|}{ Adaptability (\%) } \\
\hline & & Added (SAM) & Found by ISE & Found by FAAS & ISE & FASS \\
\hline \multirow{2}{*}{\multicolumn{2}{|c|}{ Mineral water }} & 0.0 & $\mathrm{Nd}^{\mathrm{b}}$ & - & - & - \\
\hline & & $3.2 \times 10^{-3}$ & $2.9( \pm 0.5) \times 10^{-3}$ & $3.1( \pm 0.5) \times 10^{-3}$ & 90.6 & 96.8 \\
\hline \multirow{2}{*}{\multicolumn{2}{|c|}{ Al-Mg syrup }} & 0.0 & $\mathrm{Nd}$ & - & - & - \\
\hline & & $9.3 \times 10^{-3}$ & $9.0( \pm 0.2) \times 10^{-3}$ & $9.7( \pm 0.2) \times 10^{-3}$ & 96.7 & 104.3 \\
\hline \multirow{2}{*}{\multicolumn{2}{|c|}{ Black tea leaves $\left(\mathrm{mgg}^{-1}\right)$}} & 0.0 & $\mathrm{Nd}$ & - & - & - \\
\hline & & $5.5 \times 10^{-3}$ & $6.2( \pm 0.3) \times 10^{-3}$ & $6.5( \pm 0.3) \times 10^{-3}$ & 112.7 & 118.2 \\
\hline Ore samples & Basalt & 0.0 & $\mathrm{Nd}$ & - & - & - \\
\hline
\end{tabular}




\begin{tabular}{l|l|lllll}
$\left(\mathrm{mgg}^{-1}\right)$ & & $5.0 \times 10^{-3}$ & $4.7( \pm 0.6) \times 10^{-3}$ & $5.2( \pm 0.6) \times 10^{-3}$ & 94.0 & 104.0 \\
\cline { 2 - 7 } & \multirow{2}{*}{ Andesite } & 0.0 & $\mathrm{Nd}$ & - & - & - \\
& $6.0 \times 10^{-3}$ & $5.5( \pm 0.5) \times 10^{-3}$ & $5.8( \pm 0.5) \times 10^{-3}$ & 91.6 & 96.6 \\
\hline
\end{tabular}

${ }^{a}$ Values in parentheses are SDs based on three replicate analyses.

${ }^{\mathrm{b}}$ Not Detected

Moreover, the potentio-titrimetric analysis of $\mathrm{Al}(\mathrm{III})$ containing sample solution was performed with a known concentration of EDTA utilizing the proposed indicator electrode in conjunction with an $\mathrm{Ag} / \mathrm{AgCl}$ reference electrode. To do so, $30.0 \mathrm{~mL}$ of $1.0 \times 10^{-4} \mathrm{molL}^{-1}$ of $\mathrm{Al}\left(\mathrm{NO}_{3}\right)_{3}$ solution was titrated by $1.0 \times 10^{-2}$ molL $^{-1}$ EDTA solution at the $\mathrm{pH}$ of about 4.0. The resulting titration curve and the corresponding first derivative ( $\mathrm{dE} / \mathrm{dV}$ vs. titrant volume) graph for the direct titration of $\mathrm{Al}^{3+}$ cation solution with EDTA are shown in Fig. 10. As can be evidently seen, a sharp potential change and break at the endpoint of titration illustrates that, the proposed sensor is well adapted to the determination of aluminium in solutions, where the direct titration with EDTA is satisfactorily practicable.

\section{Conclusion}

Relying on the achieved results, the Cs-Nano-polyoxomolybdate (Cs-Nano-PMo $\mathrm{M}_{12}$ ) can be deservedly considered as a suitable ion-sensitive agent for construction of a carbon paste based selective electrode for the potentiometric assessment of $\mathrm{Al}(\mathrm{III})$ ion in aqueous samples. It was also found that, among various pasting agents being paraffin oil (PO), dioctyl phthalate (DOP) and dibutyl phthalate (DBP), room temperature ionic liquid (RTIL), the last one based on its extraordinary physicochemical features, is surprisingly able to promote the sensitivity, response time, and stability of the modified electrode. In particular, IL along with Nano$\mathrm{PMo}_{12}$ makes an exceptional approach to have a robust and sensitive sensor. With this expounding, the inherent advantages of the Nano-PMo ${ }_{12} / \mathrm{IL}-\mathrm{CPE}$ are its hyper-sensitivity and selectivity, simple operation, high stability, wide dynamic range, low detection limit and fast response time as compared to bare CPE. Moreover, amount of graphite powder (GP), $\mathrm{PMo}_{12} / \mathrm{GP}$ weigh percentage ratio, type of binder and preconcentration time, were considered as process critical parameters to be optimized using Taguchi statistical method. As the result of taguchi analysis in this study, $\mathrm{PMo}_{12} / \mathrm{GP}$ weigh percentage ratio and type of binder were the most influencing parameters respectively on the electrochemical performance of the proposed sensor. With this approach, the provided sensor possess an acceptable practical applicability for the determination of $\mathrm{Al}$ (III) content in the ore, pharmaceutical and aqueous 
sample matrices. By the way, such an electrode compared with the previously reported similar sensors, illustrates the best performance in some crucial aspects.

\section{Acknowledgement}

Our research group are kindly appreciative of all the supports given by Chairman of Faculty of Chemistry, general chemistry (I, II) laboratory staffs, and especially sincere cooperation of staffs and supervisor of the inorganic chemistry research lab.

\section{Figure captions:}

Scheme 1 Portrayal representation of the $[\mathrm{Bmim}]_{3}{ }^{+}\left[\mathrm{PMo}_{12} \mathrm{O}_{40}\right]^{3-}$ synthesis process

Scheme 2 Depiction of potentiometric response mechanism of $\mathrm{Al}(\mathrm{III})$-selective $\mathrm{PMo}_{12} / \mathrm{IL}$ CPE.

Fig. 1 a) Chemical structure of RTIL [Bmim]. $\mathrm{BF}_{4}$ as a carbon paste binder, b) Electrostatic coupling of imidazolium moiety (positive moiety) of IL with $\left[\mathrm{PMo}_{12}\right]^{3-}[22-24,26,33]$.

Fig. 2 Chemical structure of DOPh and DBPh as nonconductive pasting agent.

Fig. 3 UV? Vis spectra of $\left[\mathrm{PMo}_{12} \mathrm{O}_{40}\right]$ and $[\mathrm{Bmim}]_{3}\left[\mathrm{PMo}_{12} \mathrm{O}_{40}\right]$ in methanol solution.

Fig. 4 Potentiometric response of various modified CPEs to $\mathrm{Al}(\mathrm{III})$ ion.

Fig. 5 Potentiometric calibration curves of the various cations afforded by Nano-PMo $12 / \mathrm{IL}-$ CPE.

Fig. 6 Calibration curve for $\mathrm{Al}$ (III) Nano-PMo ${ }_{12} / \mathrm{IL}-\mathrm{CPE}$ at $\mathrm{pH}$ 4.0. Inset: Practical working range with Nernstian slope of $19.9( \pm 0.2) \mathrm{mVdecade}^{-1}$.

Fig. 7 The effect of solution $\mathrm{pH}$ varieties on the cell potential drawn out by the modified sensor at A) $2.2 \times 10^{-4}$ and B) $5.2 \times 10^{-6} \mathrm{molL}^{-1}$ of $\mathrm{Al}$ (III) solutions.

Fig. 8 Dynamic response of the Nano-PMo $\mathrm{PM}_{12} / \mathrm{IL}-\mathrm{CPE}$ for step changes in concentrations from low to high and vice versa. A) $2.2 \times 10^{-7}$, B) $2.2 \times 10^{-6}$, C) $2.2 \times 10^{-5}$, and D) $2.2 \times 10^{-4} \mathrm{molL}^{-1}$. 
Fig. 9 Reversibility of Nano-PMo ${ }_{12} / \mathrm{IL}-\mathrm{CPE}$ over $\mathrm{Al}(\mathrm{III})$ ion step-changes of concentration from (a) $1.0 \times 10^{-3}$ to (b) $1.0 \times 10^{-4} \mathrm{molL}^{-1}$ and vice versa.

Fig. 10 Potentiometric direct titration and first derivative $\left(\mathrm{dE} \cdot \mathrm{dV}^{-1}\right.$ vs. titrant volume $)$ curves of $30.0 \mathrm{~mL} 1.0 \times 10^{-4} \mathrm{molL}^{-1} \mathrm{Al}(\mathrm{III})$ solution with $1.0 \times 10^{-2}$ molL $^{-1}$ EDTA at $\mathrm{pH} 4.0$ using the proposed sensor as an indicator electrode.

\section{References}

[1] H.X. Jiang, L.S. Chen, J.G. Zheng, S. Han, N. Tang, B.R. Smith, Aluminum-induced effects on Photosystem II photochemistry in citrus leaves assessed by the chlorophyll a fluorescence transient, Tree Physiol 28 (2008) 1863-71.

[2] S.V. Verstraeten, L. Aimo, P.I. Oteiza, Aluminium and lead: molecular mechanisms of brain toxicity, Arch Toxicol 82 (2008) 789-802.

[3] M.H. Mashhadizadeh, H. Khani, Sol-Gel-Au nano-particle modified carbon paste electrode for potentiometric determination of sub ppb level of $\mathrm{Al}(\mathrm{III})$, Anal. Methods 2 (2010) 24-31.

[4] P. Buhlmann, Li.D. Chen, Ion-Selective electrodes with ionophore-doped sensing membranes, John Wiley \& Sons 5 (2012) 2539-2576.

[5] M.B. Gholivand, F. Ahmadi, E. Rafiee, A Novel Al(III)-Selective Electrochemical Sensor Based on N,N'-Bis(salicylidene)-1,2-phenylenediamine Complexes, Electroanalysis 18 (2006) 1620-1626.

[6] E. Nossol, A.J.G. Zarbin, Carbon paste electrodes made from novel carbonaceous materials: Preparation and electrochemical characterization, Electrochim. Acta 54 (2008) $582-589$. 
[7] D. Gligor, F. Balaj, A. Maicaneanu, R. Gropeanu, I. Grosu, L. Muresan, I.C. Popescu, Carbon paste electrodes modified with a new phenothiazine derivative adsorbed on zeolite and on mineral clay for NADH oxidation, Mater. Chem. Phys. 113 (2009) 283-289.

[8] A. Babaei, M. Zendehdel, B. Khalilzadeh, A. Taheri, Simultaneous determination of tryptophan, uric acid and ascorbic acid at Iron(III) doped zeolite modified carbon paste electrode, Colloid Surf. B 66 (2008) 226-232.

[9] S. Ramezani, M. Ghobadi, B. Nemati Bideh, Voltammetric monitoring of Cd (II) by nano- $\mathrm{TiO}_{2}$ modified carbon paste electrode sensitized using 1,2-bis-[o-aminophenyl thio] ethane as a new ion receptor, Sens. Actuat. B 192 (2014) 648-657.

[10] S. Ramezani, M.H. Mashhadizadeh, S. Jalilian, M. Aghili, Structure-switching of an organothiol neutral carrier by gold nanoparticles decorated on SH-MWCNTs for ultra-trace voltammetric assay of $\mathrm{Hg}$ (II) using a carbon paste electrode, Anal. Methods 7 (2015) $7765-7775$.

[11] S. Ramezani, M. H. Mashhadizadeh, M. Ghobadi, S. Jalilian, Silica gel/gold nanoparticles/(NS) $)_{2}$ ligand Nanoporous platform-modified ionic liquid carbon paste electrode for potentiometric ultra-trace assessment of $\mathrm{Ag}(\mathrm{I})$, Int. J. Environ. Sci. Technol. 13 (2016) $2175-2188$.

[12] M.H. Mashhadizadeh, S. Ramezani, M.K. Rofouei, Development of a novel MWCNTstriazene-modified carbon paste electrode for potentiometric assessment of $\mathrm{Hg}$ (II) in the aquatic environments, Mater. Sci. Eng. C 47 (2015) 273-280.

[13] I. Švancara, A. Walcarius, K. Kalcher, K. Vytřas, Carbon paste electrodes in the new millennium, Cent. Eur. J. Chem. 7 (2009) 598-656.

[14] M.H. Mashhadizadeh, S. Ramezani, A. Shockravi, M. Kamali, Comparative study of carbon paste electrodes modified by new pentaaza macrocyclic ligands and gold nanoparticles embedded in three-dimensional sol-gel network for determination of trace amounts of Ag(I), J Incl. Phenom. Macrocycl. Chem. 76 (2013) 283-291.

[15] H. Liu, P. He, Z. Li, C. Sun, L. Shi, Y. Liu, G. Zhu, J. Li, An ionic liquid-type carbon paste electrode and its polyoxometalate-modified properties, Electrochem. Commun. 7 (2005) $1357-1363$. 
[16] Z-K. Qu, K. Yu, Z-F. Zhao, Z-h. Su, J-Q. Sha, C-M. Wang, B-B. Zhou, An organicinorganic hybrid semiconductor material based on Lindqvist polyoxomolybdate and a tetranuclear copper complex containing two different ligands, Dalton Trans. 43 (2014) 6744-6751.

[17] Y. Liang, P. He, Y. Ma, Y. Zhou, C. Pei, X. Li, A novel bacterial cellulose-based carbon paste electrode and its polyoxometalate-modified properties, Electrochem. Commun. 11 (2009) 1018-1021.

[18] I.V. Kozhevnikov, Catalysis by heteropoly acids and multi-component Polyoxometalates in liquid-phase reactions. Chem. Rev. 98 (1998) 171-198.

[19] M. Opallo, A. Lesniewski, Review: A review on electrodes modified with ionic liquids, J. Electroanal. Chem. 656 (2011) 2-16.

[20] Z.C. Zhang, Catalysis in ionic liquids. Adv. Catal. 49 (2006) 153-237.

[21] C.P. Mehnert, Supported ionic liquid catalysis. Chem. Eur. J. 11(2005) 50-56.

[22] K. Yamaguchi, C. Yoshida, S. Uchida, N. Mizuno, Peroxotungstate immobilized on ionic liquid-modified silica as a heterogeneous epoxidation catalyst with hydrogen peroxide. J. Am. Chem. Soc. 127 (2005) 530-531.

[23] W. Jiang, D. Zheng, S. Xun, Y. Qin, Q. Lu, W. Zhu, H. Li, Polyoxometalate-based ionic liquid supported on graphite carbon induced solvent-free ultra-deep oxidative desulfurization of model fuels, Fuel 190 (2017) 1-9.

[24] X. Wu, W. Wu, Q. Wu, W. Yan, Thermoresponsive polyoxometalate/ionic liquid supramolecular gel electrolytes for supercapacitors: fabrication, structure, and heteropolyanion structure effect, Langmuir 33 (2017) 4242-4249.

[25] T. Huang, N. Tian, Q. Wu, W. Yan, Keggin-type polyoxometalate-based ionic liquid gels, Soft Matter. 11 (2015) 4481-4486.

[26] J. Casamada Ribot, C. Guerrero-Sanchez, R. Hoogenboom, U.S. Schubert, Aqueous gelation of ionic liquids: Reverse thermos-responsive ion gels, Chem. Commun. 46 (2010) 6971-6973. 
[27] Z.F. He, H.B. Wang, Y.L. Wang, Y. Wu, H.L. Li, L.H. Bi, L.X. Wu, Substitution effect in reversible gel-liquid phase transformation polyoxometalate ionic liquid compounds, Soft Matter. 8 (2012) 3315-3321.

[28] P. He, B. Xu, X. Xu, L. Song, X. Wang, Surfactant encapsulated palladium Polyoxometalates: controlled assembly and their application as single-atom catalysts, Chem. Sci. 7 (2016) 1-5.

[29] M. Shamsipur, J. Tashkhourian, B. Hemmateenejad, H. Sharghi, Application of artificial neural network to simultaneous potentiometric determination of silver(I), mercury(II) and copper(II) ions by an unmodified carbon paste electrode, Talanta 64 (2004) 590.

[30] L. Zhang, W. Yang, X. Kuang, X. Wua, C. Lu, pH-dependent assembly of two polyoxometalate host-guest structural isomers based on Keggin polyoxoanion templates, Dalton Trans. 43 (2014) 16328-34.

[31] R.C, Van Nostrand, Design of experiments using the taguchi approach: 16 steps to product and process improvement, Technometrics 44 (2002) 289.

[32] J. Rutherford, Practical experiment designs for engineers and scientists, Technometrics 44 (2002) 400-401.

[33] J.L. Rosa, A. Robin, M.B. Silva, C.A. Baldan, M.P. Peres, Electrodeposition of copper on titanium wires: Taguchi experimental design approach, J. Matter. Process. Technol. 209 (2009) 1181-1188.

[34] M. Masteri-Farahani, S. Shahbazi, Preparation of Keggin-type polyoxometalate hybrid nanomaterial with one pot multicomponent reaction in reverse micelle nanoreactors, Inorganic Chem. Commu.15 (2012) 297-300.

[35] P. Swetha, A. S. Kumar, Phosphomolybdic acid Nano-aggregates immobilized nafion membrane modified electrode for selective cysteine electrocatalytic oxidation and antidermatophytic activity, Electrochimica Acta 98 (2013) 54- 65.

[36] W. Zhu, W. Huang, H. Li, M. Zhang, W. Jiang, G. Chen, C. Han, Polyoxometalatebased ionic liquids as catalysts for deep desulfurization of fuels, Fuel Process. Technol. 92 (2011) 1842-1848. 
[37] M. Ammamz, J. Fransaer, Ionic liquid-heteropolyacid: Synthesis, characterization, and supercapacitor study of films deposited by electrophoresis, J. Electrochem. Soc. (2011) $14-21$.

[38] R. Wang, D. Jia, Y. Cao, Facile synthesis and enhanced electrocatalytic activities of organic-inorganic hybrid ionic liquid polyoxometalate nanomaterials by solid-state chemical reaction, Electrochimica Acta 72 (2012)101-107.

[39] P.J. Ross, Taguchi Techniques for Quality Engineering. Second edition, Mc. Graw-Hill, USA, 1996.

[40] A. Bendell, J. Disney, W.A. Pridmore, Taguchi Methods: Applications in world industry, IFS Publications, UK, 1989.

[41] S.T. Kim, M.S. Park, H.M. Kim, Systematic approach for the evaluation of the optimal fabrication conditions of a $\mathrm{H}_{2} \mathrm{~S}$ gas sensor with Taguchi method, Sens. Actuators B 102 (2004) 253-260.

[42] Y. Ji, L. Huang, J. Hu, C. Streb, Y-F. Song, Polyoxometalate-functionalized Nano carbon materials for energy conversion, energy storage and sensor systems, Energy Environ. Sci. 8 (2015) 776-789.

[43] IUPAC, Analytical chemistry division, commission on analytical electrodes, Pure Appl. Chem. 48 (1979) 127-131.

[44] M.B. Saleh, S.S. M. Hassan, A.A. Abdel Gaber, N.A. Abdel Kream, Novel potentiometric membrane sensor for selective determination of aluminum (III) ions, Anal. Chim. Acta 434 (2001) 247-253.

[45] Y. Umezawa, P. Buhlmann, K. Umezawa, K. Tohda, S. Amemiya, Potentiometric selectivity coefficients of ion-selective electrodes, Pure Appl. Chem. 72 (2000) 1851-2082.

[46] E. Bakker, E. Pretsch, P. Buhlmann, Selectivity of Potentiometric Ion Sensors, Anal. Chem. 72 (2000) 1127-1133.

[47] M. Arvand, S.A. Asadollahzadeh, Ion-selective electrode for aluminum determination in pharmaceutical substances, tea leaves and water samples, Talanta 75 (2008) 1046-1054. 
[48] A. Abbaspour, A.R. Esmaeilbeig, A.A. Jarrahpour, B. Khajeh, R. Kia, Aluminium(III)selective electrode based on a newly synthesized tetradentate Schiff base, Talanta 58 (2002) $397-403$.

[49] V.K. Gupta, A.K. Jain, G. Maheshwari, Aluminum(III) selective potentiometric sensor based on Morin in poly(vinyl chloride) matrix, Talanta 72 (2007) 1469-1473.

[50] Y-H. Ma, R. Yuan, Y-Q. Chai, X-L. Liu, A new aluminum(III)-selective potentiometric sensor based on N,N'-propanediamide bis-(2-salicylideneimine) as a neutral carrier, Mat. Sci. Eng. C 30 (2010) 209-213.

[51] A. Yari, L. Darvishi, M. Shamsipur, Al(III)-selective electrode based on newly synthesized xanthone derivative as neutral ionophore, Anal. Chim. Acta 555 (2006) 329-335.

[52] Y. Li, Y. Chai, R. Yuan, W. Liang, L. Zhang, G. Ye, Aluminium(III)-Selective Electrode Based on a Newly Synthesized Glyoxal-bis-Thiosemicarbazone Schiff Base, J. Anal. Chem. 63 (2008) 1090-1093.

[53] M. Arvand, M. Kermanian, Potentiometric Determination of Aluminum in Foods, Pharmaceuticals, and Alloys by AlMCM-41-Modified Carbon Paste Electrode, Food Anal. Methods 6 (2013) 578-586.

[54] M. Esmael pourfarkhani, Gh.H. Rounaghi, M.H. Arbab-Zavar, Construction of a New Aluminum(III) Cation Selective Electrode Based on 12-Crown-4 as an Ionophore, J. Braz. Chem. Soc. 26 (2015) 963-969.

[55] A.D. Eaton, L.S. Glesceri, A.E. Greenberg, Standard methods for the examination of water and wastewater, American Public Health Association, Washington, 1995, Part 3000, pp. 3-43.

\section{Figures}




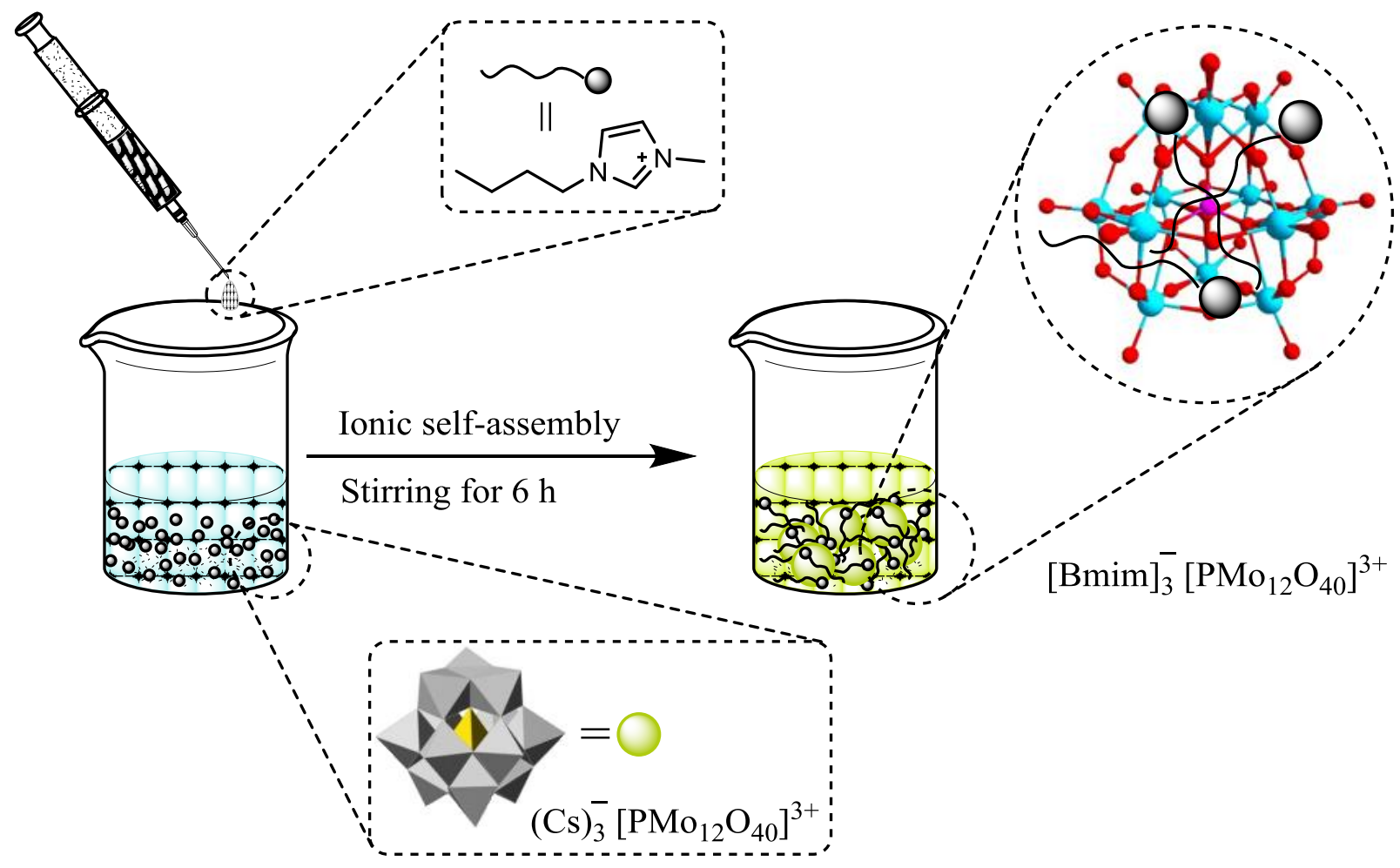

Scheme 1 


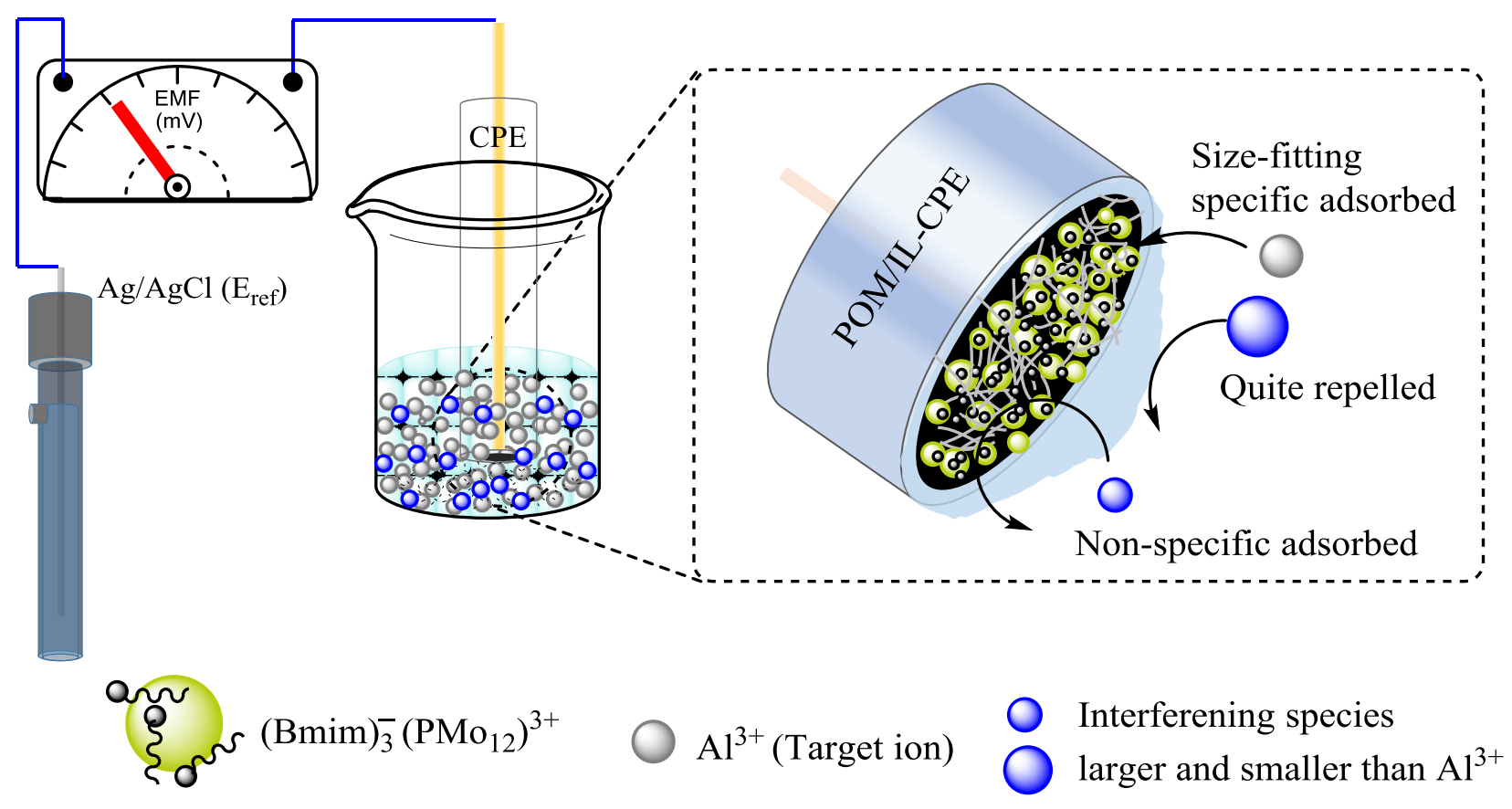

Scheme 2 
(a)<smiles>CCCCn1cc[n+](C)c1</smiles><smiles>F[B-](F)(F)F</smiles>

1-n-butyl-3-methylimidazolium tetrafluoroborate $\left(\mathrm{Bmim} \mathrm{BF}_{4}\right)$

(b)<smiles>CCCCCn1cc[n+](C(C)(C)[N+]([O])O[Al])c1</smiles>

POM-IL

Fig. 1<smiles>CCCCCCCCCOC(=O)c1ccccc1C(=O)OCCCCCCC</smiles>

dioctyl phthalate (DOP)<smiles>CCCCOC(=O)c1ccccc1C(=O)OCCCC</smiles>

dibutyl phthalate (DBP)

Fig. 2 


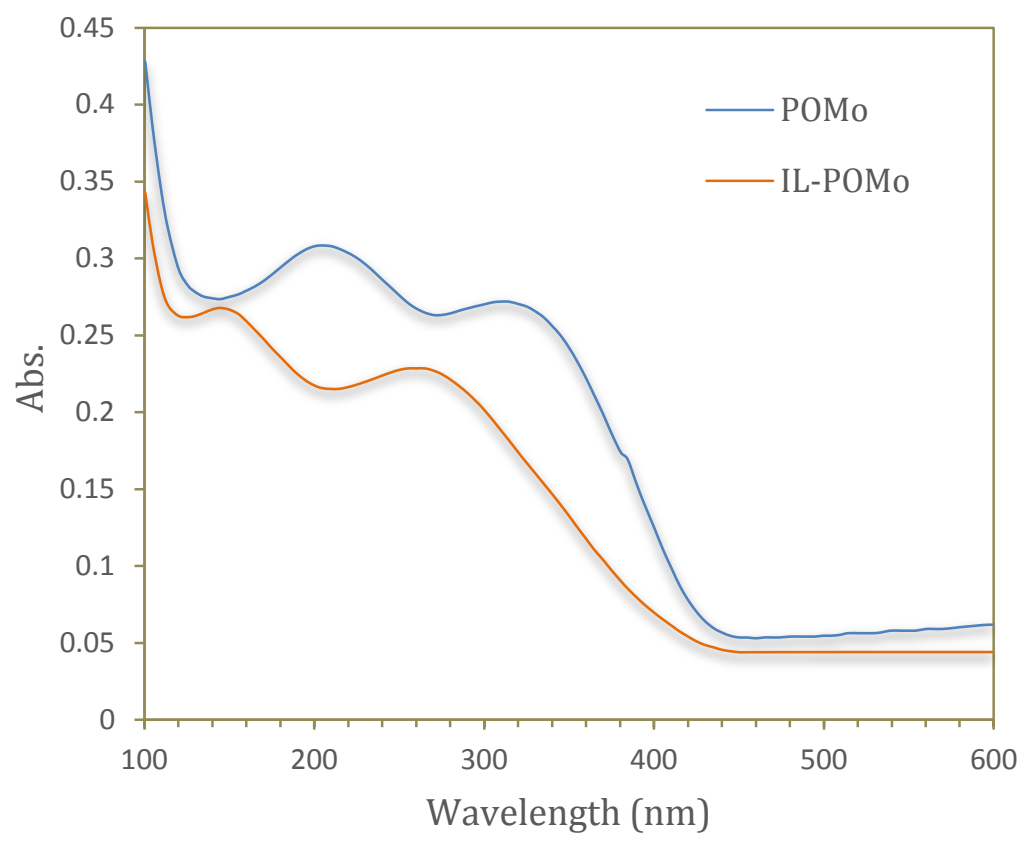

Fig. 3

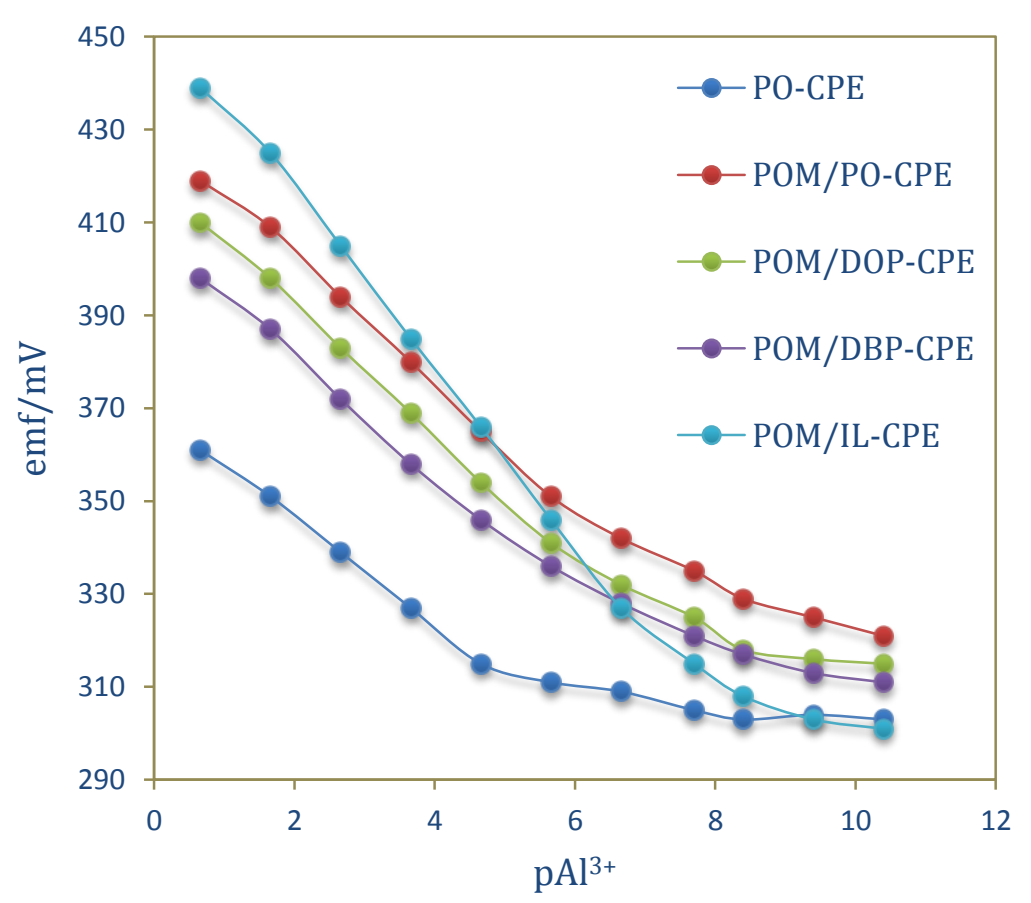

Fig. 4 


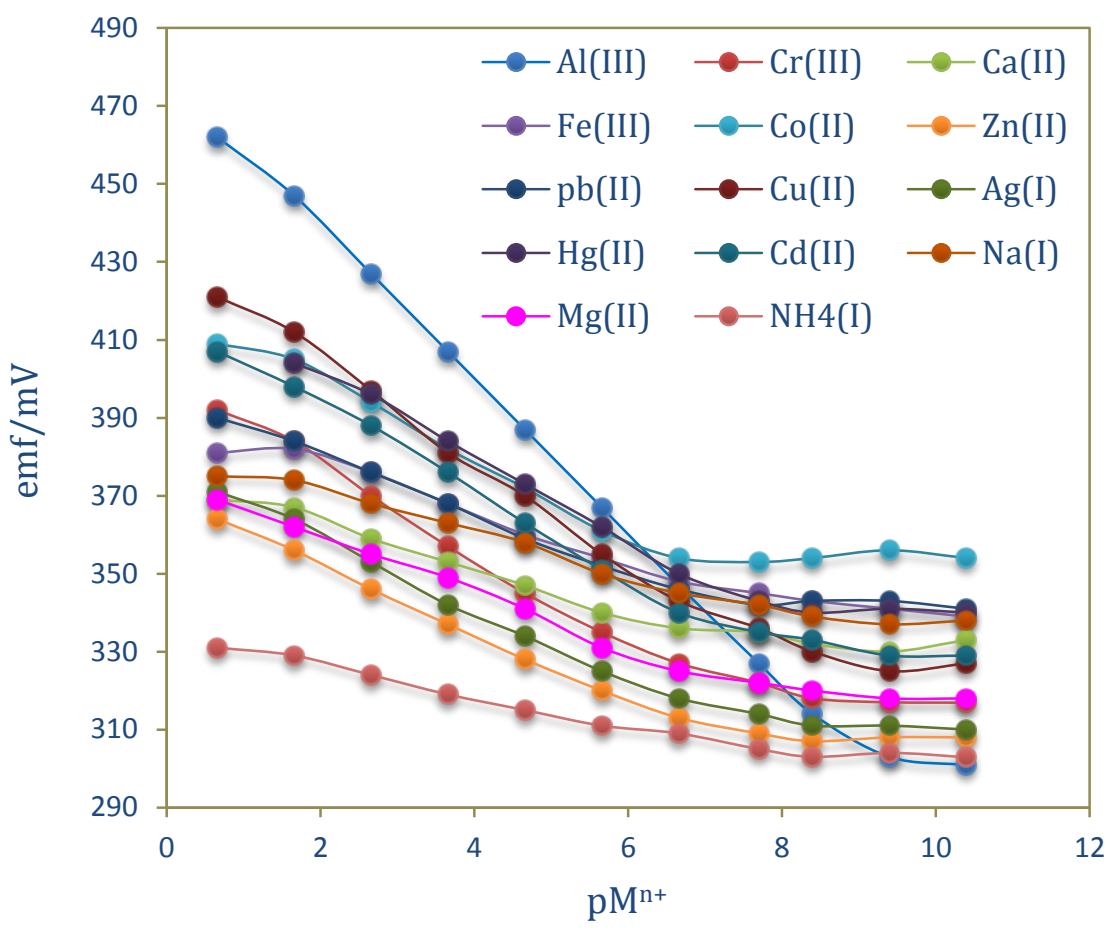

Fig. 5

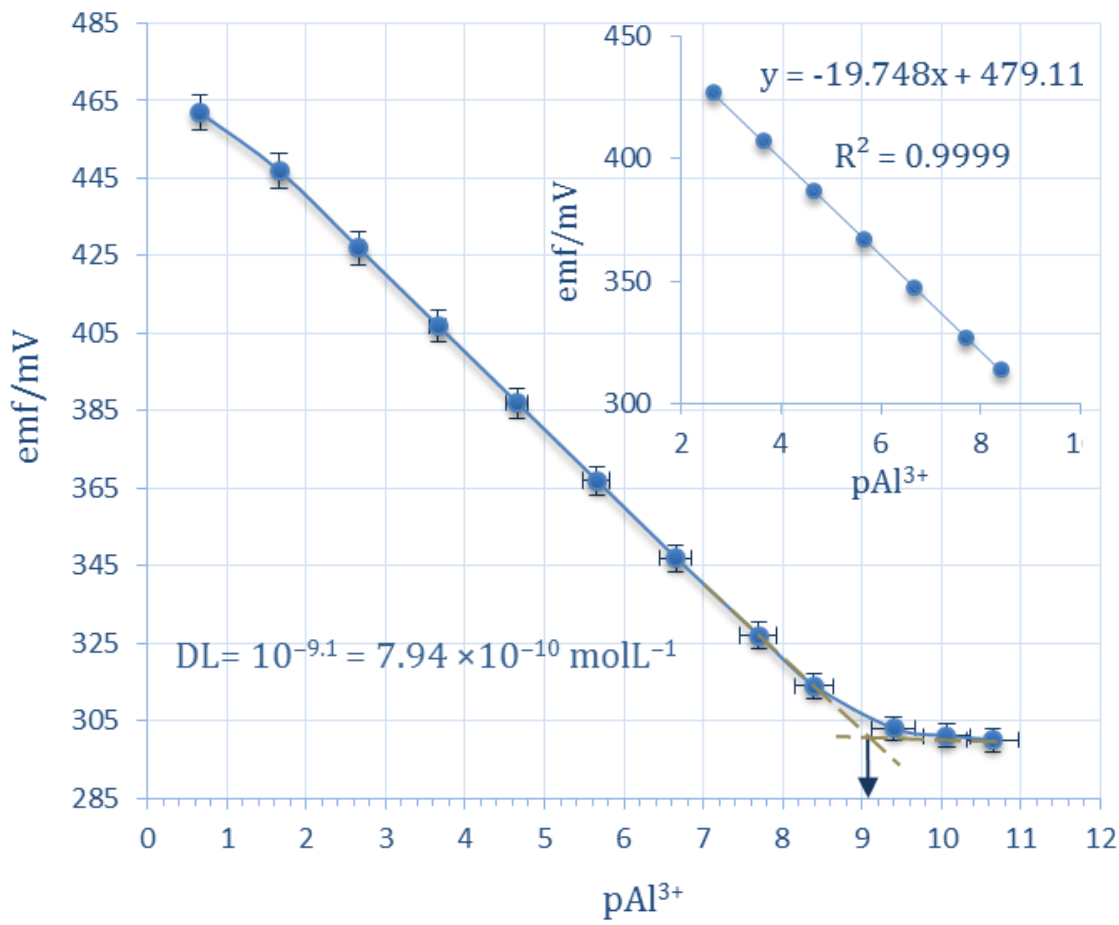

Fig. 6 


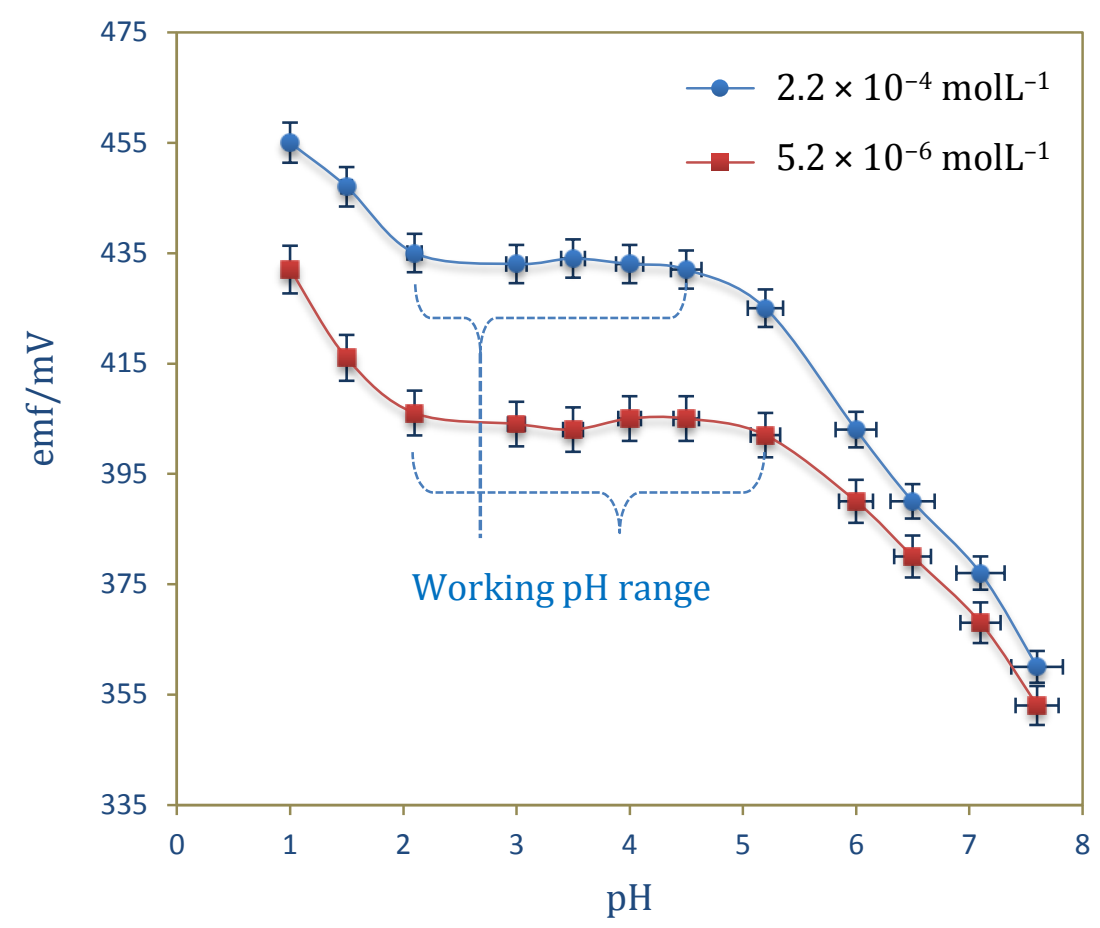

Fig. 7

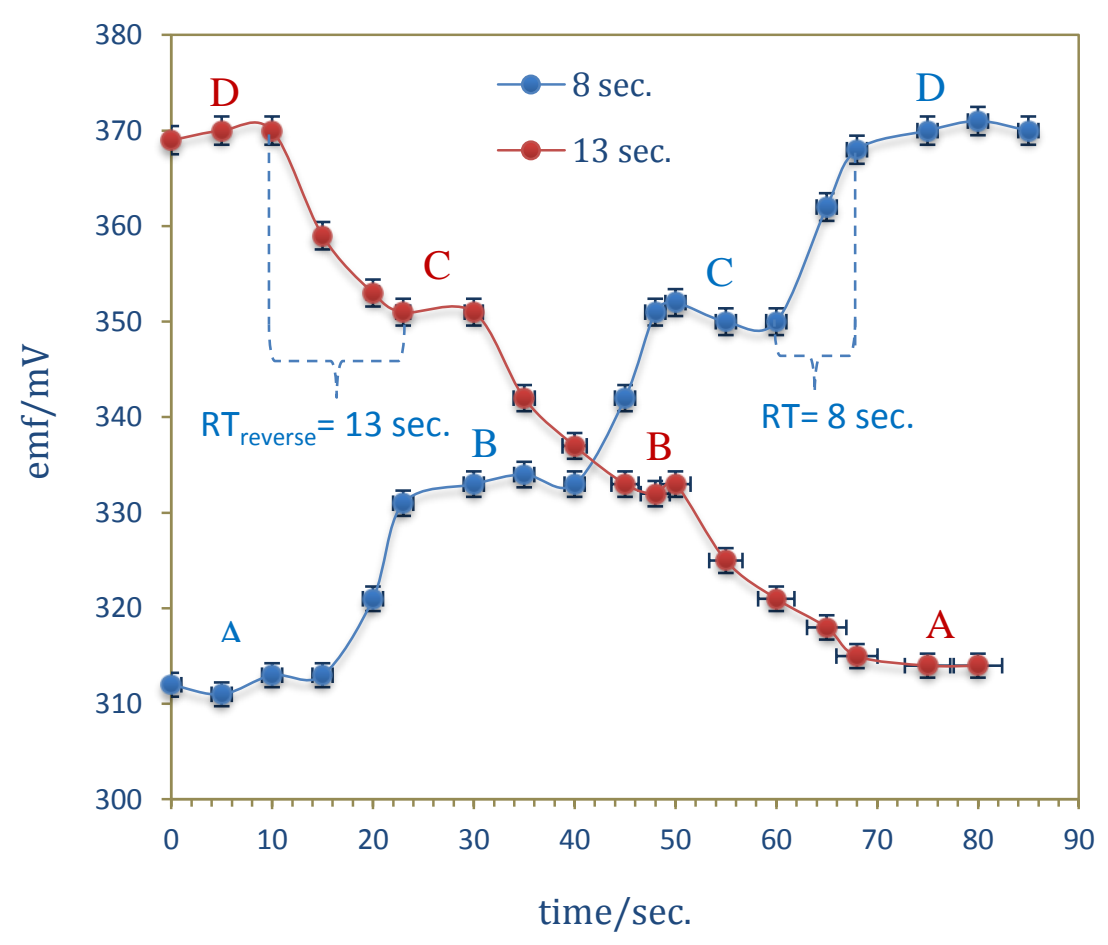

Fig. 8 


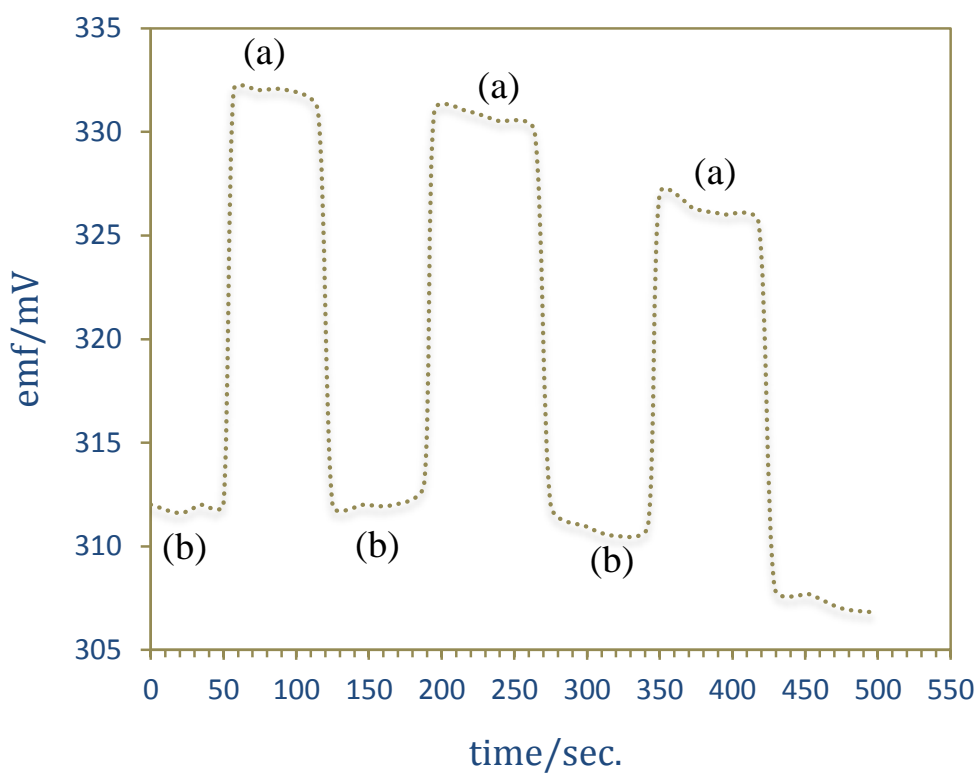

Fig. 9

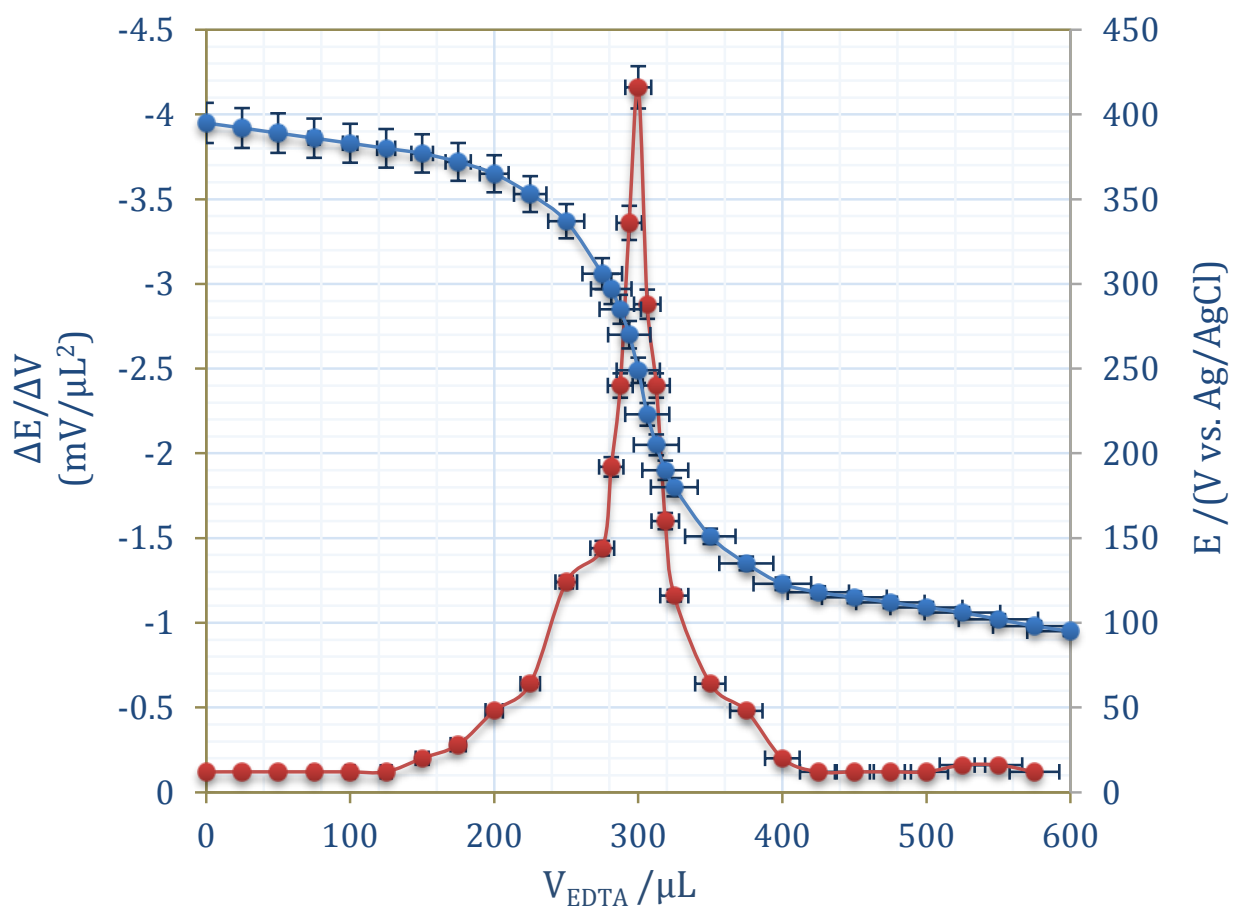

Fig. 10 